Check for updates

Cite this: RSC Adv., 2018, 8, 41048

Received 31st October 2018 Accepted 28th November 2018

DOI: $10.1039 / c 8 r a 09038 f$

rsc.li/rsc-advances

\section{Applications of SBA-15 supported Pd metal catalysts as nanoreactors in $\mathrm{C}-\mathrm{C}$ coupling reactions}

\author{
Ghodsi Mohammadi Ziarani, (D) *a Sahar Rohani, ${ }^{a}$ Abolfazl Ziarati (D) ${ }^{b}$ \\ and Alireza Badiei ${ }^{\mathrm{b}}$
}

Nanoreactors are material structures with engineered internal cavities which create exclusive confined nanoscale surroundings for chemical reactions. The cavities of mesoporous silica SBA-15 can be used as nanoreactors for incorporating catalytic species such as metal nanoparticles, complexes etc. Since SBA15 silica has a neutral framework, organic functional groups and heteroatoms have been embedded by direct or post-synthesis approaches in order to modify their functionality. Palladium is the most used transition metal for $\mathrm{C}-\mathrm{C}$ bond formations. Because of the great importance of $\mathrm{C}-\mathrm{C}$ coupling reactions, this review article aims at providing a deep insight into the state of art in the field of the synthesis and the application of mesoporous SBA-15 silica-supported Pd catalysts in C-C coupling transformations. In most cases, synthesis and modification of the catalyst, time and yield of reactions, recyclability and leaching of the Pd species from the SBA-15 support are discussed to reveal the role of SBA-15 in C-C coupling reactions.

\section{Introduction}

A nanoreactor concept can be defined as a complex material system which has been engineered to catalyze, host, or steer a chemical reaction procedure occurring in its nanoscale cavity. ${ }^{1}$ High reactivity and selectivity were detected when
${ }^{a}$ Department of Chemistry, Faculty of Science, University of Alzahra, Tehran, Iran E-mail: gmohammadi@alzahra.ac.ir; Fax: +98 21 8041575; Tel: +98 218041575 ${ }^{b}$ School of Chemistry, College of Science, University of Tehran, Tehran, Iran

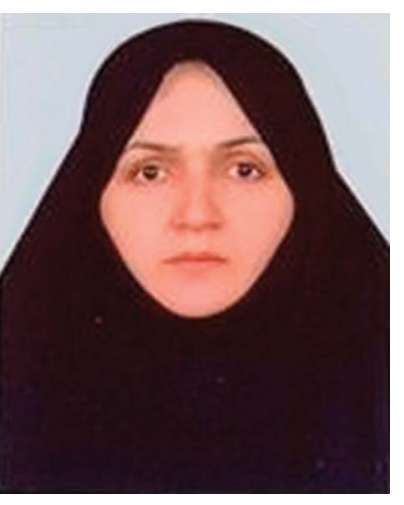

Ghodsi Mohammadi Ziarani was born in Iran, in 1964. She received her BSc degree in Chemistry from the Teacher Training University (currently is named as Kharazmi University), Tehran, Iran, in 1987. She then received her MSc degree in Organic Chemistry from the same university, under the supervision of Professor Jafar Asgarin and Professor Mohammad Ali Bigdeli in 1991. She obtained her PhD degree in asymmetric synthesis (biotransformation) from Laval University, Quebec, Canada under the supervision of Professor Chenevert, in 2000. She is currently a full Professor in the Science faculty of Alzahra University. Her research interests include organic synthesis, heterocyclic synthesis, asymmetric synthesis, natural products synthesis, synthetic methodology and applications of nano-heterogeneous catalysts in multicomponent reactions.

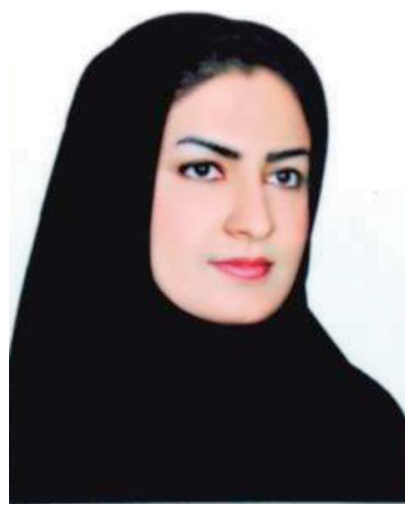

Sahar Rohani was born in 1987 in Shiraz, Iran. She received her B.Sc. degree in pure Chemistry from the Kharazmi University, Tehran, Iran, in 2009 and her MSc. degree in Organic Chemistry at Kashan University, Iran (2012) under the supervision of Dr Abdolhamid Bamoniri. She is currently working towards her PhD in Organic chemistry at Alzahra University under the supervision of $\mathrm{Dr}$ Ghodsi Mohammadi Ziarani. Her research field is synthesis of various nanocatalysts and their application in coupling reactions. 
reactions were carried out in nanoreactors. ${ }^{2}$ Additionally, a nanoreactor protects the catalyst against deactivation, and facilitates its recovery and reusability. To date, several types of nanoreactors have been developed, including metal-organic frameworks (MOF) ${ }^{3}$ dendrimers, ${ }^{4}$ montmorillonites, ${ }^{5}$ zeolites, ${ }^{6}$ carbon nanotubes $(\mathrm{CNT})^{7}$ and mesoporous silicas. ${ }^{8}$ In recent decades, ordered mesoporous silicas (OMS) have gained much attention as potential adsorbents, ${ }^{9}$ in drug delivery, ${ }^{10-14}$ and as catalysts/catalyst supports $^{15}$ and sensors. ${ }^{16,17}$ Among the OMS, the SBA-15 hybrid material, first synthesized by Stucky's group, ${ }^{18}$ with uniform pore size, large specific surface area, high thermal and chemical stability has been widely used as a support in heterogeneous catalysts for synthetic and industrial processes. ${ }^{2,19-28}$ However, naked SBA15 has a lack of functionality, hence, its surface was modified by grafting or co-condensation to make this material more versatile in terms of its possible applications. ${ }^{29}$ An effective method to modification of these silica support catalysts, is creating of anchoring sites for capturing catalytic species. It can be achieved by functionalization the surface of mesoporous silica SBA-15 materials with different groups including phosphorus, sulfur, and amine-based functional groups. On the other hands, the inner meso-channels of silica SBA-15 are full of silanol groups which can serve as handle for incorporation of various catalytic species such as nanoparticles, and defined transition metal complexes in catalytic methods. Among the different metal nanocatalysts, palladium nanoparticles (Pd NPs) have generated much interest. ${ }^{30}$ Mesoporous SBA-15 based Pd catalysts have developed some of the most interesting catalytic fields in organic synthesis, partially in different types of carbon-carbon coupling reactions. ${ }^{31,32}$ As SBA-15 possess large specific surface area containing highly ordered two-dimensional (2D) hexagonal mesostructure, it can be used for capturing of Pd complexes. Besides, the capturing decreases the leaching of Pd species into the solution, which is a usual problem associated with other Pd supported catalysts. Additionally, it also solves or minimizes the problem of Pd aggregation which leads to deactivation of the catalyst through formation of Pd black, thereby reduces the catalyst loading. ${ }^{33}$ The $\mathrm{C}-\mathrm{C}$ bond formation reactions are the most important synthetic transformations that play a key role in many academic and industrial researches such as preparation of natural products, drugs, pharmaceuticals, conducting polymers, herbicides and industrially important starting materials. ${ }^{34-37}$ There are many review articles and books ${ }^{38-50}$ on the synthesis and application of different OMS anchoring Pd as catalysts in $\mathrm{C}-\mathrm{C}$ coupling reactions. In 2009, Polshettiwar and co-workers reviewed the performances of silica-supported Pd catalysts for cross-coupling reactions. ${ }^{51}$ In 2016, Karimi's group published a comprehensive review on the applications of modified ordered/periodic mesoporous silicas and organosilicas as catalyst supports in $\mathrm{C}-\mathrm{C}$ coupling reactions. ${ }^{29}$ In the other work in 2017, Heravi and his groups published a review article on the utility of functionalized SBA mesoporous silica for developing encapsulated nanocatalysts. ${ }^{52}$ Moreover, in 2013, Molnár published a special book chapter concerning the applications of various ordered porous materials as solid supports in Pd-catalyzed cross-coupling reactions. ${ }^{45}$ Taking the importance of this study and following our previous publications, ${ }^{\mathbf{8}, 10,23,53,54}$ herein, we intend to review the applications of Pd-based mesoporous silica SBA-15 as catalyst in $\mathrm{C}-\mathrm{C}$ couplings. The majority of this review is about the three most important $\mathrm{C}-\mathrm{C}$ coupling reactions including the SuzukiMiyaura (S-M), Mizoroki-Heck (M-H) and Sonogashira couplings with Pd anchored on SBA-15 catalysts. It has also been attempted to cover other $\mathrm{C}-\mathrm{C}$ coupling reactions such as Stille, Hiyama, Ullmann and Glaser. Furthermore, we tried to present an overview of the synthesis, modification, performance, stability, and reusability of these types of catalysts. At the end, we summarize the significance and challenges of SBA15 and Pd based SBA-15 catalysts and perspectives for further developments.

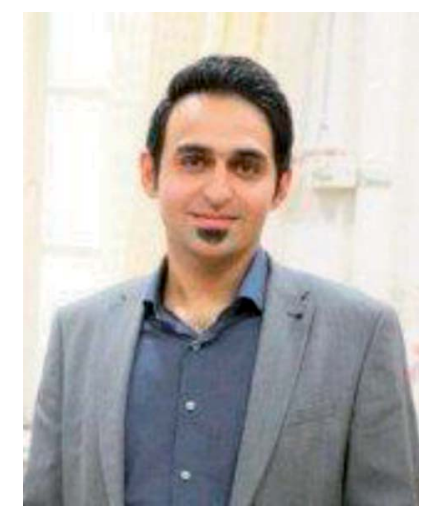

Abolfazl Ziarati obtained his BSc Pure Chemistry degree in 2010, and his MSc Organic Chemistry degree in 2012, both from the University of Kashan, Iran. He is currently working towards his PhD in Nano chemistry in the University of Tehran under the supervision of Prof. Alireza Badiei. His area of research interest is architectural engineering of advanced materials for application in catalytic and photocatalytic reactions.

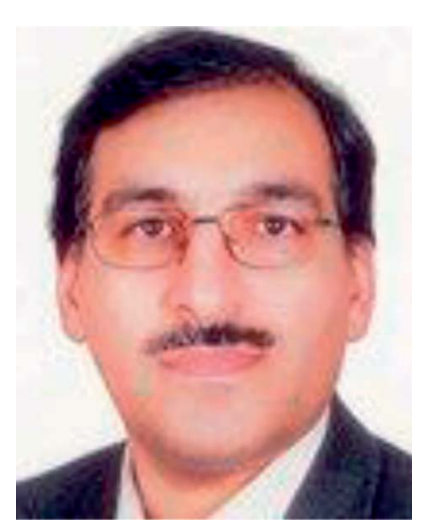

Alireza Badiei was born in Iran, in 1965. He received his BSc and $\mathrm{MSc}$ degrees in Chemistry and Inorganic Chemistry from the Teacher Training University (Kharazmi), Tehran, Iran, in 1988 and 1991, respectively, and his $P h D$ degree in the synthesis and modification of nanoporous materials from Laval University, Quebec, Canada, in 2000. He is currently a full Professor in the Chemistry faculty of Tehran University. His research interests include nanoporous materials synthesis, modification of nanoporous materials and application of organic-inorganic hybrid materials in various fields such as catalysis, adsorption, separation and sensors. 


\section{2. $\mathrm{C}-\mathrm{C}$ coupling reactions using SBA- 15 based catalysts}

\subsection{Suzuki-Miyaura reaction}

The Suzuki cross-coupling reaction, also known as the "SuzukiMiyaura reaction" (signified as S-M coupling reaction) is one of the strongest methods for the of $\mathrm{C}-\mathrm{C}$ bond formation. This reaction, first discovered by Nobel laureate Akira Suzuki in 1979 , is the Pd-catalyzed reaction between an organoboron

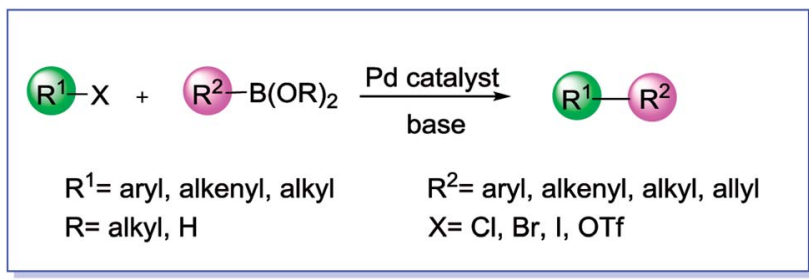

Scheme 1 The S-M coupling reaction.

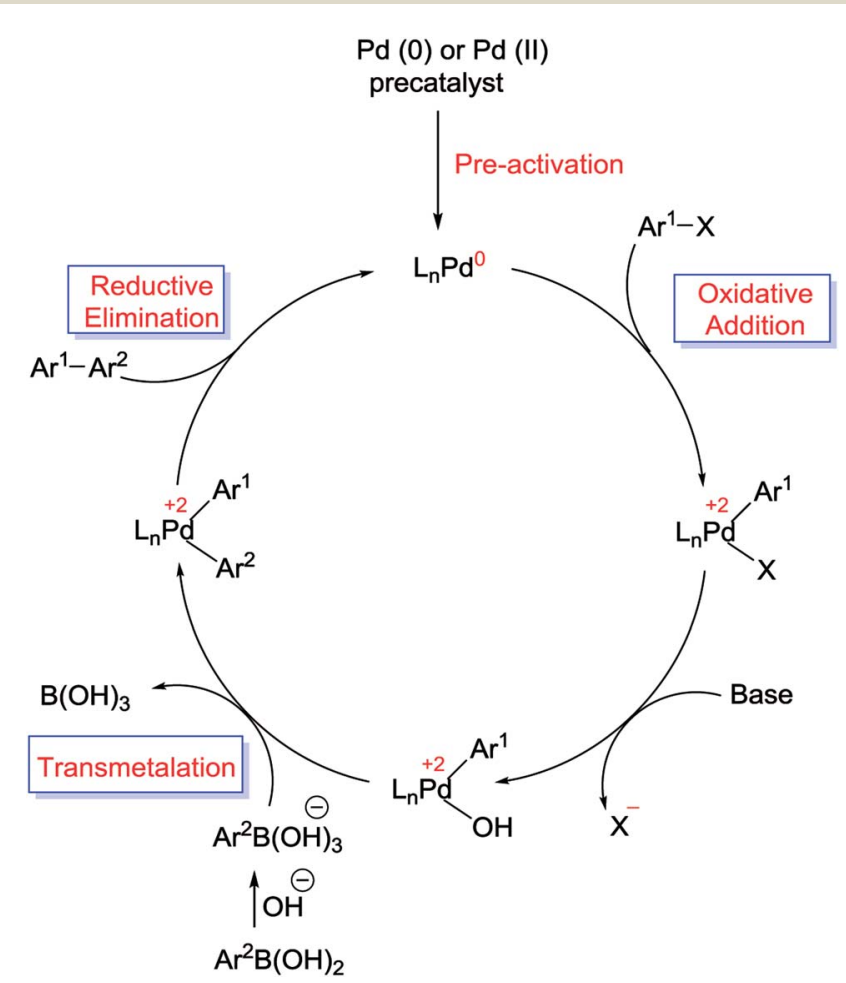

Scheme 2 Proposed reaction mechanism for the S-M coupling reaction. ${ }^{57}$ compound (usually an arylboronic acid) with a halogencontaining hydrocarbon (usually an arylhalide) or an aryl triflate to form biaryl compounds (Scheme 1). ${ }^{55-58}$ The biaryl scaffold is a privileged structure constituents of numerous biologically active natural products, polymers, pharmaceuticals and functional molecules. ${ }^{59}$ This motif has also exhibited activity across a wide range of therapeutic classes, which contain anti-tumor, anti-inflammatory, anti-rheumatic, antifungal, and anti-hypertensive agents. ${ }^{\mathbf{6 0 6 1}}$ Three key reasons have been established for the development of this reaction: (i) this reaction is practicable over a wide range of substrates in either aqueous or organic solvents and the reaction conditions are relatively mild; (ii) organoboron starting materials are commercially available, nontoxic, ease of handling, stable and sustainable and the boron-containing by-product can be easily separated from the reaction mixture and (iii) the high stereo and regioselectivity of the reaction are just a little influenced with steric hindrance and the incorporation of numerous functional groups in the reactants. ${ }^{62}$ In general, as shown in Scheme 2, S-M coupling reactions catalyzed by Pd immobilized SBA-15 follow a general catalytic reaction mechanism (similar to homogenous catalysis). The first step in this mechanism is the oxidative addition of organohalide to $\operatorname{Pd}(0)$ to form organopalladium(II) halide. Reaction of this specie with base followed by transmetalation with boronate complex forms organopalladium(II) specie. Reductive elimination of the desired biaryl or divinyl restores the original palladium(0) catalyst and the catalytic cycle can begin again. ${ }^{58,63}$

This part focuses on some of the recently developed important Pd decorated SBA-15 nanocatalysts for Suzuki reaction.

Recently, Pd and Pd-Au NPs highly dispersed in immobilized SBA-15 silica were prepared and employed in S-M reaction. The surface of SBA-15 was modified via positively charged groups, and anionic metal ions were consequently bonded into the channel system by ion exchange. Finally, Pd/SBA-15 (1) and Pd-Au/SBA-15 (2) catalysts were produced via reduction of anionic metal precursors by using of either $\mathrm{NaBH}_{4}$ solution or $\mathrm{H}_{2}$ flow. Then the both catalytic activities were tested in Suzuki reaction at $N$-methylpyrrolidone (NMP) solvent with the temperatures range from room temperature to $120{ }^{\circ} \mathrm{C}$ but the yields are usually not higher than $15 \%$ (Scheme 3 ). A reason for the low catalytic activity is that the produced boronic acid has powerful interactions with the silica pore systems, and is consequently not transported out and accumulates the pore system. ${ }^{64}$

More recently, Crudden and his group have shown that thiolimmobilized mesoporous silica SBA-15 was an effective Pd

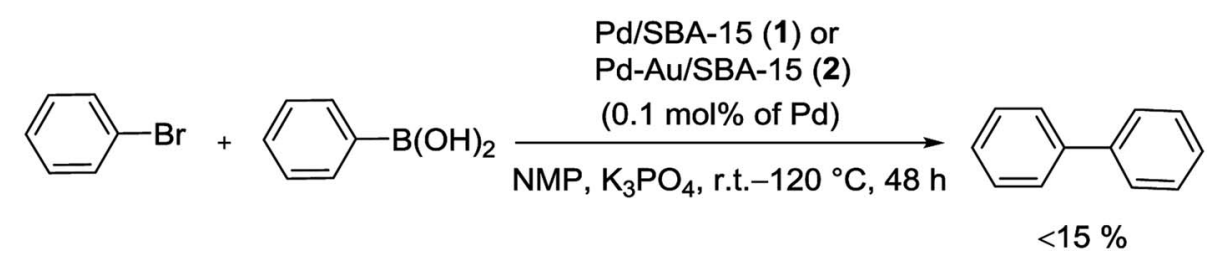

Scheme 3 Suzuki cross-coupling reaction catalyzed by Pd/SBA-15 (1) and Pd-Au/SBA-15 (2). 

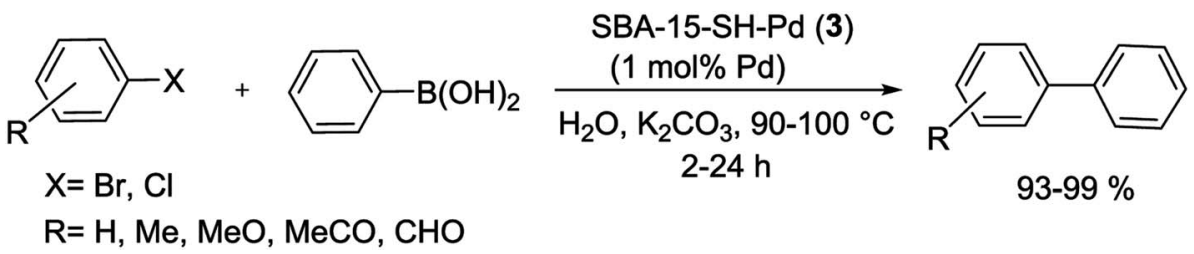

Scheme 4 The SBA-15-SH-Pd (3) catalyzed Suzuki-Miyaura reaction.

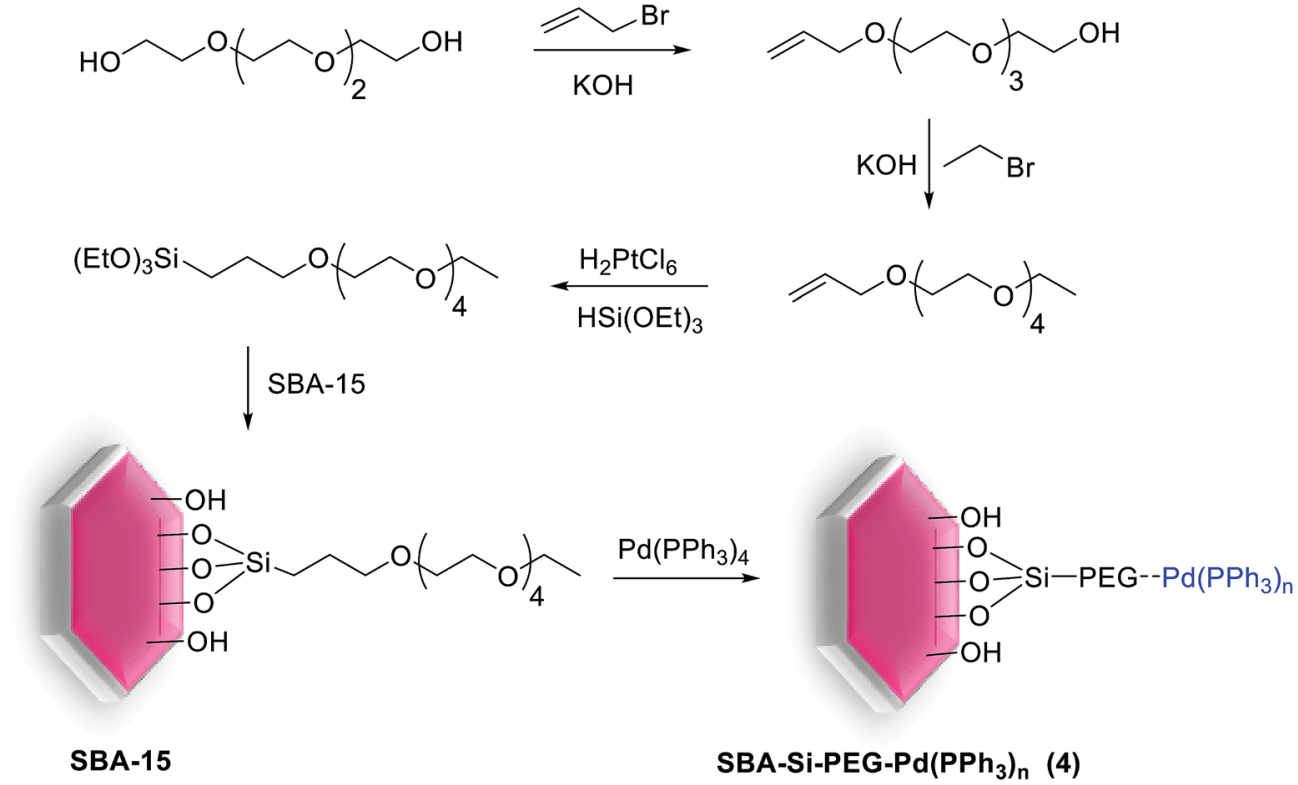

Scheme 5 Synthesis of SBA-Si-PEG-Pd(PPh $)_{n}(4)$

scavengers and produced SBA-15-SH-Pd (3) catalyst. The resulting $\mathrm{Pd}$ encapsulated material catalyzed the S-M reactions of less reactive aryl chlorides and bromides in organic and aqueous solutions. Fairly high yields of the coupling products were obtained at $90-100{ }^{\circ} \mathrm{C}$ in the presence of $1 \mathrm{~mol} \%$ of $\mathrm{Pd}$ catalyst (Scheme 4). The SBA-15-SH-Pd catalyst was recycled four times with no detectable deactivation and no significant Pd leaching. The heterogeneity tests including three-phase tests and hot filtration experiments have exhibited that the reaction was occurred predominantly in the pores or on the surface of the silica. ${ }^{65}$

The research group of Xiao developed and synthesized a highly active Pd catalyst supported on PEG-modified silica SBA-15 signified as SBA-Si-PEG-Pd( $\left(\mathrm{PPh}_{3}\right)_{n}$ (4). As shown in Scheme 5 , this heterogeneous catalyst was prepared through coated mesoporous silica SBA-15 which contained a layer of easily available PEG with a labile coordinating ability for Pd. As determined by ICP, the $\mathrm{Pd} \%$ in this modified catalyst was $0.050 \mathrm{mmol} \mathrm{g}^{-1}(0.53 \%$ by wt $){ }^{66}$

Under the various conditions, the synthesized catalyst proved efficient performance in S-M reactions of different aryl halides $(\mathrm{X}=\mathrm{Cl}, \mathrm{Br}, \mathrm{I})$ with a variety of aryl boronic acids (Scheme 6). The authors indicated that the catalyst could be reused several times without any obvious loss of the activity and leaching of the Pd into the organic layer was not observed. ${ }^{66}$
The S-M reaction by mesoporous silica SBA-15 supported aryldicyclohexylphosphine as ligand has been studied by Dufaud and co-workers. The benzyliminopropyl modified SBA15 silica was synthesized via heating the benzylimine silane by a suspension of calcined SBA-15. The remaining silanol groups in supported benzylimine were coated through silylation with chlorotrimethylsilane. After elimination of the excess silane, the imine-grafted fragment was then converted to the corresponding amine which was condensed with $2^{\prime}$ (dicyclohexylphosphino)biphenyl-4-carboxylic acid to yield the desired SBA-15 silica supported dicyclohexylphosphine. Then the latter react with bis(benzonitrile)palladium(II) chloride, $\left[\mathrm{PdCl}_{2}(\mathrm{PhCN})_{2}\right]$, in dichloromethane to produce the SBA-15 supported dicyclohexylphosphine/ $\mathrm{PdCl}_{2}$ (5) (Scheme 7). ${ }^{67}$

The efficiency of heterogeneous SBA-15 supported dicyclohexylphosphine/ $\mathrm{PdCl}_{2}$ (5) catalyst have been investigated in

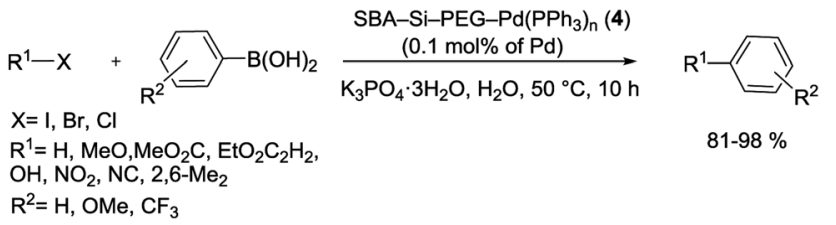

Scheme 6 The SBA-Si-PEG-Pd(PPh$)_{n}$ (4) catalyzed Suzuki-Miyaura coupling of various substrates. 


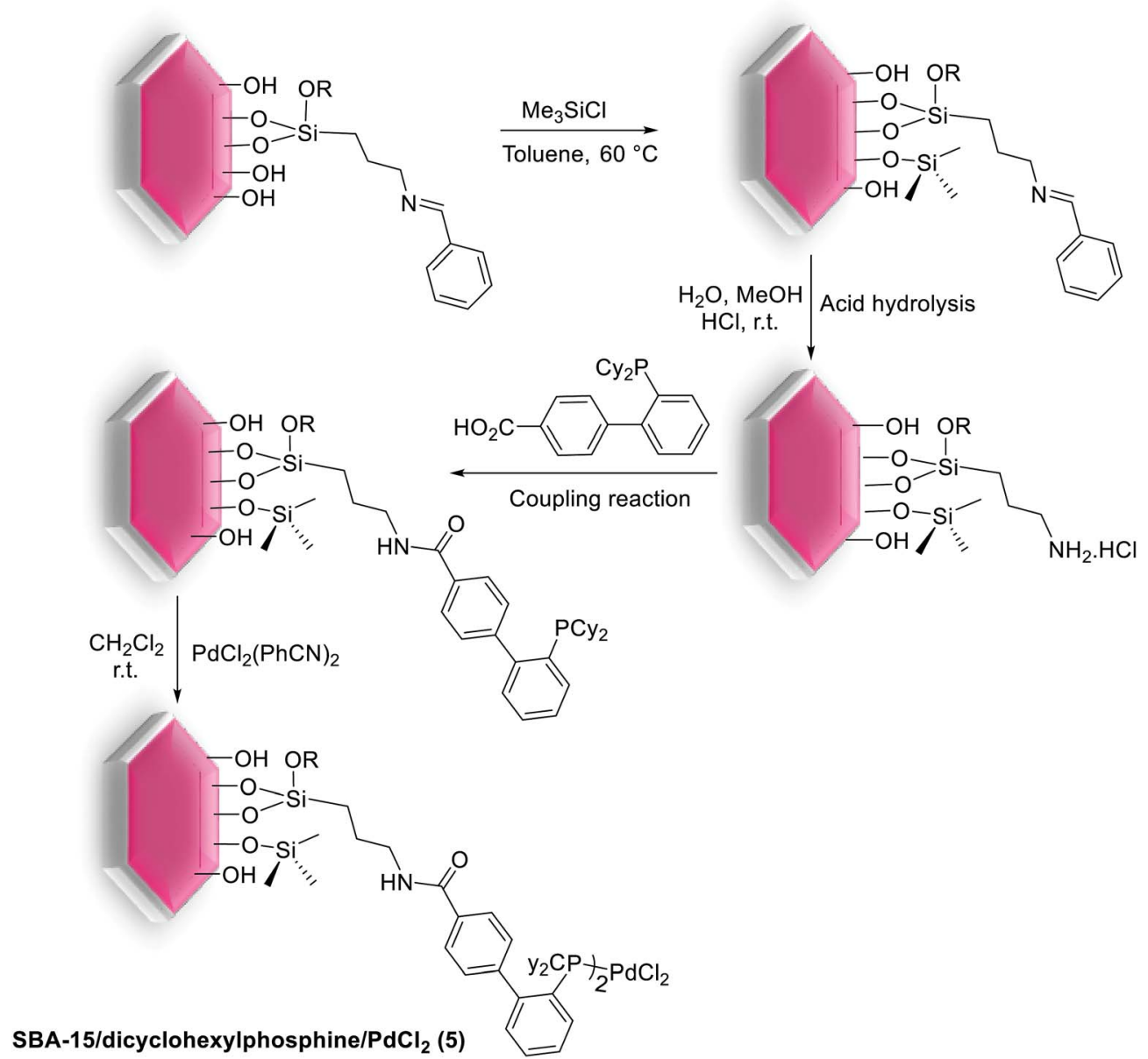

Scheme 7 SBA-15/dicyclohexylphosphine/ $\mathrm{PdCl}_{2}$ (5) prepared by stepwise transformation of a benzylimino-grafted species.

S-M coupling reaction. Both systems demonstrated good to excellent conversions and yields for coupling of phenylboronic acid with activated aryl chlorides (Scheme 8). ${ }^{67}$

In another study, Gao and his group have prepared a facile one-step approach for attaching Pd NPs in mesoporous channels of SBA-15 during sol-gel route under reductive atmosphere. The XRD pattern showed 2D hexagonal structure of Pd/ SBA-15 (6) nanocomposite while transmission electron microscopy (TEM) spectrum indicate a well dispersion of Pd NPs into the mesoporous SBA-15 pore channels. The Pd loading results in the decrease of specific surface area, pore volume and pore size in the range of 5-10 $\mathrm{nm}$. The authors have demonstrated that the loading amount of Pd NPs in silica SBA-15 can be readily controlled via different amounts of Pd salts. The resulting catalyst indicated high activity for the S-M coupling of activated aryl bromides (85-99\%) without ligand at $85^{\circ} \mathrm{C}$ in air. Nevertheless, the coupling of deactivated aryl bromides needed longer times and offered lower yields than the activated aryl bromides (Scheme 9). The reusability of the catalyst was investigated in the reaction of $p$-bromoacetophenone with phenylboronic acid. After 5 reuses, the catalyst continued to afford reaction yields above $95 \%{ }^{68}$

Pleixats and his group have established new air-stable catalysts including a 15-membered azatriolefinic macrocyclic $\mathrm{Pd}^{0}$ complex attached to silica materials. The grafting route (postsynthesis modification) was employed to produce $1.55 \%$ Pd-

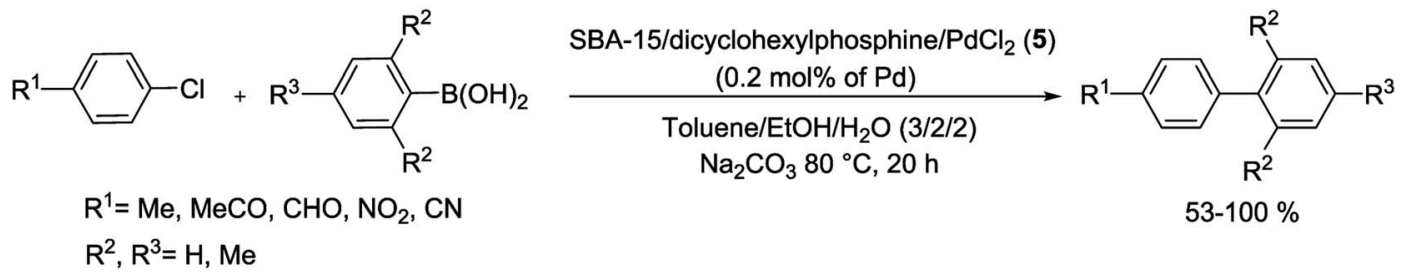

Scheme 8 The SBA-15/dicyclohexylphosphine/PdCl 2 (5) catalyzed S-M cross-coupling of aryl chlorides and boronic acids. 


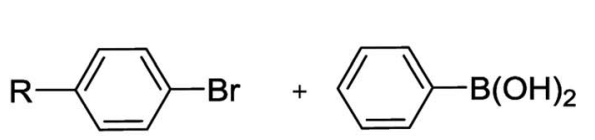

$\mathrm{R}=\mathrm{H}, \mathrm{MeO}, \mathrm{MeCO}, \mathrm{NO}_{2}$
Pd/SBA-15 (6)

$(0.2 \mathrm{~mol} \%$ of $\mathrm{Pd})$

$\mathrm{EtOH} / \mathrm{H}_{2} \mathrm{O}(1: 3), \mathrm{K}_{2} \mathrm{CO}_{3}, 85^{\circ} \mathrm{C}$

5-10 h

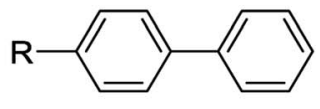

$85-99 \%$

Scheme 9 Suzuki cross-coupling reactions catalyzed by Pd/SBA-15 (6).

SBA-15 (7a) catalyst. Another catalyst, $\mathrm{Pd}_{-} \mathrm{SiO}_{2}-(7 \mathbf{b})$, was prepared via cogelification of complex $7 \mathbf{b}$ and tetraethyl orthosilicate (TEOS). The third case, Pd-SBA-15 (7c), was synthesized through grafting of monosilylated precursor $7 \mathbf{b}$ to SBA-15 followed by complexing with bis(dibenzylideneacetone)palla$\operatorname{dium}(0)\left(\operatorname{Pd}(\mathrm{dba})_{2}\right)$. When two catalysts $(7 \mathbf{a}, \mathbf{c})$ estimated in the $\mathrm{S}-\mathrm{M}$ reaction of phenylboronic acid with deactivated 4-iodoanisole, both 61-of them offered quickly decreasing yields (61$98 \%$ ) in five repeated runs. In the reaction of 4-methoxyphenylboronic acid with cinnamyl bromide, in contrast, the product was obtained in medium to high yields (Scheme 10). The grafting method seems to yield somewhat better catalysts. It was also found that two catalysts displayed better performance than those prepared via attaching azamacrocyclic Pd complexes to polystyrene or other silica-modified macrocycles. ${ }^{69}$

In the earliest reported synthesis, Gao et al. reacted a wide range of aryl bromides and dibromoarenes with arylboronic acids in the presence of Pd-imidazolium-silica composites (PdM-T-S) (8) as catalyst at room-temperature (Scheme 12). The preparation of the catalyst is illustrated in Scheme 11. Firstly, pore walls of SBA-15 silica with template P123 were immobilized by chlorotrimethylsilane. Then imidazolium salts were covalently bonded inside the channel of SBA- 15 albeit without the template. Finally, Pd salts are loaded in the pore channels of functionalized mesoporous silica by electrostatic interaction. ${ }^{70}$

Similarly, aggregation of Pd catalyst can be efficiently controlled owing to pore-containing effect of mesoporous silica and stabilized imidazolium salt existed on the inner walls. The resulting catalyst could be recycled at least 4-6 times and its TOF (Turn-Over Frequency) could reach up to $84000 \mathrm{~h}^{-1}$ at $50{ }^{\circ} \mathrm{C}$. Comparison the performance of Pd-M-T-S with $\mathrm{Pd}(\mathrm{II}) /$ SBA-15 and $\mathrm{PdCl}_{2}$ catalyst for S-M reaction at room temperature indicated that among them, Pd-M-T-S catalyst exhibited higher activity with low Pd leaching because imidazolium-silica composite can strongly prevent leaching of Pd. ${ }^{70}$

Simultaneously, as shown in Scheme 13, a series of modified catalysts, Pd/SBA-15/Pr-NH-Ethyl-NEt ${ }_{2}(\mathbf{9 a}-\mathbf{c}, 10)$ were produced via the reaction of mesoporous molecular sieve SBA-15 bearing $\equiv \mathrm{Si}\left(\mathrm{CH}_{2}\right)_{3} \mathrm{NH}\left(\mathrm{CH}_{2}\right)_{2} \mathrm{NEt}_{2}$ groups and $\mathrm{Pd}(\mathrm{II})$ ions. $^{.1}$

Then to investigate the performance of metal loading and innocent surface modifications with trimethylsilyl (TMS) groups, these catalysts were tested in S-M reactions. Biaryl coupling reactions were done using aryl halides and phenylboronic acid, in the presence of an amount of corresponding catalysts $(\mathbf{9 a}-\mathbf{c}, 10)$ with $0.5 \mathrm{~mol} \% \mathrm{Pd}$, and $\mathrm{K}_{3} \mathrm{PO}_{4}$ as a base (Scheme 14). The catalytic performance of such materials differs by the degree of metalation and is also adjusted by the<smiles>[X]c1ccc(C=CC(Br)c2ccccc2)cc1</smiles>

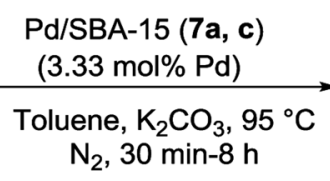
$\mathrm{N}_{2}, 30$ min-8 $\mathrm{h}$

RHN

$$
\begin{aligned}
& \mathrm{X}=\mathrm{Cl}, \mathrm{Br}, \mathrm{I} \\
& \mathrm{R}=\mathrm{H}, \mathrm{OMe}
\end{aligned}
$$

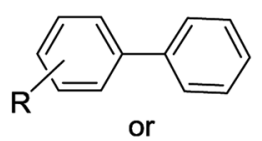<smiles>[R]c1ccc(CC=Cc2ccccc2)cc1</smiles>

Catalysts Pd/SBA-15 7a: $61-97 \%$ Catalysts Pd/SBA-15 7c: $94-98 \%$

$\operatorname{Ar}=2,4,6-$ triisoPrC $6{ }_{6} \mathrm{H}_{2}$

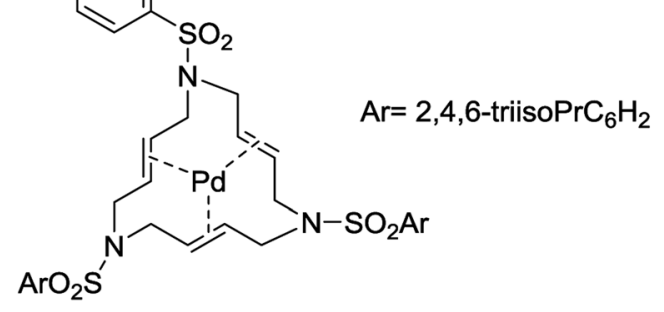




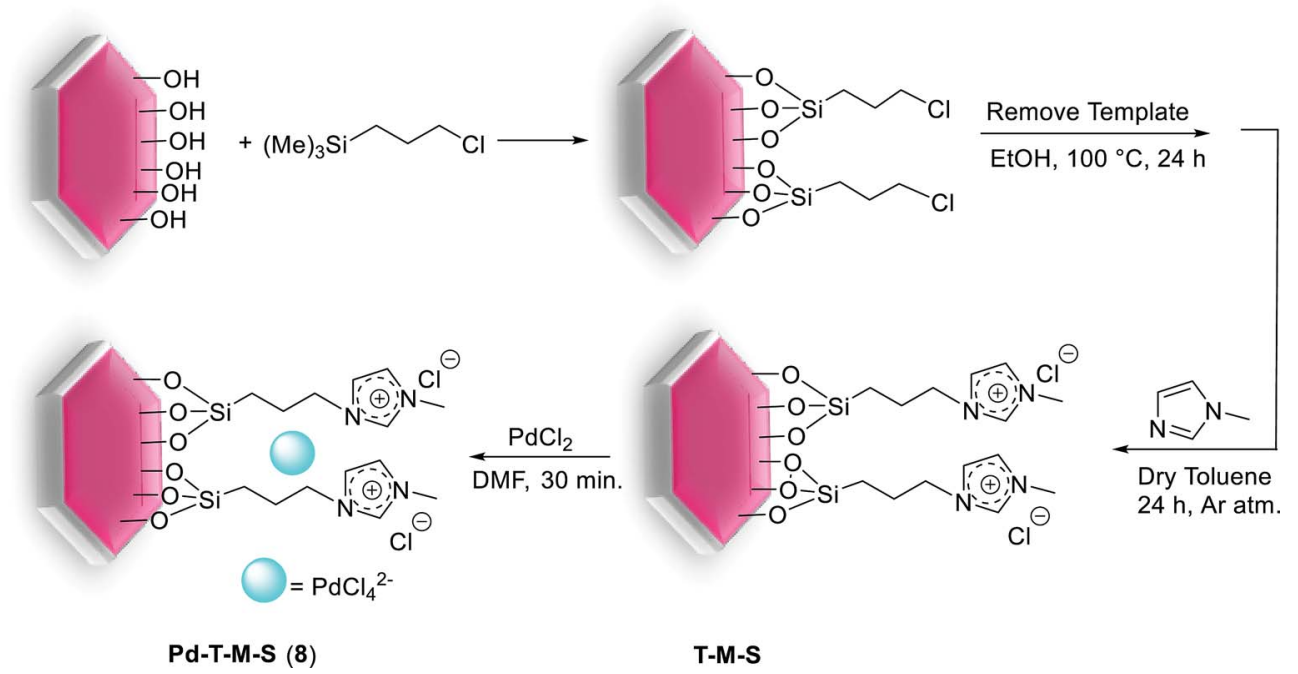

Scheme 11 Illustration of the procedure for immobilization of $\mathrm{PdCl}_{4}{ }^{2-}$ in imidazolium-functionalized mesoporous silica SBA-15, [Pd-M-T-S (8)].

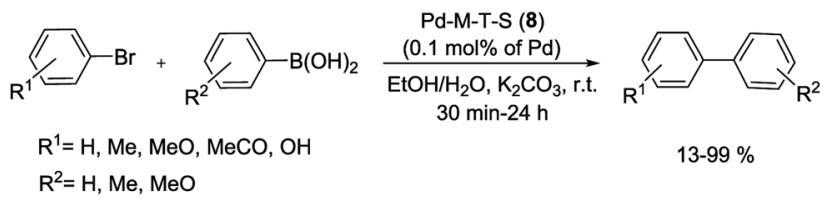

Scheme 12 Suzuki cross-coupling reaction of aryl halide with arylboronic acids catalyzed by Pd-M-T-S ( 8 ).

characteristics of the support surface. In the Suzuki reaction, the catalyst activity increased by enhancing amount of the Pd decorated SBA-15 nanocomposite. The catalyst bearing the highest amount of Pd (lowest $\mathrm{N}$ : Pd ratio) executed best in the series. ${ }^{71}$

Pd NPs (SBA-15-SH-Pd) (11) has offered leach-resistant, reusable catalyst that was capable of conducting a Suzuki reaction. A good yield was obtained in the coupling of phenyl boronic acid pinacol ester (PhBpin) with aryl bromide at $80^{\circ} \mathrm{C}$ in DMF : $\mathrm{H}_{2} \mathrm{O}$ mixture using $\mathrm{K}_{2} \mathrm{CO}_{3}$ as base (Scheme 15). The results indicated that the basic conditions of the Suzuki coupling result in a rapid and destruction reordering of another stable mesoporous silicate materials. This degradation is decreased through the formation of boric acid as a reaction byproduct. Because of low leaching of Pd, it was found that probably mercaptopropyl trialkoxysilane-functionalized materials could act both as scavengers for soluble Pd and as reusable catalysts. $^{72}$

Feng et al. have more recently reported excellent results. In their research a novel technique for the preparation of SBA-15supported Pd catalyst (Ph-SBA-15- $\left.\mathrm{PPh}_{3}-\mathrm{Pd}\right)$ (12) for the coupling of various aryl bromides with arylboronic acids in supercritical carbon dioxide $\left(\mathrm{scCO}_{2}\right)$ was employed. According to the process demonstrated in Scheme 16, the internal and external surfaces of SBA-15 were successfully modified using $(\mathrm{MeO})_{3} \mathrm{SiPh}$ and a colorless viscous liquid phosphine ligand, $(\mathrm{MeO})_{3} \mathrm{Si}\left(\mathrm{CH}_{2}\right)_{3}-$ $\mathrm{SCH}_{2} \mathrm{C}_{6} \mathrm{H}_{4} \mathrm{PPh}_{2}$. Finally, after removing the template, the Pd species were anchored inside the cavity of the mesoporous material $\mathrm{Ph}-\mathrm{SBA}-15-\mathrm{PPh}_{3}$ through a ligand-exchange reaction to afford Ph-SBA-15-PPh ${ }_{3}$-Pd catalyst (12). ${ }^{73}$

Substituted biaryls were obtained in good to excellent yields under the optimized reaction conditions (Scheme 17). The PhSBA-15- $\mathrm{PPh}_{3}$-Pd (12) catalyst has the small amount of leaching $\mathrm{Pd}$ and could be recycled at least 7 times without significant loss of its catalytic activity. ${ }^{73}$

In a recent study, Cao et al. successfully describe a facile method to produce size-controllably (1-3 nm) monodisperse Pd and $\mathrm{Pd} / \mathrm{Au}$ bimetallic NPs planted in SBA-15 followed by controlling the $\mathrm{pH}$ value, the amount of precursors and the interaction time between the metal species and the G4-poly (amido-amine) (G4-PAMAM, G represents the generation) dendrimer functionalized SBA-15. Monodisperse NPs are uniformly stabilized in the channel network of SBA-15 silica as observed by the TEM images. Next, the activity and recyclability of resulting catalysts, denoted as Pd-G4-PAMAM-SBA-15 (13) and Pd/Au-G4PAMAM-SBA-15 (14), were studied in microwave (MW) assisted S-M reactions by $0.5 \mathrm{~mol} \%$ catalyst. Unfortunately, in spite of MW-assisted heating, the Pd NPs displayed poor performance in the coupling of aryl bromides with arylboronic acids. Also, as compared to pure Pd NPs, under the same conditions, the Pd/ $\mathrm{Au}$ alloy NPs showed superior catalytic activity. Moreover, these bimetallic NPs can also catalyze coupling between arylboronic acids and aryl chloride by moderate yields (Scheme 18). Recycling studies have demonstrated that the catalyst could be easily recovered and reused several times with no detectable deactivation. ${ }^{74}$

More recently, Crudden and his groups have prepared mercaptopropyl-functionalized silica SBA-15 for use in S-M coupling reactions with negligible Pd leaching. For synthesis of this catalyst, mercaptopropyl ligands were grafted to mesoporous SBA-15 by reaction with mercaptopropyltrimethoxysilane (MPTMS), has the high affinity of sulfur for Pd, following treated with $\mathrm{Pd}(\mathrm{OAc})_{2}$ to produce SBA-15-SH-Pd (15) catalyst. This heterogeneous catalyst was stable and active for the 


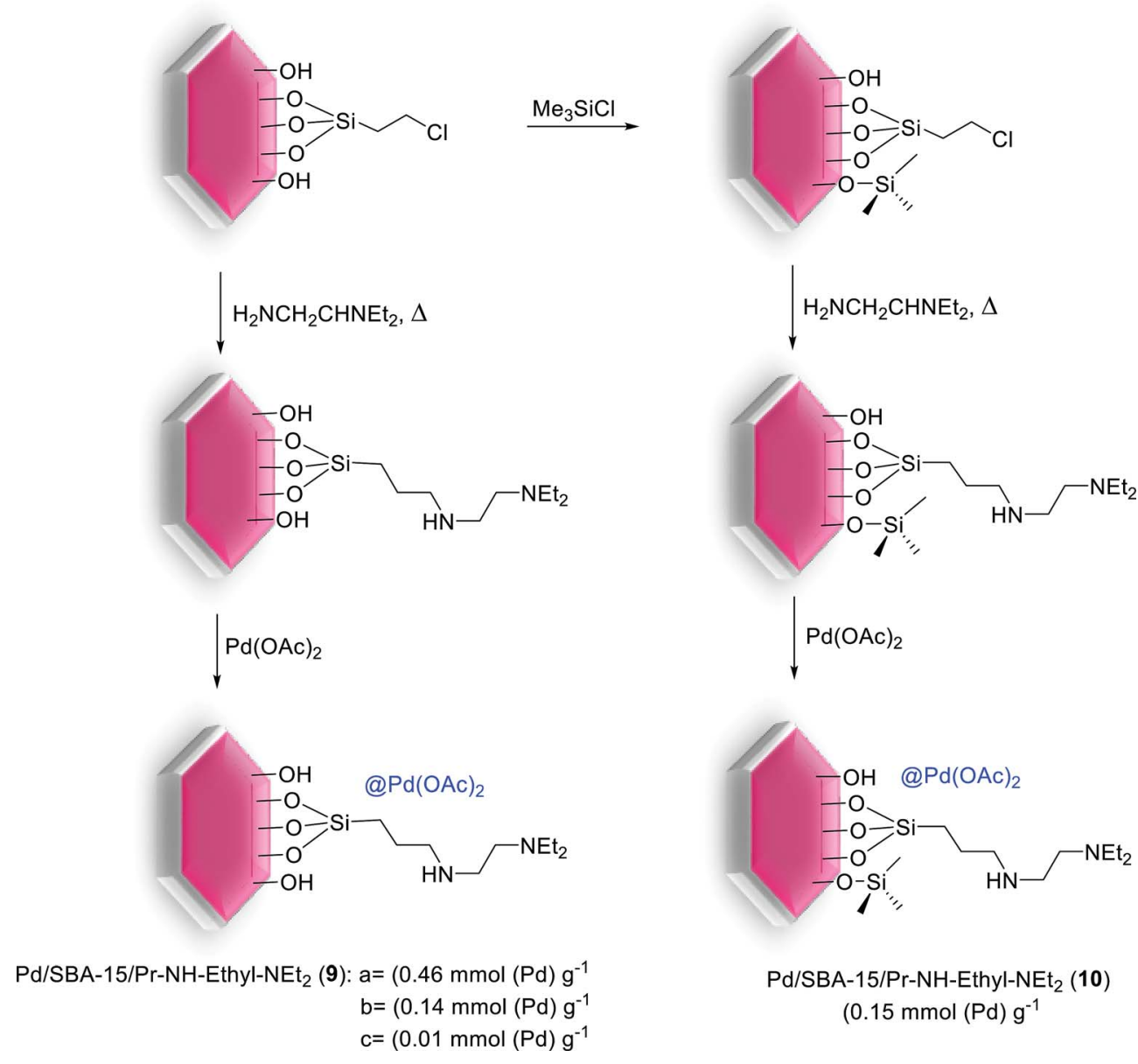

Scheme 13 Preparation of Pd/SBA-15/Pr-NH-Ethyl-NEt $2(9 a-c, 10)$ catalysts.

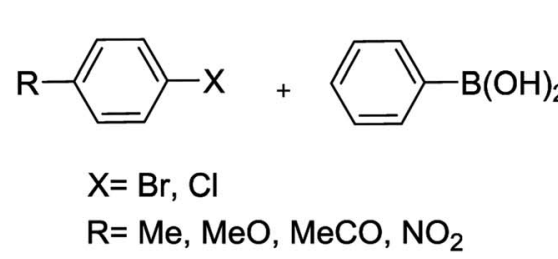

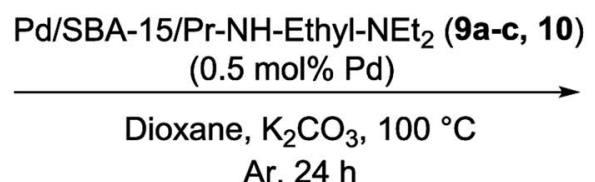

$\mathrm{Ar}, 24 \mathrm{~h}$

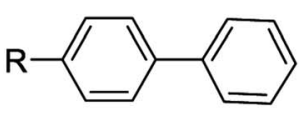

$32-95 \%$

Scheme 14 Suzuki reaction catalyzed by Pd/SBA-15/Pr-NH-Ethyl-NEt $(9 a-c, 10)$ catalysts.

coupling of PhBpin with a large variety of heterocyclic and polycyclic aryl bromides in high yields through both inert and air atmospheres (Scheme 19). Nevertheless, the authors indicated that turn-over number (TON) and TOF of this catalyst were higher for reactions run in an inert atmosphere. ${ }^{75}$
Hesemann et al. reported the synthesis of novel functional silica materials by difunctional thiol-amide substructures. The modified materials were prepared by both post-grafting and one-pot co-condensation methods. The catalytic behavior of these catalysts, SBA-15-(1/8-KCl)-Pd (16), SBA-15-G-Pd (17) and<smiles>CC(=O)c1ccc(Br)cc1</smiles>

SBA-15-SH.Pd (11) (1 mol\% Pd)

$\mathrm{DMF} / \mathrm{H}_{2} \mathrm{O}, \mathrm{K}_{2} \mathrm{CO}_{3}, 80^{\circ} \mathrm{C}, \mathrm{Ar}$ $20 \mathrm{~h}$

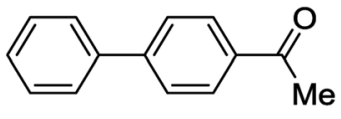

Scheme 15 The Suzuki-Miyaura cross-coupling reaction catalyzed by SBA-15-SH-Pd (11). 


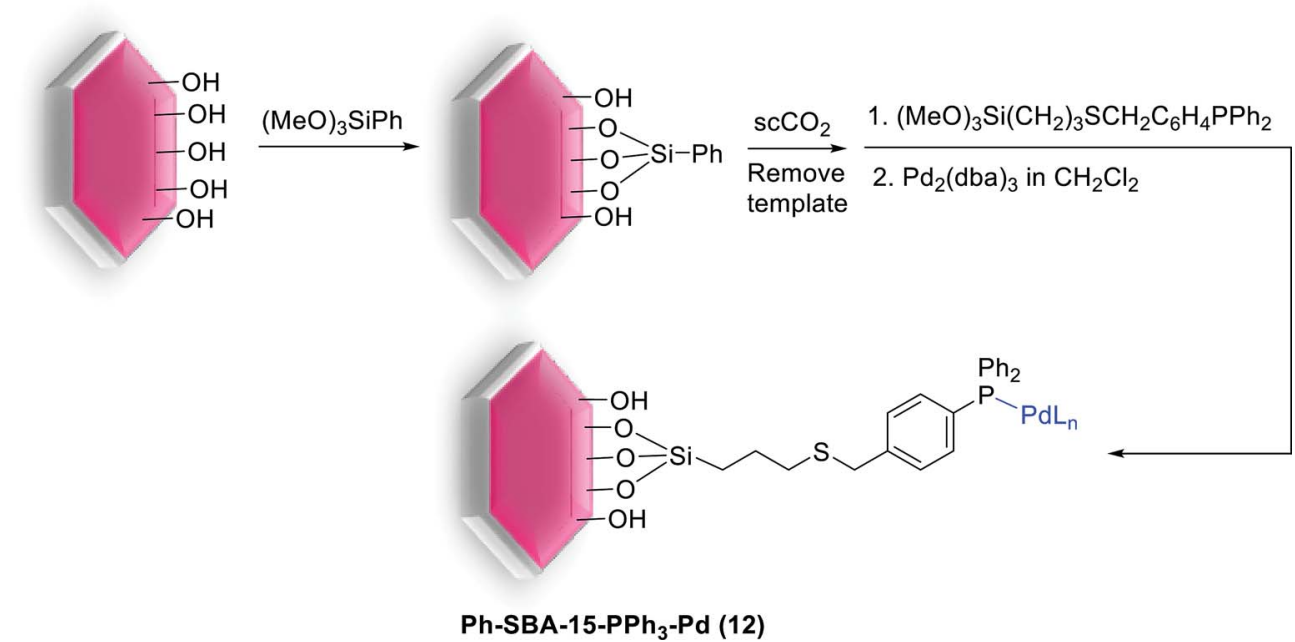

Scheme 16 Schematic illustration for the preparation of the Ph-SBA-15-PPh $-\mathrm{Pd}$ catalyst (12) catalyst.

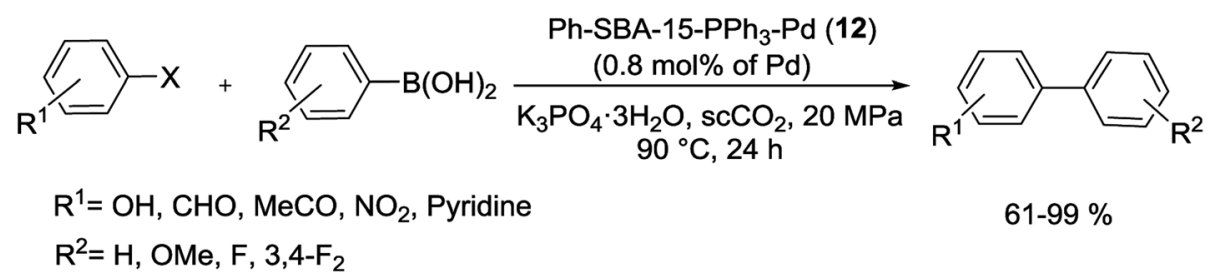

Scheme 17 Suzuki coupling reaction of aryl bromides with arylboronic acids catalyzed by Ph-SBA-15-PPh $-\mathrm{Pd}(12)$.

SBA-15-SH-Pd (18) were studied in S-M coupling of several aryl bromides with PhBpin (Scheme 20). ${ }^{76}$

Compared by conventional thiol-functionalised materials prepared with mercaptopropyl-trialkoxysilane precursors, these new thiol-modified silica materials display significantly improved reusability (Fig. 1). ${ }^{76}$

This result can be ascribed to the higher hydrophobicity of the new materials, due to the usage of the bulkier bis-silylated amide-thiol precursor. In this series for both catalytic reusability and activity, the grafted material SBA-15-G-Pd (17) demonstrated the highest performance. The high stability of this material can be assigned to the high degree of condensation of the silica centers over the mesoporous structure [66]. The group of $\mathrm{Hu}$ investigated the effect of the $\mathrm{Pd}(\mathrm{II})$ coordination

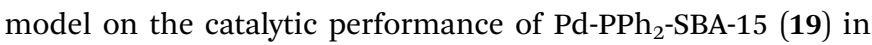
the S-M coupling reaction (Scheme 21). A series of heterogenized $\mathrm{Pd}$ (II) organometallic catalysts were produced through coordinating $\mathrm{Pd}$ (II) species with the $\mathrm{PPh}_{2}-\mathrm{CH}_{2}-\mathrm{CH}_{2}-$ ligands originally attached to SBA-15 silica support. The facile ${ }^{31} \mathrm{P}$ CP MAS NMR spectra exhibits that there were two types of

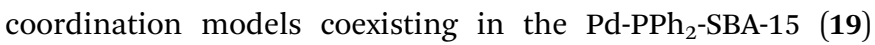
catalysts. Scheme 21 demonstrates that the formation of the various coordination models was strongly dependent on the Pdcontent grafted on the SBA-15 support [67].

At high Pd-content, the Pd(II) ions preferentially coordinated by two $\mathrm{PPh}_{2}$ ligands (denoted as $\mathrm{Pd}-2 \mathrm{P}$ model) due to the strong chelating bond. Nevertheless, at low Pd-content, the Pd ions often coordinated by one $\mathrm{PPh}_{2}$ ligand (signified as Pd-1P model) owing to long distance between two neighboring $\mathrm{PPh}_{2}$ ligands. Then the pure Pd-2P coordination model was synthesized by cocondensation between TEOS and $\operatorname{PdCl}_{2}\left[\mathrm{PPh}_{2}\left(\mathrm{CH}_{2}\right)_{2^{-}}\right.$ $\left.\mathrm{Si}\left(\mathrm{OCH}_{2} \mathrm{CH}_{3}\right)_{3}\right]_{2}$. Through Suzuki reaction (Scheme 22), the Pd-
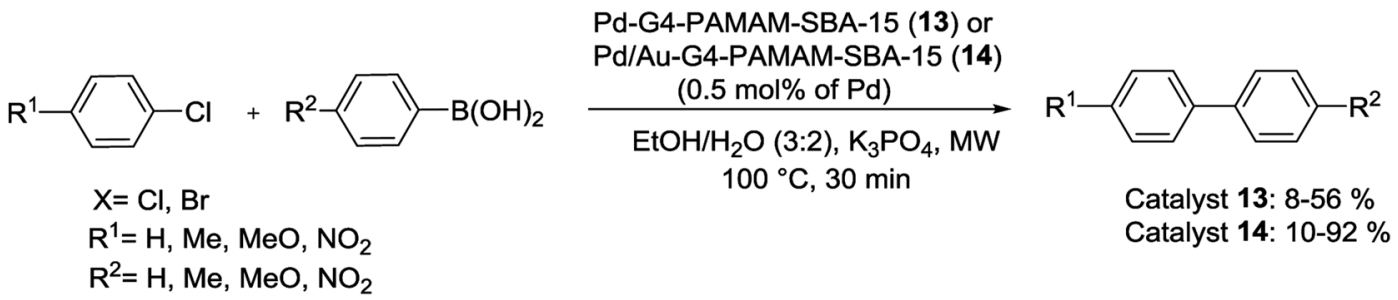

Scheme 18 Suzuki cross-coupling reactions catalyzed by Pd-G4-PAMAM-SBA-15 (13) and Pd/Au-G4-PAMAM-SBA-15 (14). 

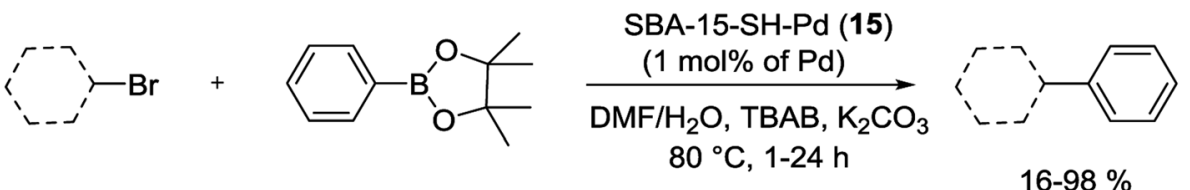

Arylbromide:

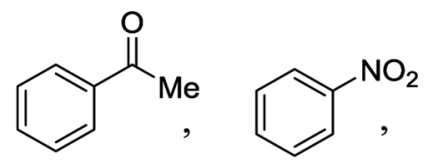<smiles>Nc1ccccc1</smiles><smiles>O=[N+]([O-])c1cccnc1</smiles><smiles>Brc1cccnc1</smiles><smiles>c1ccc2ncccc2c1</smiles><smiles>COc1ccc2ccccc2c1</smiles><smiles>C=Cc1ccccc1C=C</smiles>

Scheme 19 S-M cross-coupling reaction catalyzed by SBA-15-SH-Pd (15).

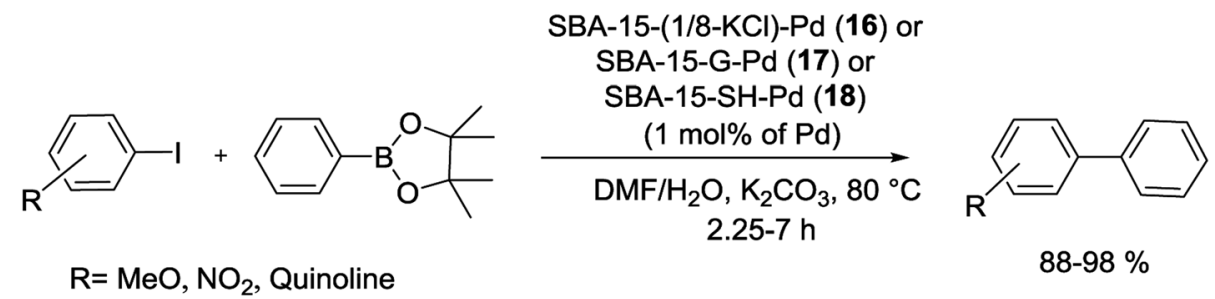

Scheme 20 S-M coupling reactions catalyzed by SBA-15-(1/8-KCl)-Pd (16), SBA-15-G-Pd (17) and SBA-15-SH-Pd (18).

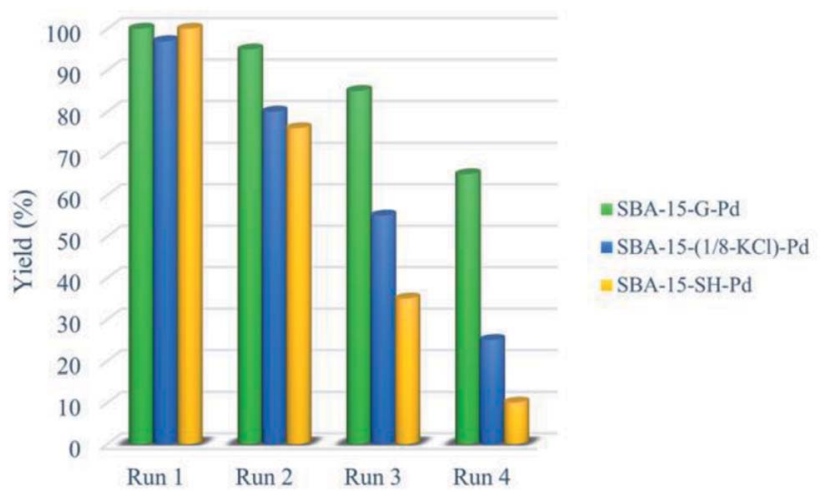

Fig. 1 Recyclability of the materials SBA-15-(1/8-KCl)-Pd (16), SBA$15-\mathrm{G}-\mathrm{Pd}$ (17) and SBA-15-SH-Pd (18) in S-M coupling reaction of $1-$ bromo-4-nitrobenzene with PhBpin.

2P model demonstrated higher catalytic selectivity and activity than the Pd-1P which can probably be attributed to the, coordination configuration, electronic state and uniform distribution of the $\operatorname{Pd}(\mathrm{II})$ active sites together with the stability of Pd ions against leaching. ${ }^{77}$

Recently, the carbon thin film-lined SBA-15 nanoreactor was synthesized by formation monolayers of enediyne compounds inside activated SBA-15 accompanied by Bergman cyclization and carbonization. Finally Pd@SBA-15@ (20) was obtained via a wetness impregnation method by $\mathrm{H}_{2} \mathrm{PdCl}_{4}$ as the precursor accompanied via reduction of $\operatorname{Pd}(\mathrm{II})$ to $\mathrm{Pd}(0)$ under $\mathrm{H}_{2} / \mathrm{Ar}(1: 9)$ atmosphere at $400{ }^{\circ} \mathrm{C}$ (Scheme 23). ${ }^{78}$
The resulting nanoreactors catalyzed the S-M coupling of various aryl bromides with different substituents phenylboronic acid, by addition of tetrabutylammonium bromide (TBAB) as a phase transferring agent to yield the corresponding biphenyls up to $99 \%$ (Scheme 24$)^{78}$

The catalyst was easily separated and reused five times without negligible loss of its catalytic activity. A kinetic study demonstrated that the carbon thin film lining was necessary for both the high reactivity and stability of the nanoreactor. The inductive coupled plasma-atomic emission spectroscopy (ICPAES) analysis exhibited very low Pd leaching $(<0.12 \%$ of the total Pd). ${ }^{78}$

Gruttadauria and co-workers have introduced multi-layered covalently supported ionic liquid phase (mlc-SILP) SBA-15-Pd catalyst for the S-M reaction. The preparation of this catalyst was accomplished in two steps, as shown in Scheme 25. The reaction between a mercaptopropyl functionalized SBA-15 and an excess of 1,4-bis(3-vinylimidazolium-1-yl)bromide (IL) in the presence of azobisisobutyronitrile (AIBN) produced novel material, which has a high loading of imidazolium units. The SBA-15-IL (21) was stirred with an aqueous solution of $\mathrm{PdCl}_{4}{ }^{2-}$ and then reduced with $\mathrm{NaBH}_{4}$. Finally, a Pd catalyst containing a $10 \mathrm{wt} \%$ of the metal loading, SBA-15-Pd-IL (21), was obtained. ${ }^{79}$

This synthesized catalyst demonstrated high activity for the preparation of several biaryl compounds in excellent yields through only $0.1 \mathrm{~mol} \%$ of Pd loading at mild conditions. Good recyclability was viewed after four cycles (Scheme 26). ${ }^{79}$

The MW-assisted Suzuki coupling of aryl halides catalyzed with Pd/SBA-15 (22), containing $8.7 \mathrm{~mol} \% \mathrm{Pd}$, under solvent- 


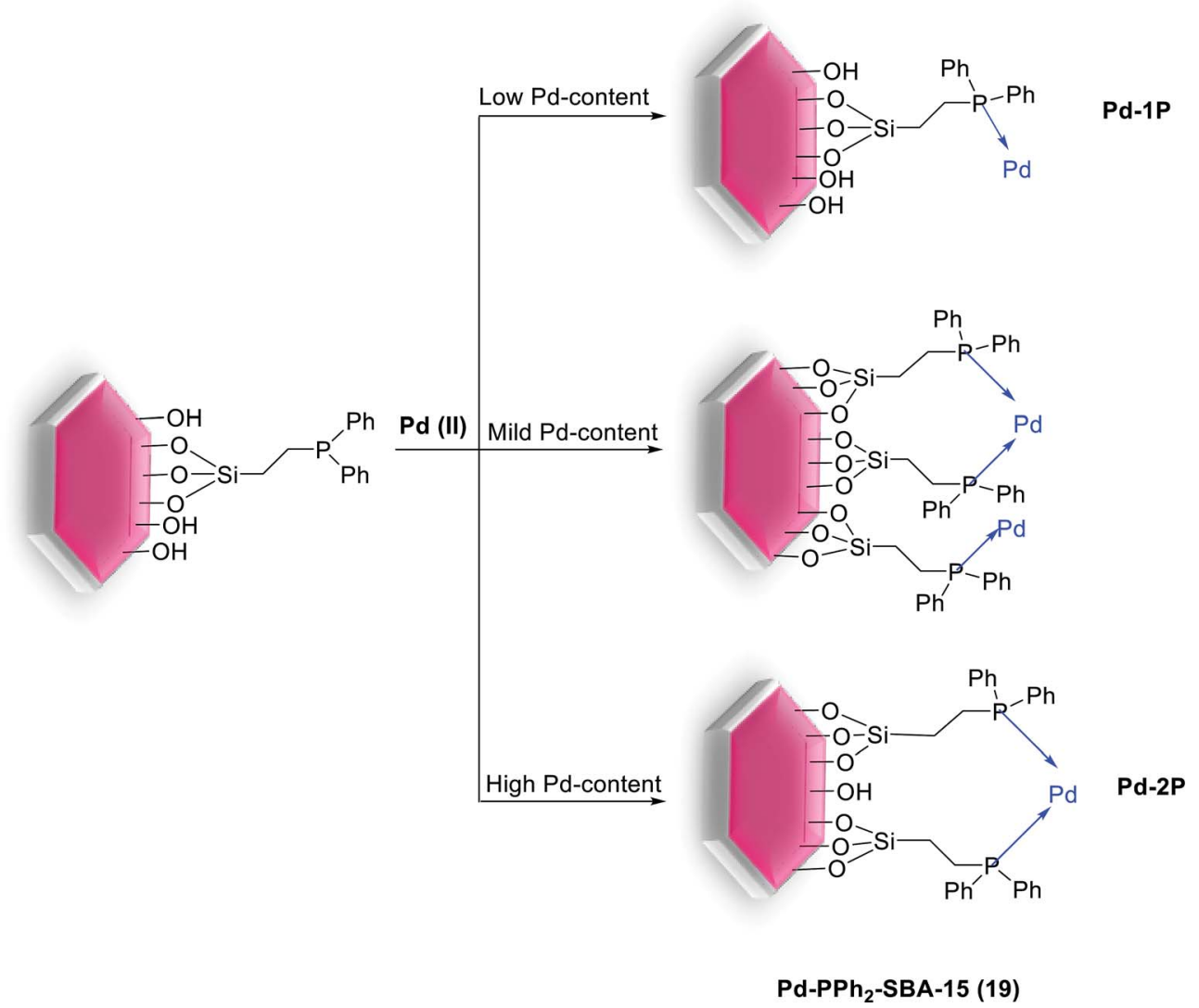

Scheme 21 Dependence of the coordination model on the Pd-content anchored on the SBA-15 support, Pd-PPh $2-S B A-15$ (19).

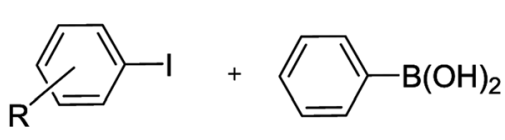

$\mathrm{R}=\mathrm{H}, \mathrm{Me}, \mathrm{MeO}, \mathrm{MeCO}$

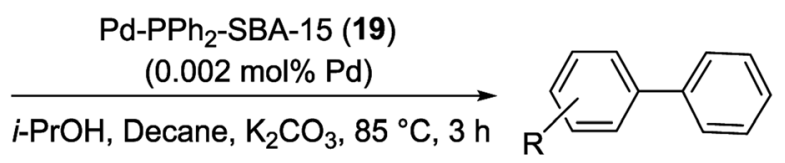

$35-99 \%$

Scheme 22 Catalytic performances of the Pd-PPh - SBA-15 (19) in Suzuki reactions.

free condition has been studied by Chang and co-workers. The reported catalyst was prepared by impregnation of an aqueous solution containing $\left[\mathrm{Pd}\left(\mathrm{NH}_{3}\right)_{4}\right] \mathrm{Cl}_{2}$ on the surface of SBA-15. In the following, reaction between various aryl iodides and bromides with phenylboronic acid gave biaryls in excellent yields at $120{ }^{\circ} \mathrm{C}$ for 10 min with $\mathrm{K}_{2} \mathrm{CO}_{3}$ as a base. Whereas the reaction with aryl chloride offered poor yield in similar condition (Scheme 27). ${ }^{80}$

In an interesting study, the SBA-15 immobilized Pd complex partially confined by imidazolium type ionic liquid (IL) has been reported. The preparation process to obtain the catalyst started from functionalization of SBA-15 by APTMS followed by the condensation with 2-acetylpyridine to yield the corresponding<smiles>C1CC2CCC3CCC4CCC5CCC6CCC(C1)C2C6C5C34</smiles>

SBA-15

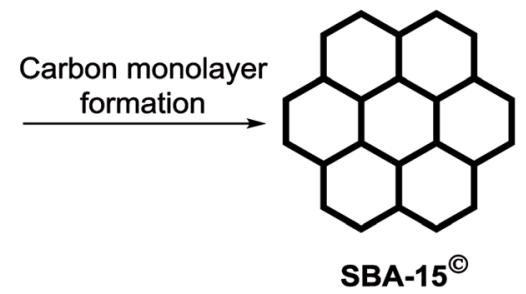

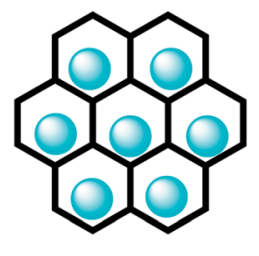

Pd@SBA-15 ${ }^{\odot}(20)$

Scheme 23 Schematic illustration for the preparation of the Pd@SBA-15@ (20). 


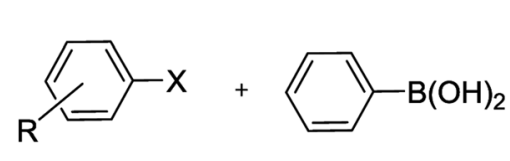

$\mathrm{X}=\mathrm{I}, \mathrm{Br}, \mathrm{Cl}$

$\mathrm{R}=\mathrm{H}, \mathrm{Me}, \mathrm{MeO}, \mathrm{MeO}_{2} \mathrm{C}, \mathrm{NO}_{2}, \mathrm{CHO}$

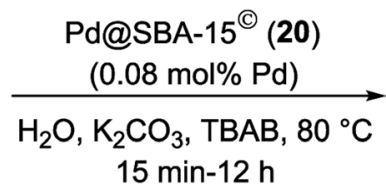

$15 \mathrm{~min}-12 \mathrm{~h}$

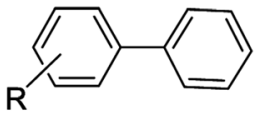

$35-99 \%$

Scheme 24 S-M coupling reactions of aryl halides over SBA-15 supported Pd catalysts.

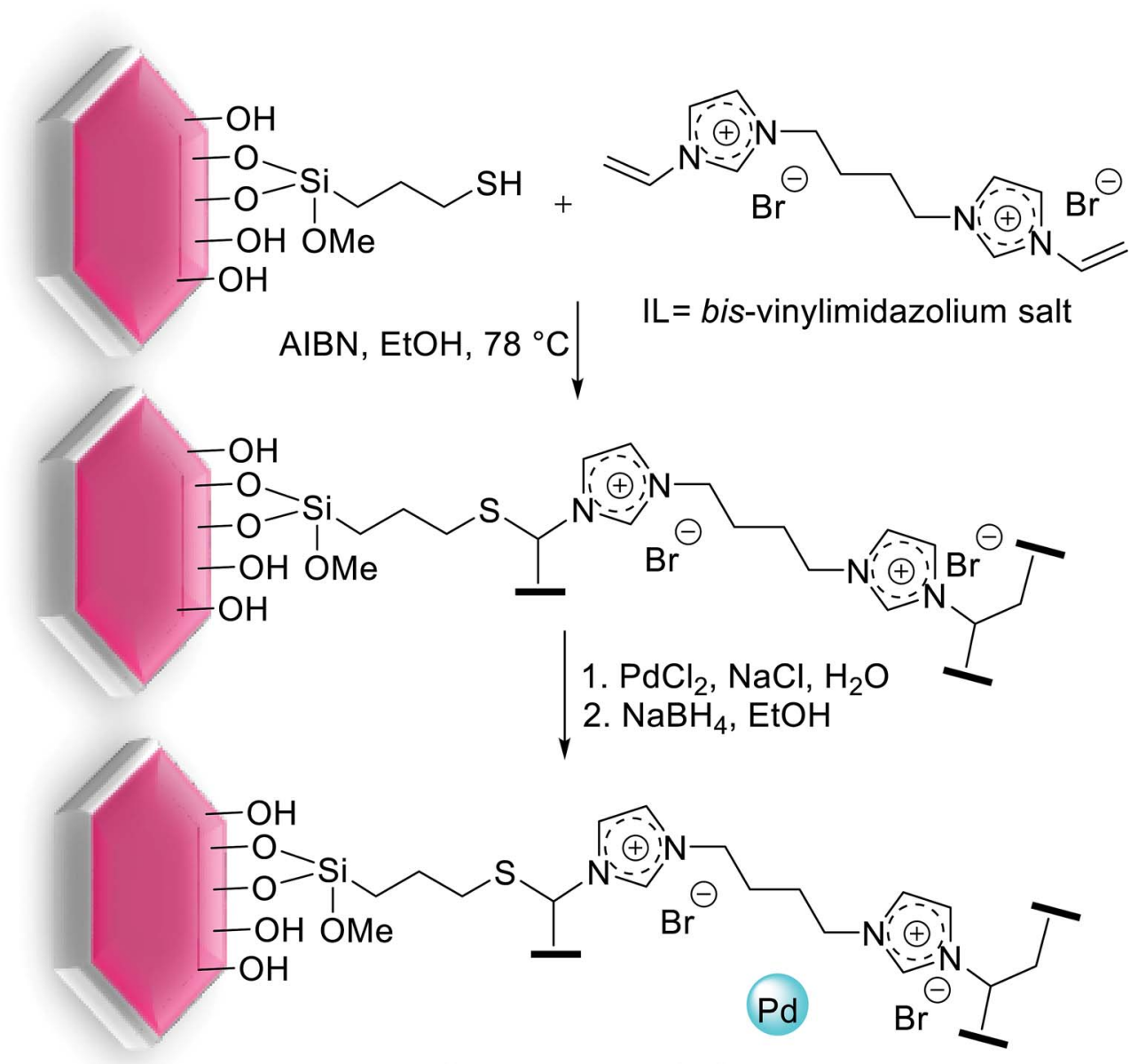

SBA-15-Pd-IL (21)

Scheme 25 Synthesis of SBA-15-Pd-IL (21) catalyst.

iminopyridine functionalized SBA-15 which was reacted with $\mathrm{Pd}(\mathrm{OAc})_{2}$ to give SBA-15-Pd. The obtained precatalyst was then react with 1-butyl-3-methylimidazolium hexafluorophosphate [BMIm] $\left[\mathrm{PF}_{6}\right]$ to yield IL@SBA-15-Pd (23) (Scheme 28). ${ }^{81}$

The Suzuki coupling of aryl and heteroaryl halides with various type of aryl boronic acids was applied to estimate the activity of this catalyst under aqueous medium (Scheme 29). The results exhibits that both electron-deficient and electronrich aryl bromides coupled efficiently at very low catalyst loading (0.05-0.1 mol\% of Pd). ${ }^{81}$

It is noteworthy that while kinetic experiments and hot filtration tests displayed the presence of soluble Pd species through the reaction process, investigation of recovery demonstrated that no significant decrease has occurred in the activity and Pd content of reused IL@SBA-15-Pd. Subsequently it is also a strong support for the generation and stabilization of active Pd NPs in the inner mesochannels of SBA-15 where physically attached ionic layers are located. ${ }^{81}$

Yang et al. prepared a Pd catalyst based on mesoporous SBA15 silica with spindle-like nitrogen donor groups, using the process shown in Scheme 30. The synthetic strategy involved the addition of (3-chloropropyl) trimethoxysilane to silica based SBA-15 followed by refluxing with 1,4-diaza-bicyclo[2.2.2]octane (DABCO) to give SBA-15@DABCO. Then by reaction with 

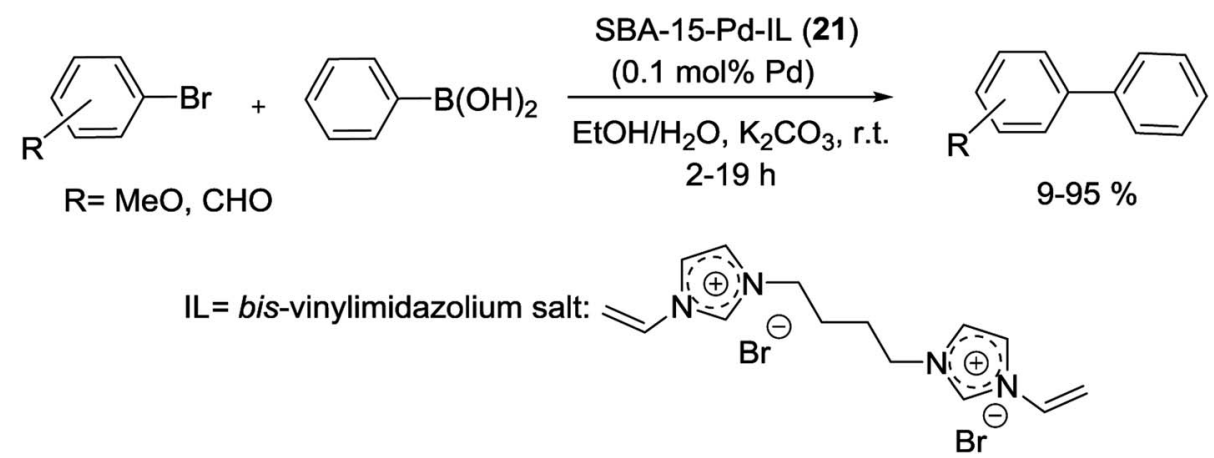

Scheme 26 Suzuki reactions between phenylboronic acid and aryl bromides catalyzed by SBA-15-Pd-IL (21).

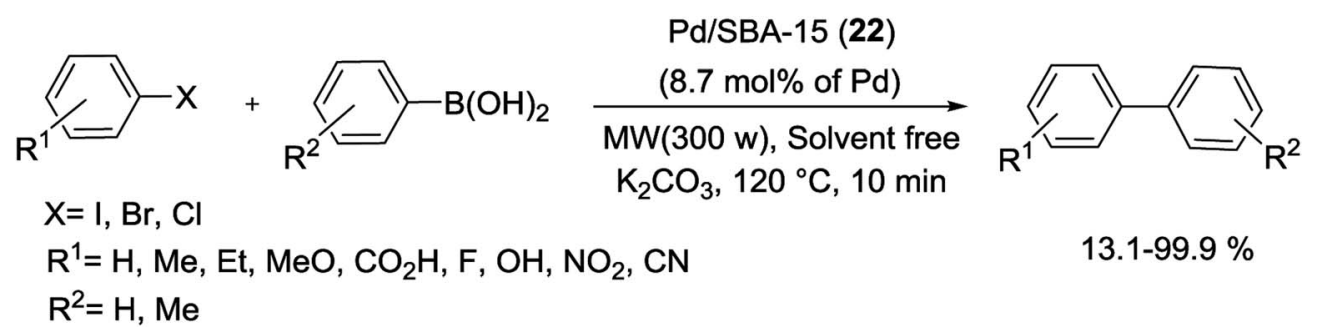

Scheme 27 MW-assisted Suzuki reaction catalyzed by Pd/SBA-15 (22) under solvent-free condition.

$\mathrm{Pd}(\mathrm{OAc})_{2}, \mathrm{Pd}$ species located in the pore channels of DABCO functionalized SBA-15 silica, and SBA-15@DABCO-Pd (24) catalyst was obtained. ${ }^{82}$

The maintained catalyst was also showed to be an efficient and air-stable heterogeneous catalyst for coupling of a series of substituted aryl halides $(\mathrm{X}=\mathrm{I}, \mathrm{Br})$ with arylboronic acids in $\mathrm{S}-\mathrm{M}$ reaction (Scheme 31). Moreover it could also be recovered simply by filtration and washing, then reused for five runs with nearly no evident loss of catalytic activity. ${ }^{82}$

A stable SBA-15 based Pd nanocomposite was simply synthesized through modification of the surface of SBA-15/Cl via metformin hydrochloride and consequently metal/ligand coordination by $\mathrm{Pd}(\mathrm{II})$ ions from $\mathrm{Pd}(\mathrm{OAc})_{2}$ (Scheme 32). ${ }^{83}$

The SBA-15/Met/Pd(II) (25) nanocomposite has potential catalytic application for the S-M reaction, gave the corresponding coupled products in $57-99 \%$ yields (Scheme 33). This heterogeneous Pd nanocomposite showed an efficient catalyst recyclability, little metal leaching and reused several times without considerable loss in its activity. ${ }^{83}$

In a careful study, different types of immobilized Pd(II) complexes bearing propyl ethylenediamine (PrEn) and propylamine $\left(\mathrm{PrNH}_{2}\right)$ in mesoporous SBA-15 were synthesized. Among them, the Pd(OAc) $)_{2} @ S B A-15 / \operatorname{PrEn}(26)$ (or Pd(OAc) $)_{2} @ S B A-15 /$ $\mathrm{PrNHEtNH}_{2}$ ) demonstrations higher selectivity and activity to $\mathrm{S}-\mathrm{M}$ reaction in a mixture of DMF and water (Scheme 35). For prepared of Pd@SBA-15/PrNH 2 (27) and Pd@SBA-15/PrEn (26) catalysts, the calcinated SBA-15 react with 3-aminopropyltriethoxysilane (APTES) to produced SBA-15/ $\mathrm{PrNH}_{2}$ or react with $N$-(2-aminoethyl)-3-aminopropyltrimethoxysilane (AEAPTMS) to give SBA-15/PrNHEtNH 2 . Then react with solution of Pd sources Pd(OAc) $)_{2}$ or $\mathrm{PdCl}_{2}$ to yield Pd@SBA-15/ $\mathrm{PrNH}_{2}$ (27) and Pd@SBA-15/PrEn (26), respectively (Scheme 34). ${ }^{84}$
$\operatorname{Pd}(\mathrm{OAc})_{2} @ S B A-15 / \operatorname{PrEn}(26)$ can be separated from reaction products easily and recycled after ten uses with unchanged its initial catalytic activity and a trace amount of the Pd leached. ${ }^{84}$

The Pd-SBA-15 (28) nanocomposite with controlled amino groups to Pd (N : Pd) molar ratio, displays high catalytic activity and a minimal amount of Pd leaching for the S-M coupling reaction (Scheme 36). In the synthesis of catalyst, mesoporous SBA- 15 was modified by addition of APTMS, and NH-SBA- 15 was obtained. Afterward, Pd(II) species were joined compactly on the organo-functionalized SBA-15 by the coordination bonds. Then the resulting material was reduced by formalin to yield Pd supported on SBA-15. The catalyst can also be recycled at least six runs in air with only a little decrease of activity and a partial agglomeration of Pd species. ${ }^{85}$

In a recent study, supported Pd NPs via SBA-15 and $\left[\mathrm{PdCl}_{2}(\operatorname{cod})\right]$ as a Pd precursor have been reported (with a maximum load of Pd of $12.80 \mathrm{wt} \%$ on SBA-15). This described method does not need the use of functionalized mesoporous silica. The SBA-15-Pd (29) catalyst has been examined in S-M coupling reactions of aryl and heteroaryl halides with phenylboronic acids (Scheme 37). Additionally, the hybrid material displayed higher conversion rates and a good degree of recyclability, in five run recycling studies. Pd leaching was not detected. Also, hybrid materials SBA-15-Pd (29) has been carried out in vitro against human cancer cells and demonstrated very high cytotoxic activity. ${ }^{86}$

A novel SBA-15/AO/Pd(II) (31) nanocatalyst was applied in S-M couplings and recovered by simple filtration and reused six times without losing of its activity. The catalyst synthesis started from combining of SBA-15 and 2-cyanoethyltriethoxysilane, formerly treated with hydroxylamine to produce the amidoxime grafted SBA-15 (SBA-15/AO). It then employed as platform for in 

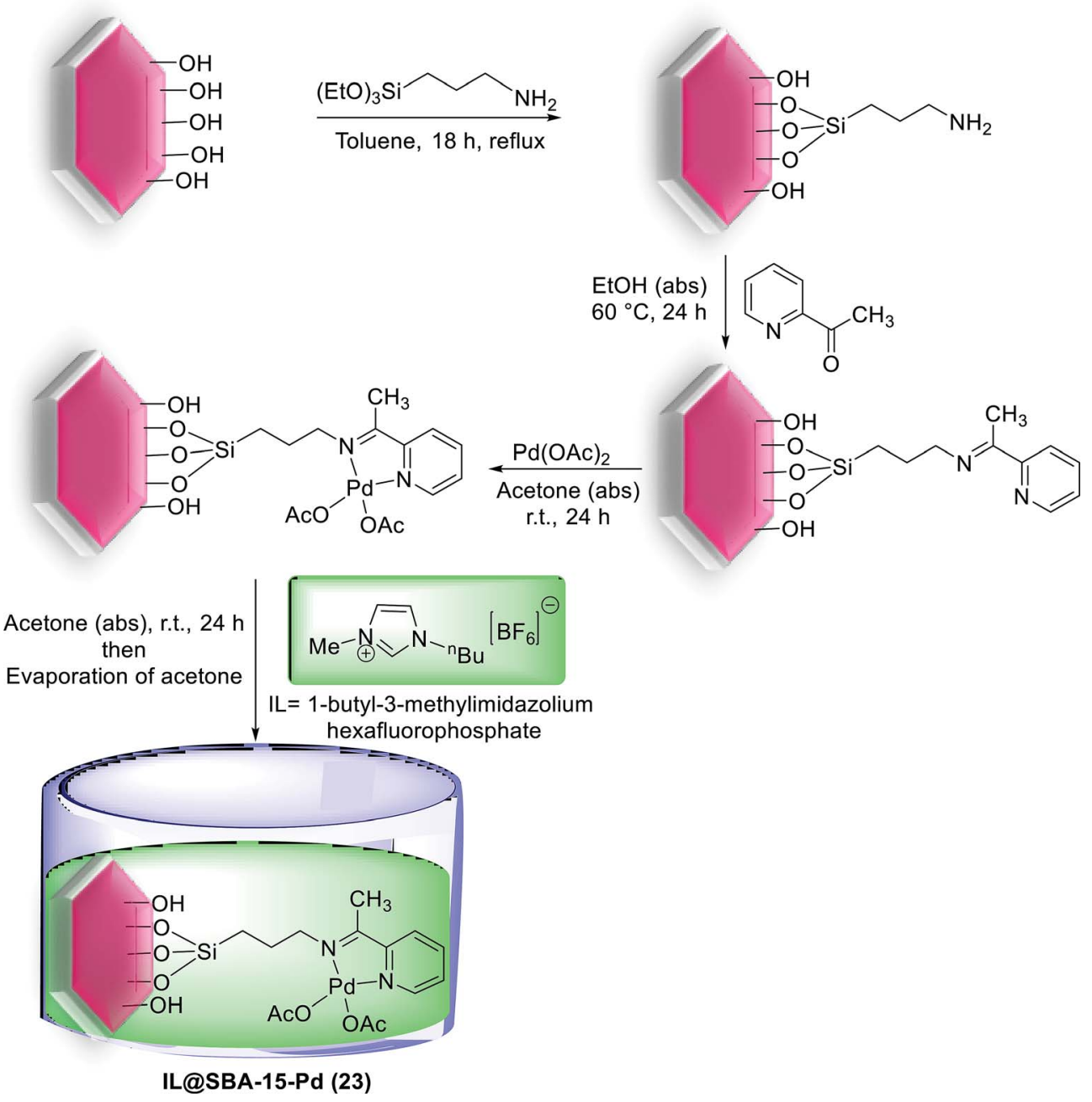

Scheme 28 A schematic pathway for preparation of SBA-15-functionalized Pd complex partially confined with [BMIm][PF 6 as IL, [IL@SBA-15-Pd (23)].

situ deposition of Pd species through react with $\mathrm{PdCl}_{2}$. The $\mathrm{Pd}$ NPs, fashioned after reduction of SBA-15/AO/Pd(II) (30) by hydrazine hydrate, are confined in the hexagonal channels of the mesoporous structure and $\mathrm{SBA}-15 / \mathrm{AO} / \mathrm{Pd}(0)$ (31) was obtained (Scheme 38). ${ }^{87}$ The SBA-15/AO/Pd(II) (30) catalyst gave high yields in the Suzuki coupling of a range of aryl and heteroaryl halides with phenylboronic acid. Reactions took place under aerobic conditions by addition of $\mathrm{K}_{2} \mathrm{CO}_{3}$ in mixture of $\mathrm{EtOH} / \mathrm{H}_{2} \mathrm{O}$. These cross coupled products were obtained in good to excellent yields (70-98) at exceedingly low Pd loading $(\sim 0.002 \mathrm{~mol} \%)$ with perfect high TOF (Scheme 39$){ }^{87}$

The highly dispersed Pd NPs into meso-structure nanocatalyst were produced using (3-mercaptopropyl)trimethoxysilane (MPTES) immobilized SBA-15. The attaching thiol groups were efficient for anchoring of Pd into the surface of silica support by $\mathrm{Pd}$ sources $\left[\mathrm{Pd}(\mathrm{OAc})_{2}\right.$ or $\left.\mathrm{PdCl}_{2}\right]$. Consequently reduction of immobilized $\mathrm{Pd}$ (II) using $\mathrm{NaBH}_{4}$ produced SBA-15/ SH-Pd-NPs (32) with $0.05 \mathrm{~mol} \%$ of Pd (Scheme 40$).^{88}$
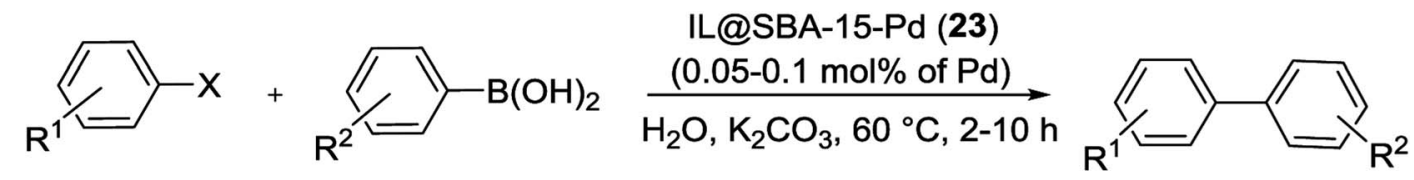

$$
\begin{aligned}
& X=\mathrm{I}, \mathrm{Br}, \mathrm{Cl} \\
& \mathrm{R}^{1}=\mathrm{H}, \mathrm{Me}, \mathrm{MeO}, \mathrm{CHO}, \mathrm{NO}_{2}, \mathrm{CN} \\
& \mathrm{R}^{2}=\mathrm{H}, \mathrm{Me}
\end{aligned}
$$

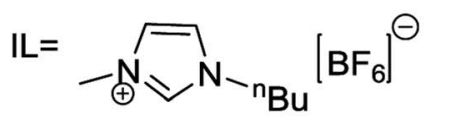

$84-100 \%$

Scheme 29 S-M coupling of aryl halides with aryl boronic acids using IL@SBA-15-Pd (23). 

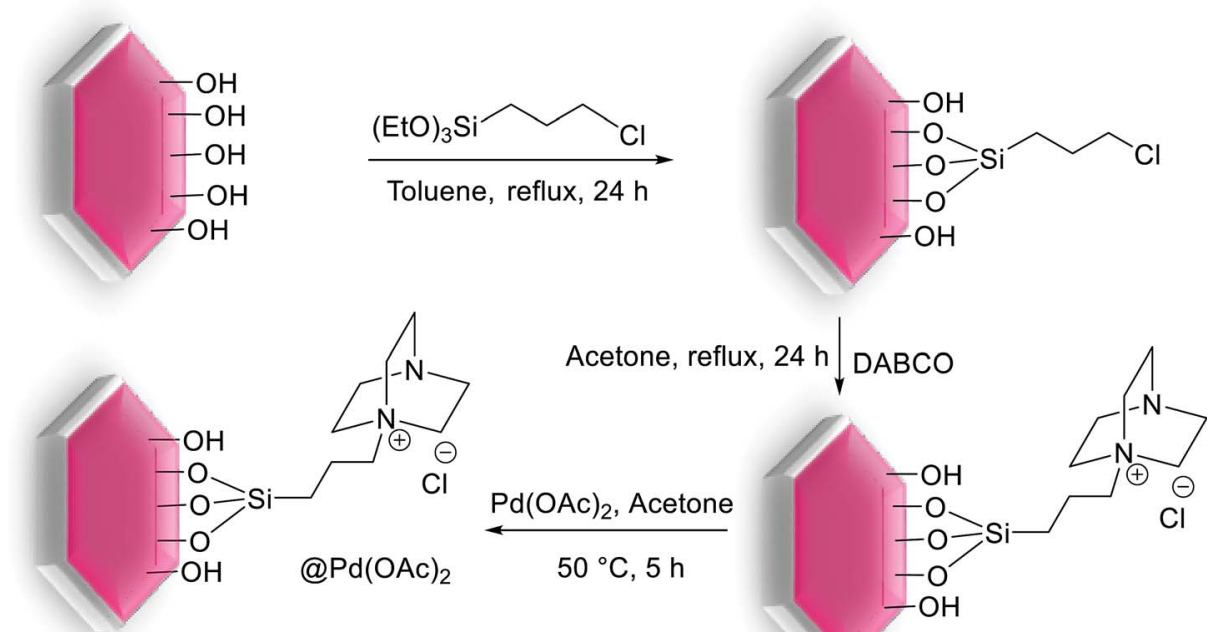

SBA-15@DABCO-Pd complex (24)

Scheme 30 Preparation of SBA-15@DABCO-Pd complex (24).

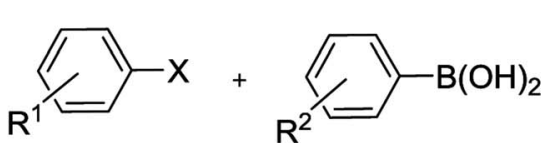

$\mathrm{X}=\mathrm{I}, \mathrm{Br}, \mathrm{C}$

$\mathrm{R}^{1}=\mathrm{H}, \mathrm{Me}, \mathrm{MeO}, \mathrm{MeCO}, \mathrm{NO}_{2}$

$\mathrm{R}^{2}=\mathrm{H}, \mathrm{MeO}$
SBA-15@DABCO-Pd (24)

$(0.3 \mathrm{~mol} \%$ of $\mathrm{Pd})$

$\mathrm{DMF} / \mathrm{H}_{2} \mathrm{O}, \mathrm{K}_{2} \mathrm{CO}_{3}, 60^{\circ} \mathrm{C}$

4-24 h<smiles>[R]c1cccc(-c2cccc([R])c2)c1</smiles>

$0.3-100 \%$

Scheme 31 SBA-15@DABCO-Pd (24) catalyzed Suzuki cross-coupling reaction.

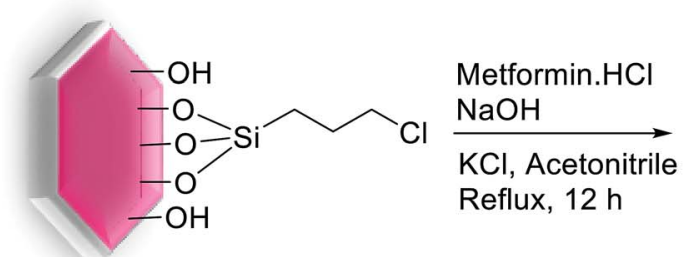

SBA-15/CI

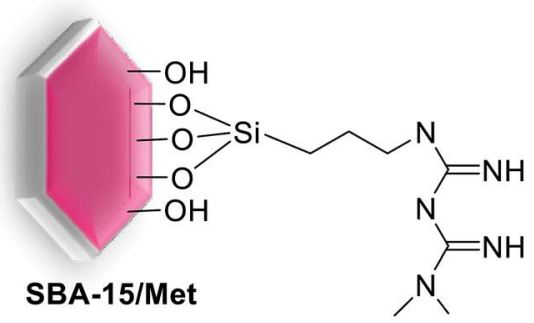

$\mathrm{Pd}(\mathrm{OAc})_{2} \downarrow$ Acetone, $4 \mathrm{~h}$

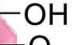

$-\mathrm{O}=\mathrm{Si} \sim \mathrm{N}$<smiles>NC(N)=N[Pb]</smiles>

SBA-15/Met/Pd(II) (25)

Scheme 32 Schematic diagram of SBA-15/Met/Pd(I) (25) preparation. 
<smiles></smiles>

$\mathrm{X}=\mathrm{I}, \mathrm{Br}, \mathrm{Cl}$

$\mathrm{R}^{1}=\mathrm{H}, \mathrm{Me}, \mathrm{MeOC}, \mathrm{NO}_{2}, \mathrm{CN}$, Thiophene

$\mathrm{R}^{2}=3,4,5-\mathrm{F}_{3}, \mathrm{NO}_{2}$

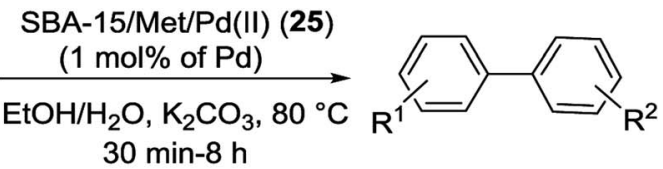

$57-99 \%$

Scheme 33 S-M cross-coupling reactions of aryl halides with arylboronic acids catalyzed by the SBA-15/Met/Pd(॥) (25).
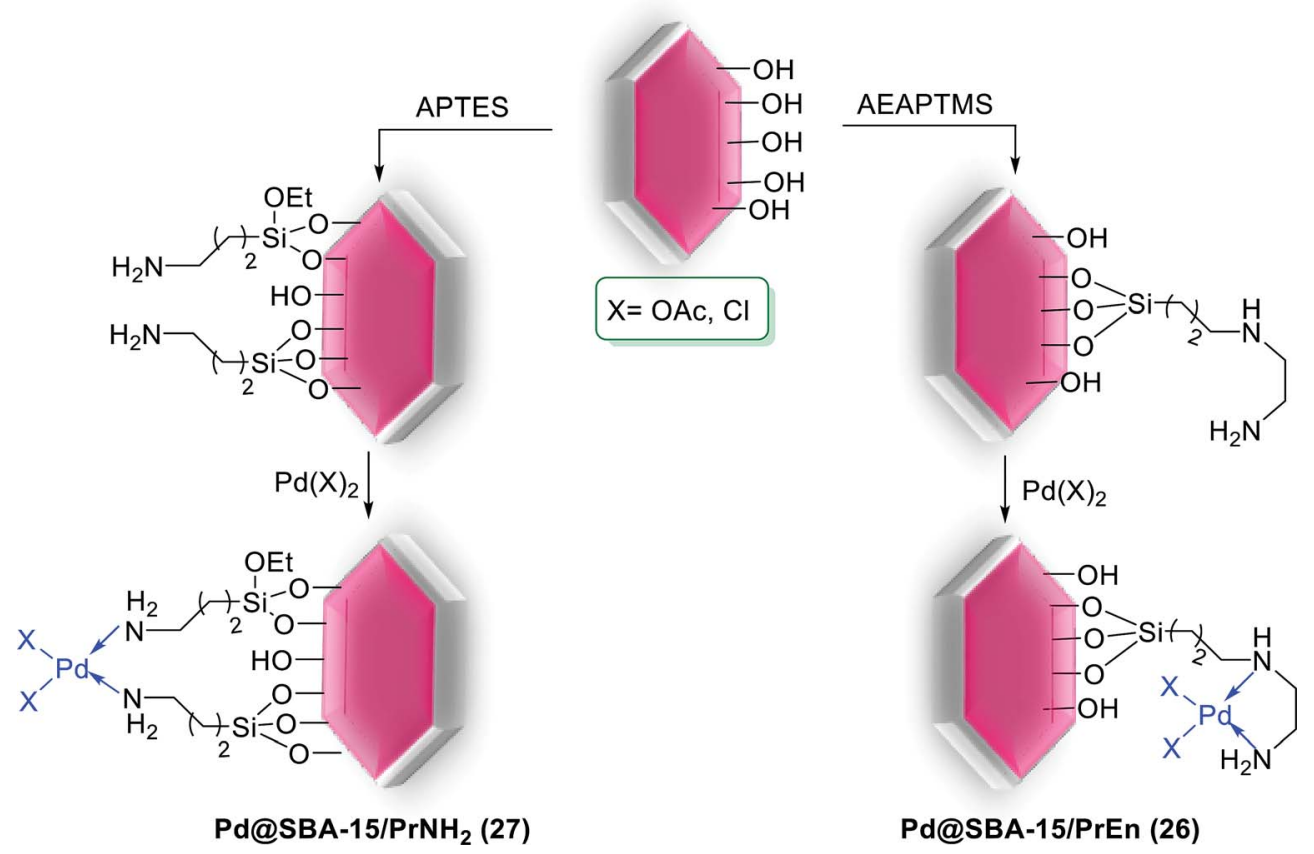

Pd@SBA-15/PrEn (26)

Scheme 34 Schematic representation of PdaSBA-15/PrNH 2 (27) and PdaSBA-15/PrEn (26) preparation.

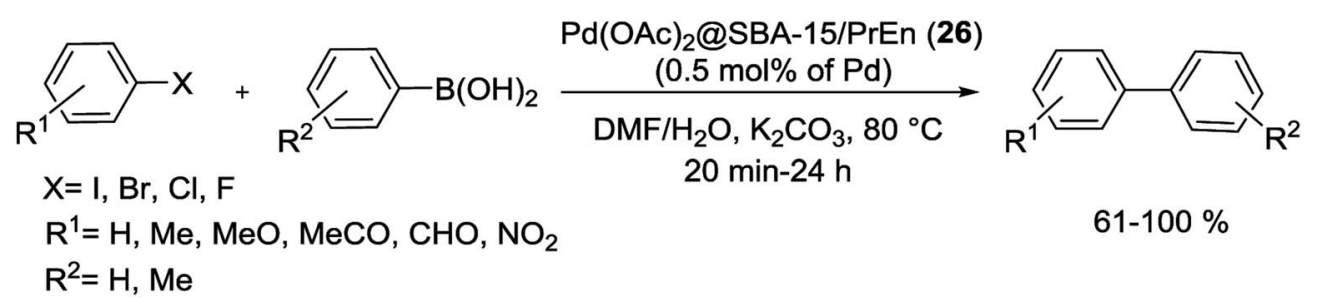

Scheme 35 Suzuki cross-coupling reaction of various substrates catalyzed by Pd(OAc) 2 (aSBA-15/PrEn (26) under optimized conditions.

This nanocatalyst was used in the synthesis of various biaryls via aerobic Suzuki coupling reaction using $0.5 \mathrm{mmol}$ of TBAB (Scheme 41). The SBA-15/SH-Pd-NPs (32) catalyst easy removed from reaction mixture and reused 11 times with negligible leaching of Pd NPs. ${ }^{88}$

Notably, Veisi and co-workers were able to synthesis SBA-15/ $\mathrm{CCPy} / \mathrm{Pd}(\mathrm{II})$ (33) as a new heterogeneous catalyst for $\mathrm{C}-\mathrm{C}$ coupling reactions (Scheme 42$).{ }^{89}$ For preparation of this catalyst, cyanuric chloride (CC) was covalently immobilized on the surface of $\mathrm{NH}_{2}$-SBA-15. Next, by addition of diisopropylethylamine to residue, the clung dipyridilamine on triazine functionalized SBA-15 (SBA-15/CCPy) was produced. Finally, SBA-15/
CCPy/Pd(II) (33) nanocatalyst was obtained by the reaction of $\mathrm{PdCl}_{2}$ with SBA-15/CCPy that reduced by hydrazine hydrate to produce SBA-15/CCPy/Pd(0) (34).

The prepared SBA-15/CCPy/Pd(II) (33) nanocatalyst, at extremely low Pd loading ( $\sim 0.3 \mathrm{~mol} \%)$, was evaluated in $\mathrm{S}-\mathrm{M}$ reaction under environmentally friendly solvents $\left(\mathrm{EtOH} / \mathrm{H}_{2} \mathrm{O}\right)$ in mild reaction conditions. The corresponding coupled products were obtained in good to excellent yields (Scheme 43). The heterogeneous catalyst showed high TOF and could be reused 7 times without significant loss in its activity and Pd is not being leached out from the solid catalyst. ${ }^{89}$ 
<smiles>[R]c1cccc(Br)c1</smiles>

$\mathrm{R}=\mathrm{H}, \mathrm{Me}, \mathrm{MeO}_{2} \mathrm{C}, \mathrm{CHO}$,

$\mathrm{NO}_{2}, \mathrm{CN}$, Pyridyl, Thienyl
Pd-SBA-15 (28)

(0.05 mol\% Pd)

$\mathrm{H}_{2} \mathrm{O}, \mathrm{K}_{2} \mathrm{CO}_{3}, 80^{\circ} \mathrm{C}, 1 \mathrm{~h}$

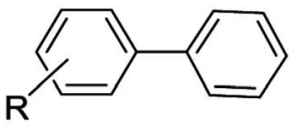

$21-99 \%$

Scheme 36 S-M coupling reactions of aryl halides over Pd-SBA-15 (28).

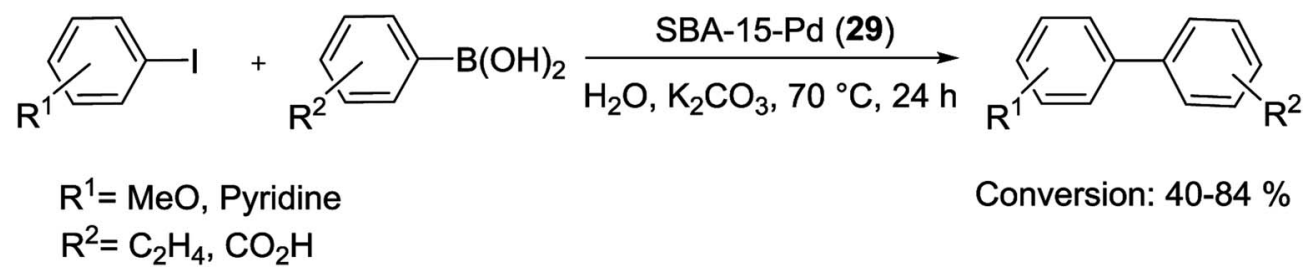

Scheme 37 Suzuki C-C coupling reaction using SBA-15-Pd catalyst (29).

Wang and co-workers have reported in situ method to synthesis of Pd in highly ordered mesoporous channels of SBA15. In this approach, molecular assembly template was used as a hydrophobic carrier to afford the compatible environment for the hydrophobic compounds. In addition to insert the Pd precursor straightly into the inner core of the surfactant micelles, the hydrophobic solvent $\left(\mathrm{CHCl}_{3}\right)$ was employed. The resulting Pd/SBA-15 (35) nanocomposite by $1.46 \mathrm{wt} \%$ Pd loading

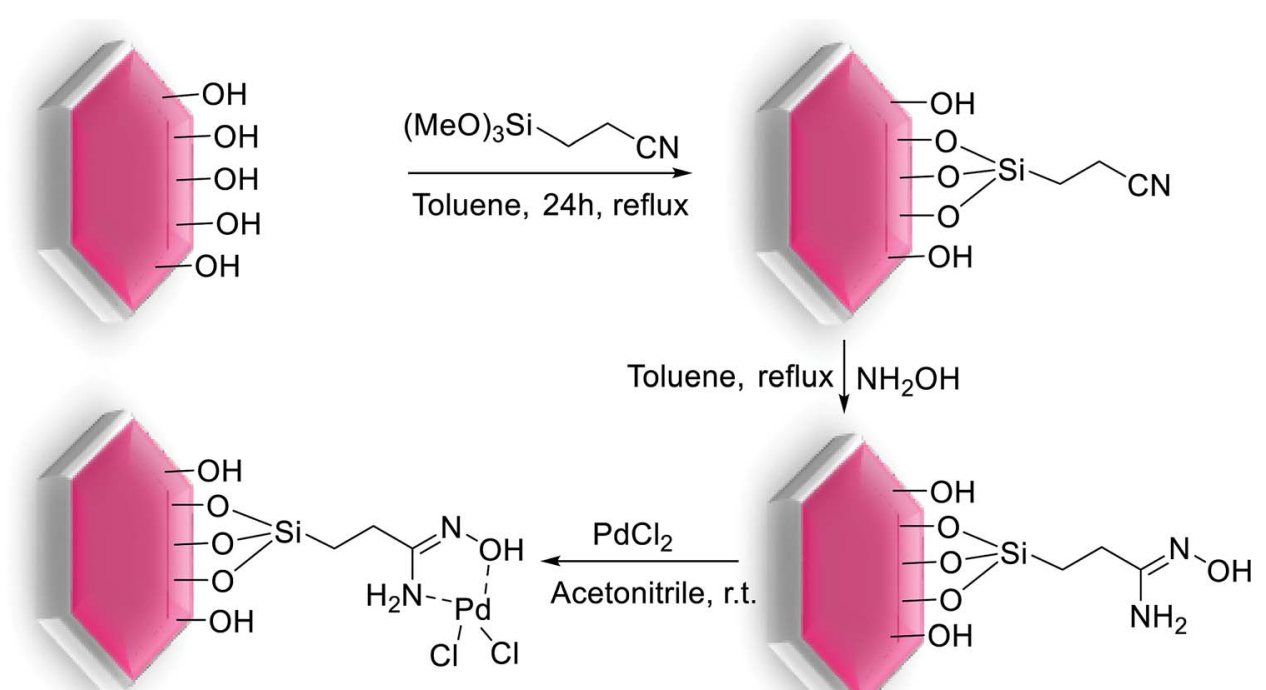

SBA-15/AO/Pd(II) (30)

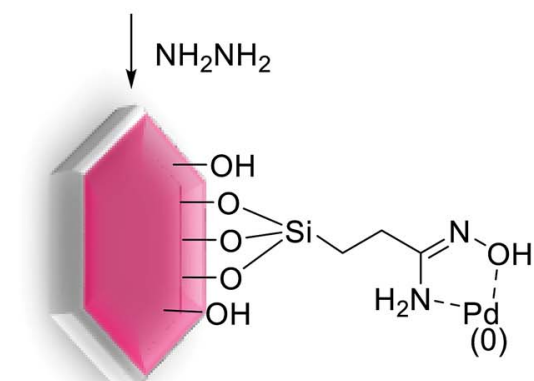

SBA-15/AO/Pd(0) (31)

Scheme 38 Schematic diagram of SBA-15/AO/Pd(॥) (30) and SBA-15/AO/Pd(0) (31) fabrications. 


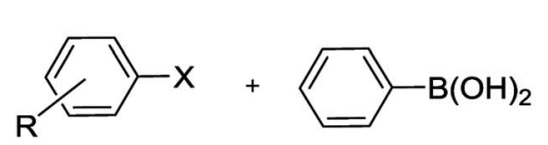
$\mathrm{X}=\mathrm{I}, \mathrm{Br}, \mathrm{Cl}$
$\mathrm{R}=\mathrm{H}, \mathrm{Me}, \mathrm{MeO}, \mathrm{MeCO}, \mathrm{NO}_{2}$,
$\mathrm{CN}, \mathrm{Cl}$, Naphthyl, Thienyl

SBA-15/AO/Pd (II) (30)

$\underset{\mathrm{EtOH} / \mathrm{H}_{2} \mathrm{O}(2: 1), \mathrm{K}_{2} \mathrm{CO}_{3}}{\stackrel{(0.002 \mathrm{~mol} \% \mathrm{Pd})}{\longrightarrow}}$

$50{ }^{\circ} \mathrm{C}, 0.3-15 \mathrm{~h}$

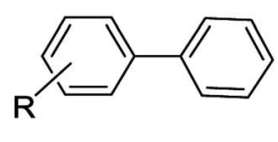

$70-98 \%$

Scheme 39 Heterogeneous S-M reaction catalyzed by SBA-15/AO/Pd(॥) (30).

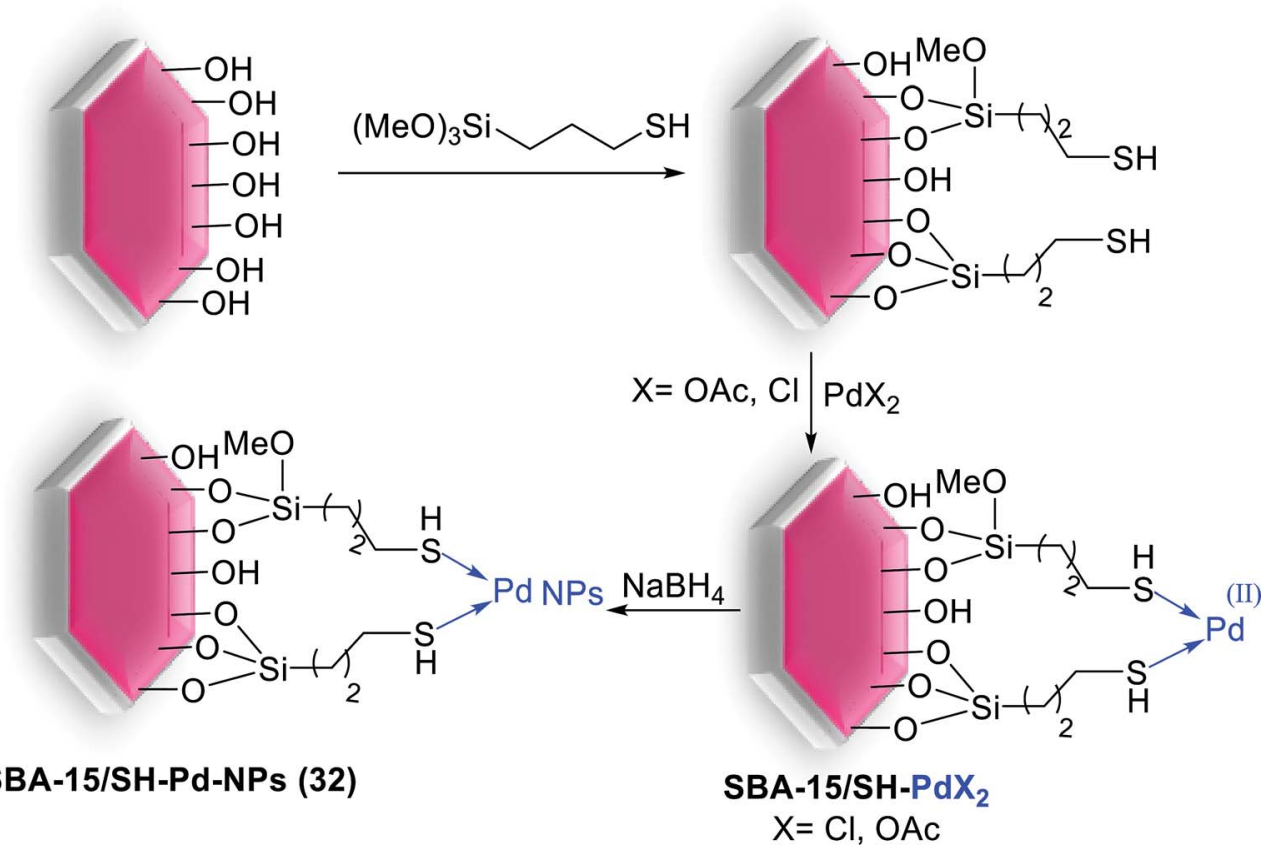

Scheme 40 Schematic representation of SBA-15/SH-Pd-NPs (32) preparation.

was obtained with well dispersed and uniform Pd NPs. The catalytic activity of the $\mathrm{Pd} / \mathrm{SBA}-15$ nanocomposite was studied in S-M coupling reaction between aryl and heteroaryl bromides with phenylboronic acid. The reactions were done at $80{ }^{\circ} \mathrm{C}$, giving biphenyl products with excellent yields (Scheme 44). ${ }^{\mathbf{9 0}}$

In 2014, phosphine obstructed highly efficient and recyclable SBA-15-EDTA-Pd(II) (36) catalyst has been produced according to the procedure outlined in Scheme 45. Starting from protection of free $-\mathrm{OH}$ groups on the $\mathrm{NH}_{2}$-SBA-15 via addition of dimethoxydimethylsilane $\left[(\mathrm{MeO})_{2} \mathrm{Me}_{2} \mathrm{Si}\right]$ (Scheme 45A). Finally Pd-ethylenediaminetetraacetic acid (Pd-EDTA) complex (Scheme 45B) was covalently anchored over the organo- modified mesoporous SBA-15 support and inside its the pore walls. ${ }^{91}$

The as-synthesized catalyst was screened for the S-M reaction and corresponding biphenyls were obtained in high yields (71-99\%) with high TONs (Scheme 46). The grafted solid catalyst can be efficiently reused more than five times, without considerable deactivation owing to the well functionalized surface properties of the SBA-15 as a support. ${ }^{91}$

In another study, a novel organic-inorganic hybrid catalyst, SBA-15-TAT-Pd(II) (37), was successfully synthesized via reaction of 2,4,6-triallyloxy-1,3,5-triazine and AIBN (initiator) with thiofunctionalized SBA-15 followed by anchoring of Pd using

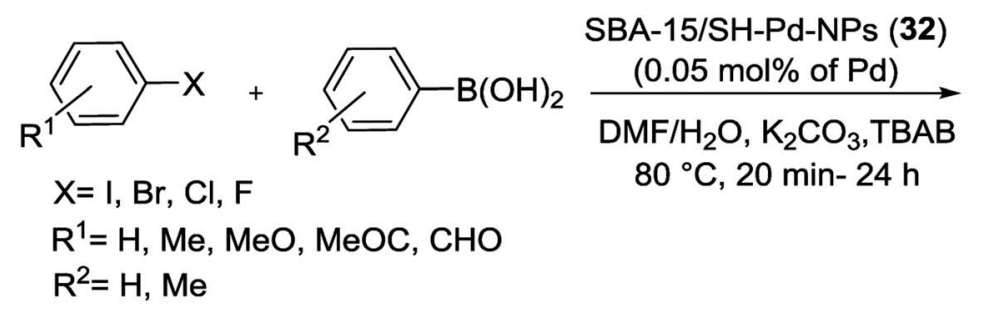

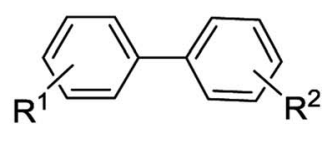

$42-97 \%$

Scheme 41 The SBA-15/SH-Pd-NPs (32) catalyzed Suzuki reactions under optimized conditions. 


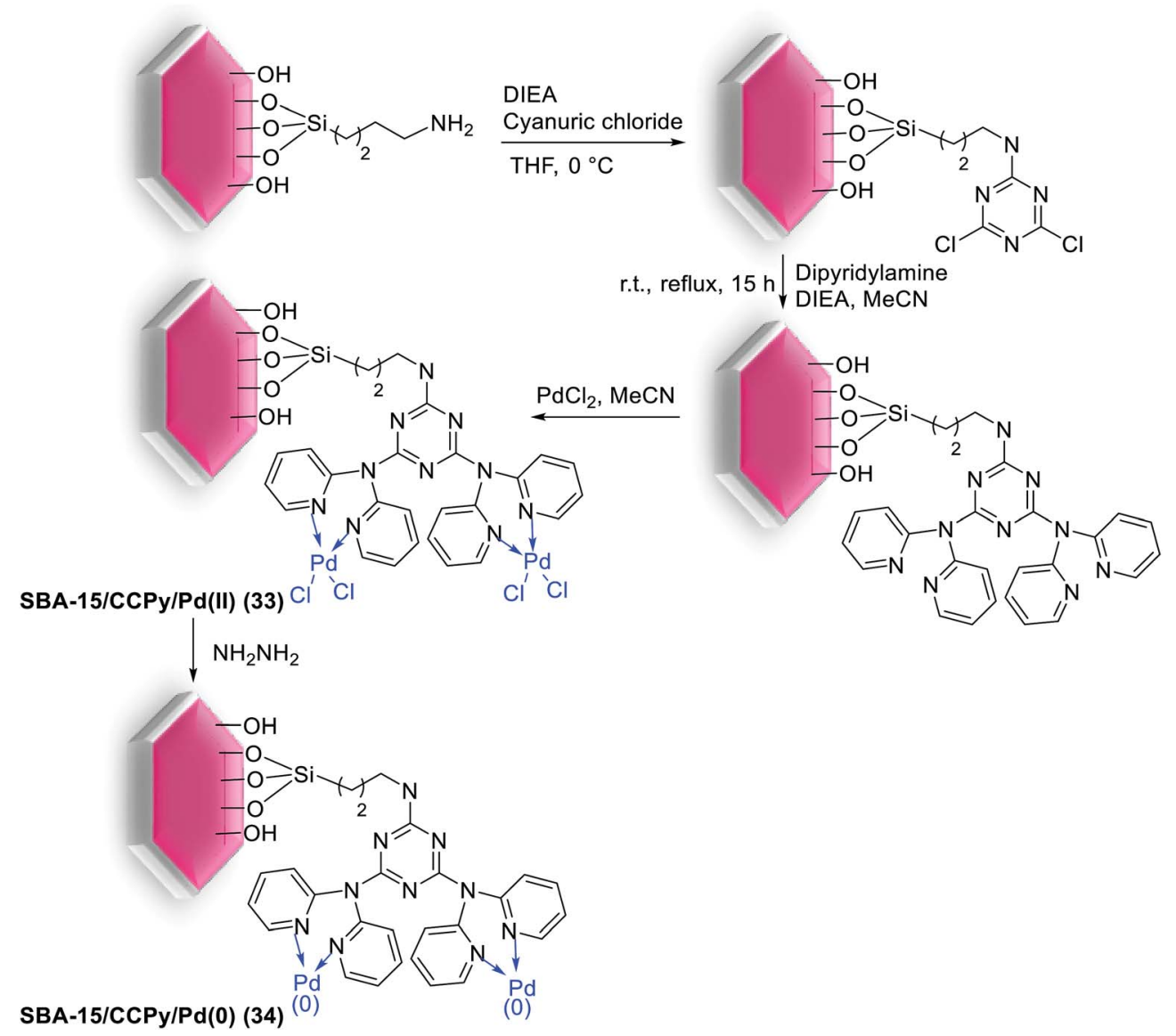

Scheme 42 Schematic diagram of SBA-15/CCPy/Pd(॥) (33) and SBA-15/CCPy/Pd(0) (34) fabrications.

a solution of $\mathrm{Pd}(\mathrm{OAc})_{2}$ (Scheme 47$)$. The XPS analysis of fresh and reused catalysts demonstrated the identical oxidation state of Pd in two catalysts. The hot filtration tests also rejected the leaching of Pd species and confirmed the heterogeneous nature of the catalysis. ${ }^{92}$

The catalytic utility of the catalyst was investigated for S-M coupling reaction of various aryl iodides with different phenyl boronic acids using DMF as solvent and $\mathrm{K}_{2} \mathrm{CO}_{3}$ as the base at $120{ }^{\circ} \mathrm{C}$. The reaction proceeded smoothly to give the corresponding product in excellent yields (Scheme 48). ${ }^{92}$

For the first time, in 2015, Aprile et al. were prepared a highly cross-linked thiazolidine-based silica SBA-15 as a new support for Pd catalyst. As shown in Scheme 49, preparing the support was started from a thiazolium-based SBA- 15 material, achieved by radical oligomerization of bis-vinylthiazolium dibromide salt on the surface of 3-mercaptopropyl-functionalized mesoporous
SBA-15. The Pd NPs were modified by treatment with a solution of sodium tetrachloropalladate $\left(\mathrm{Na}_{2} \mathrm{PdCl}_{4}\right)$. The latter was treated with $\mathrm{NaBH}_{4}$ giving a final catalyst Pd@thiazolidine@SBA-15 (38). TEM analysis of material 38 did not show traces of IL polymer as a separate domain. ${ }^{93}$

This catalyst with only $0.1 \mathrm{~mol} \%$ Pd loading, displayed good activity in the S-M coupling of aryl halides in ethanol/water at $50{ }^{\circ} \mathrm{C}$ in the presence of $\mathrm{K}_{2} \mathrm{CO}_{3}$ as base under an open atmosphere for $19 \mathrm{~h}$. Several biaryls products could be obtained in high yields (Scheme 50). The catalytic material demonstrated to be fully recoverable and it was recycled for three times in the S-M reaction without any obvious loss of the activity. ${ }^{93}$

In 2015, two series of silica materials, $\mathrm{Pd}(\mathrm{II}) @ S B A-15 / \mathrm{PrSO}_{3} \mathrm{H}$ (39) and SBA-15/ $\mathrm{PrSO}_{3} \mathrm{H}$-Pd-NPs (40) were synthesized and acts as a low Pd-leached precatalyst for Suzuki reaction. The procedure for the synthesis of these catalysts is shown in Scheme 51.

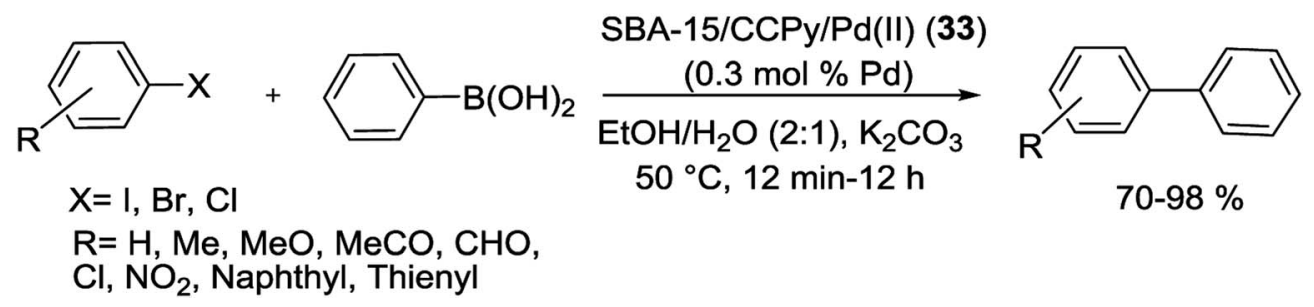

Scheme 43 Heterogeneous S-M reaction of aryl halides with phenylboronic acid catalyzed by SBA-15/CCPy/Pd(॥) (33). 


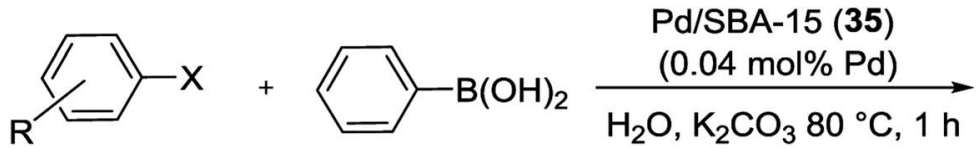

$\mathrm{X}=\mathrm{I}, \mathrm{Br}, \mathrm{Cl}$

$\mathrm{R}=\mathrm{H}, \mathrm{Me}, \mathrm{MeO}, \mathrm{MeOCO}, \mathrm{NC}$, $\mathrm{NO}_{2}$, Pyridyl, Thienyl

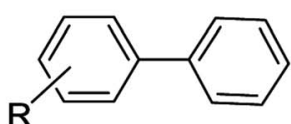

$92-99 \%$

Scheme 44 S-M coupling reactions of aryl and heteroaryl bromides over Pd/SBA-15 (35).

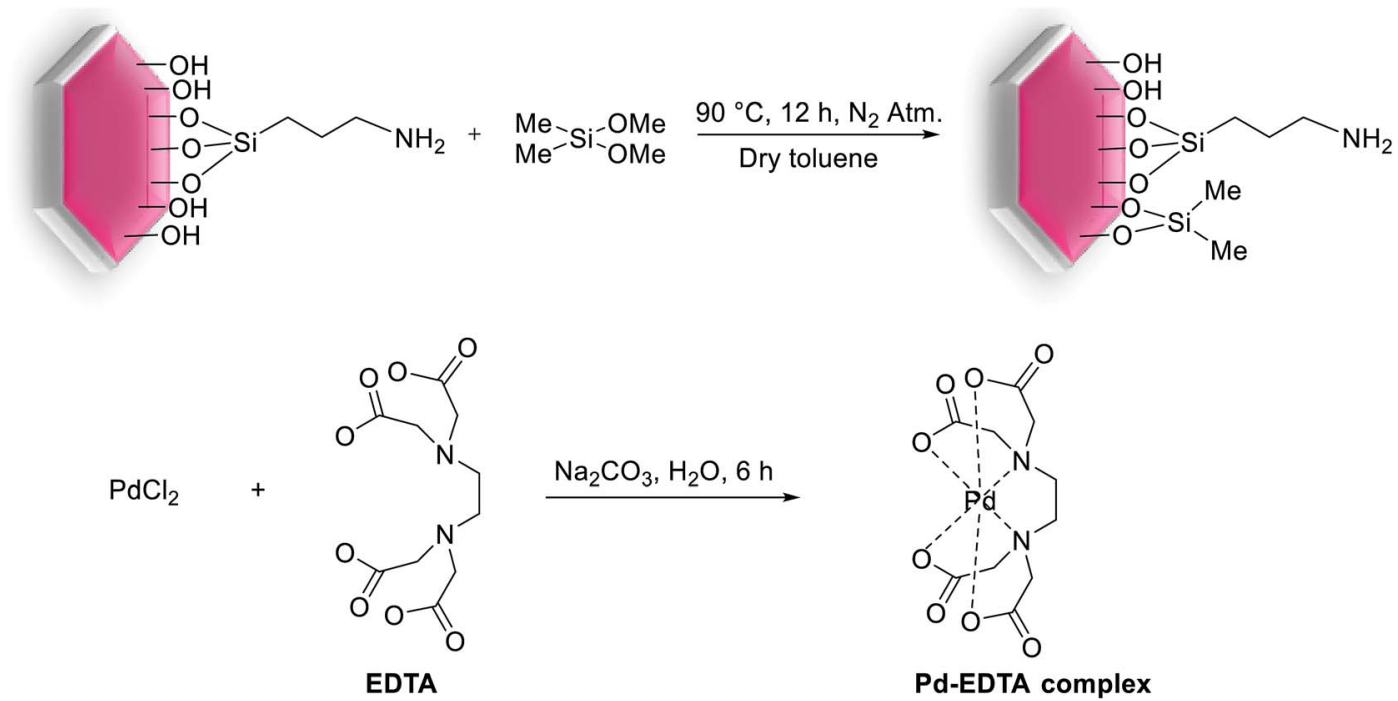

(B)

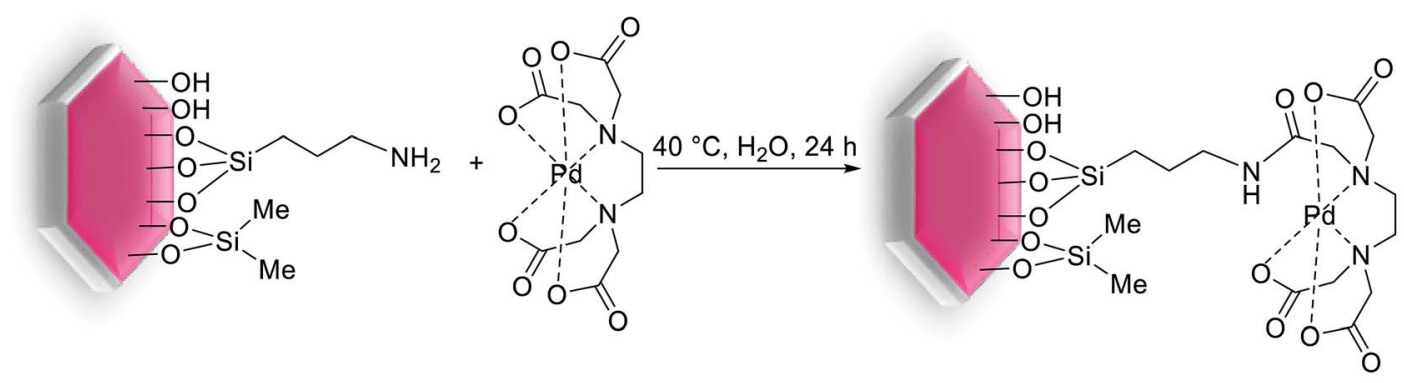

SBA-15-EDTA-Pd(II) (36)

Scheme 45 Schematic diagram of SBA-15 functionalization and heterogenization of Pd-EDTA-SBA-15 (36). (A) Protection of free -OH groups on the $\mathrm{NH}_{2}-\mathrm{SBA}-15$ via addition of dimethoxydimethylsilane [(MeO) ${ }_{2} \mathrm{Me}_{2} \mathrm{Si}$, (B) Pd-EDTA complex formation, (C) anchoring of Pd-EDTA complex over modified surface of SBA-15.

First, SBA-15 functionalized with MPTMS, then oxidized with $\mathrm{H}_{2} \mathrm{O}_{2}$ to afford SBA-15/ $\mathrm{PrSO}_{3} \mathrm{H}$. In the next step, the resulting solid react with a solution of $\operatorname{Pd}(\mathrm{MeCN})_{2}(\mathrm{Cl})_{2}$ to yield $\operatorname{Pd}(\mathrm{II})$
(aSBA-15/ $\mathrm{PrSO}_{3} \mathrm{H}$ precatalyst (39) which subsequently reduced with $\mathrm{NaBH}_{4}$ to form SBA-15/PrSO 3 H-Pd-NPs (40). ${ }^{94}$

Substituted biaryls were obtained in high yields at aerobic condition and a mixture of $\mathrm{H}_{2} \mathrm{O} / \mathrm{DMF}$ (Scheme 52). These Pd-

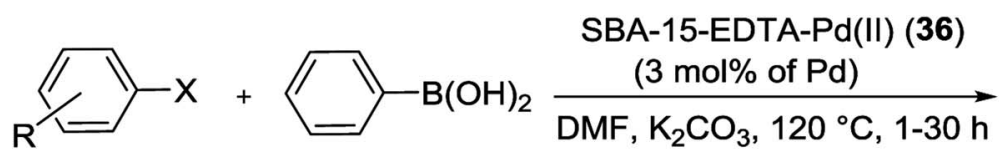

$\mathrm{X}=\mathrm{Cl}, \mathrm{Br}, \mathrm{I}$

$\mathrm{R}=\mathrm{H}, \mathrm{Me}, \mathrm{MeO}, \mathrm{NO}_{2}$

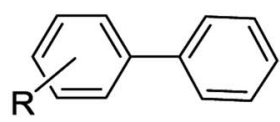

$71-99 \%$

Scheme 46 Reactivity of SBA-15-EDTA-Pd(॥) (36) catalyst for Suzuki reaction. 

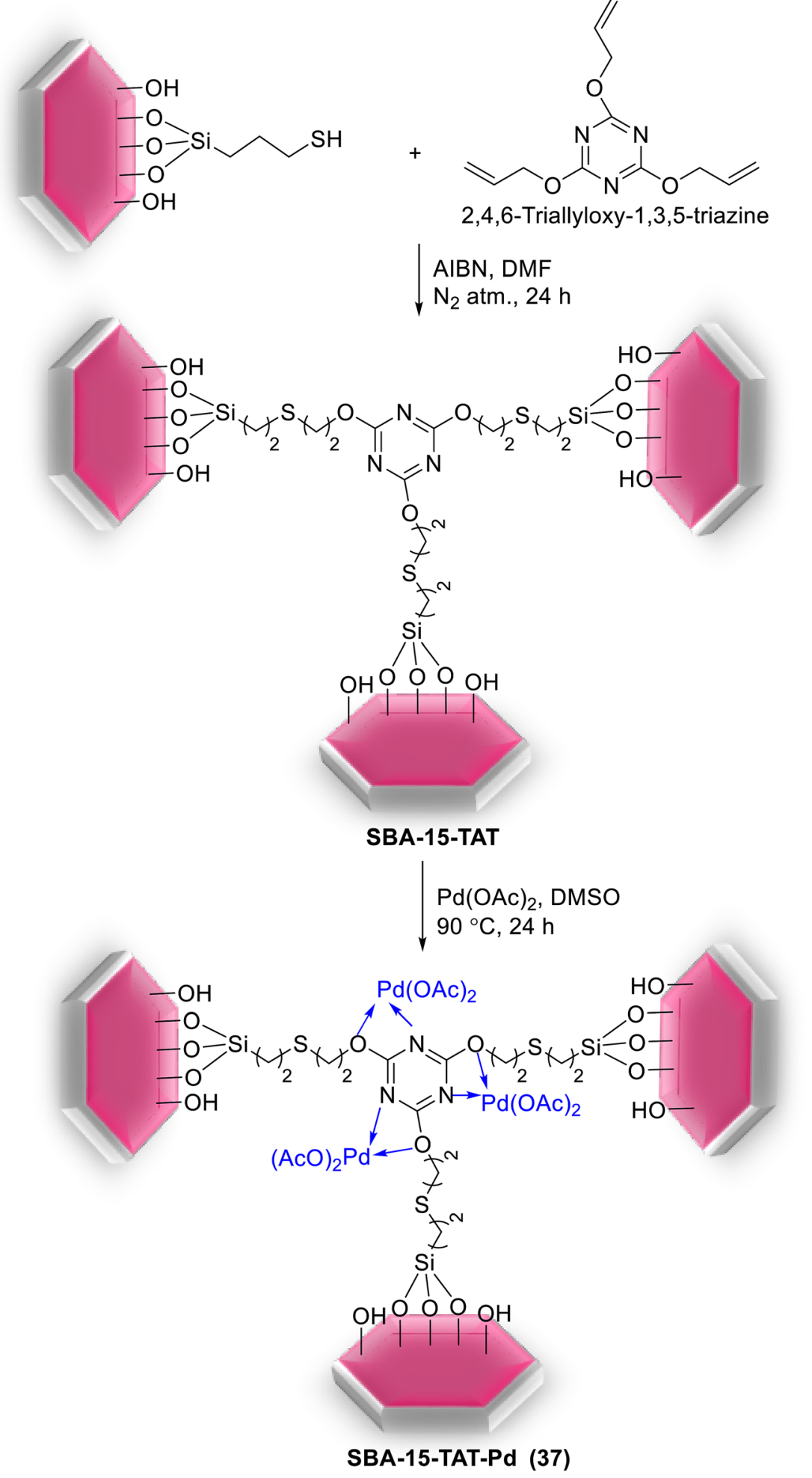

Scheme 47 Synthesis of SBA-15-TAT-Pd(॥) (37) catalyst.

based heterogeneous nanocatalysts could be easily separated from the reaction mixture and recycled at least 11 times. ${ }^{94}$

A type of catalyst based on SBA-15 supported Pd NPs was produced using the dendrimer-template method. In 2015, Pd anchored on SBA-15 was synthesized by Ncube and $c o$-workers without the need for prior functionalization of the mesoporous
SBA-15. They employed the dendrimer-template technique for the synthesis of the Pd NPs and then immobilized them inside the pores of the SBA-15. Consequently the organic dendrimer was removed through calcination and $\mathrm{Pd}^{0} / \mathrm{SBA}-15$ (41) catalyst was achieved. A scanning electron microscopy (SEM) image of the $\mathrm{Pd}^{0} / \mathrm{SBA}-15$ catalyst displayed the morphology of the catalyst 


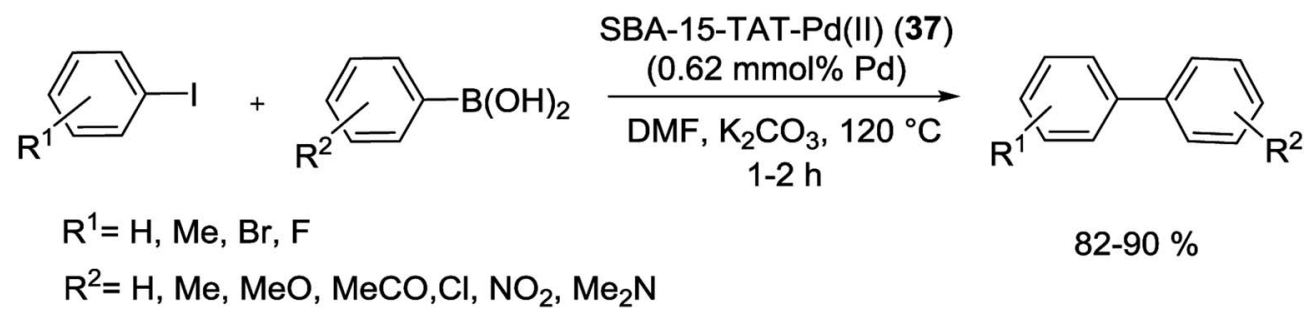

Scheme 48 Suzuki reaction of various aryl iodides with different phenyl boronic acids catalyzed by SBA-15-TAT-Pd(॥) (37).

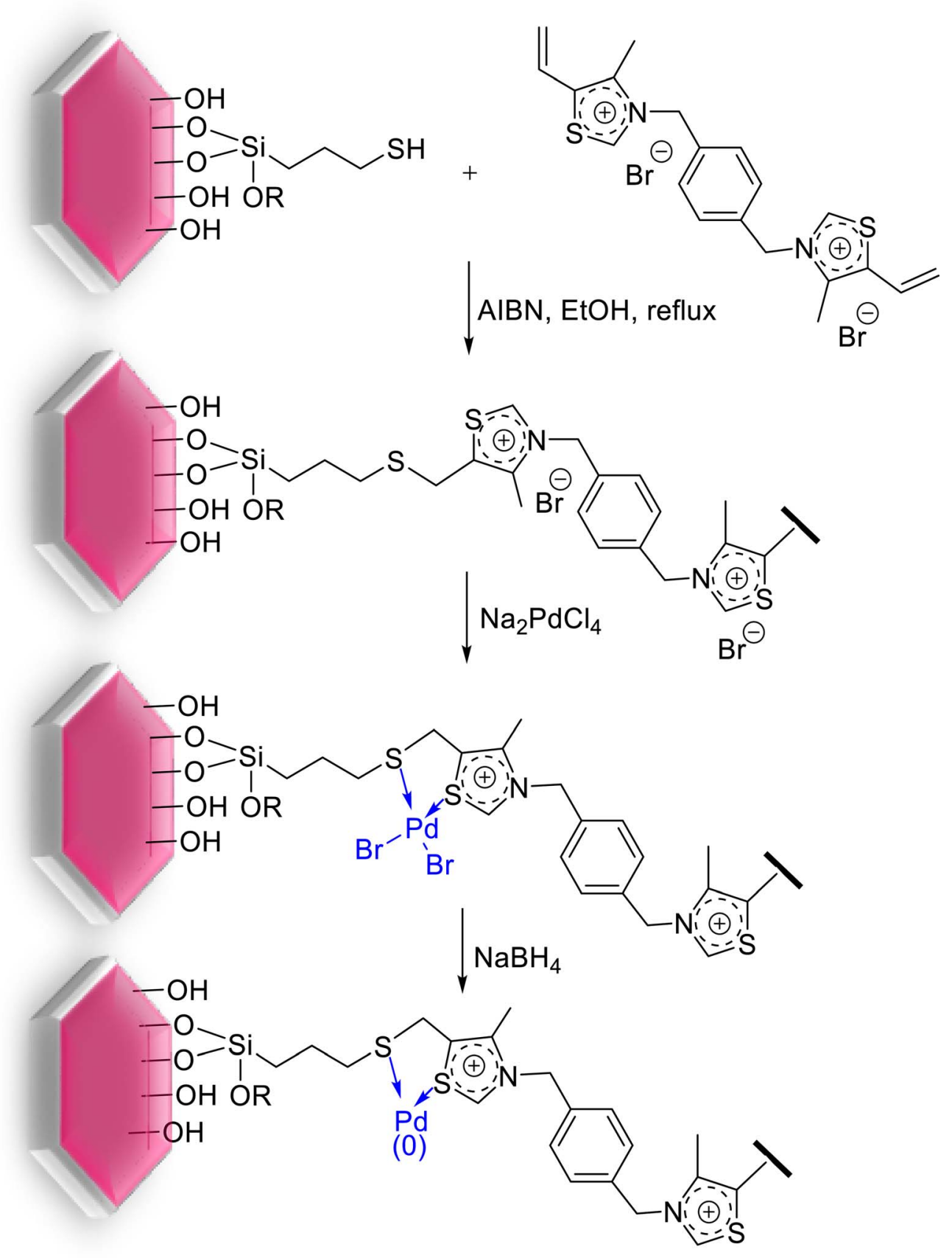

Pd@thiazolidine@SBA-15 (38)

Scheme 49 Synthesis of PdathiazolidineaSBA-15 (38). 
<smiles>[R]c1cccc([R])c1</smiles>

$\mathrm{X}=\mathrm{I}, \mathrm{Br}$

$\mathrm{R}^{1}=\mathrm{H}, \mathrm{Me}, \mathrm{MeO}, \mathrm{MeCO}, \mathrm{CHO}, \mathrm{NO}_{2}$, Naphthyl

$\mathrm{R}^{2}=\mathrm{H}, \mathrm{CHO}$
Pd@thiazolidine@SBA-15 (38)

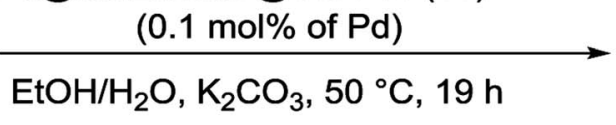

$\mathrm{R}$<smiles>[R]c1cccc(-c2cccc([R])c2)c1</smiles>

$47-99 \%$

Scheme 50 S-M reactions between phenylboronic acid and aryl halides in the presence of PdathiazolidineaSBA-15 (38).
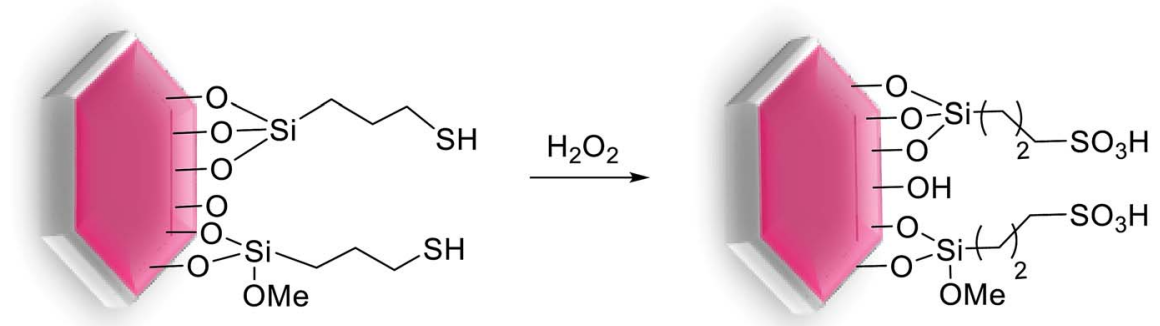

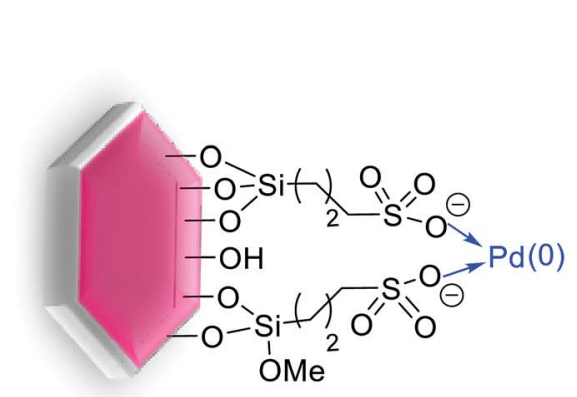

SBA-15/PrSO ${ }_{3}$ H.PdNPs (40)
SBA-15/ $\mathrm{SO}_{3} \mathrm{H}$

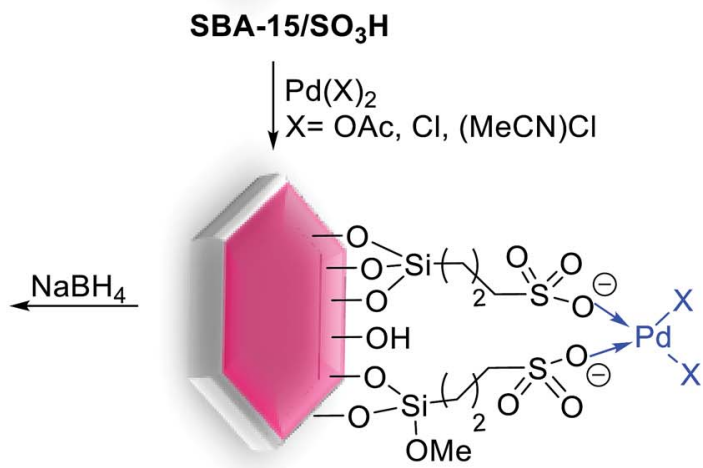

$\mathrm{Pd}(\mathrm{X})_{2} @ \mathrm{SBA}-15 / \mathrm{SO}_{3} \mathrm{H}$ (39)

Scheme 51 Schematic representation of the $\mathrm{Pd}(॥)\left(\mathrm{SBA}-15 / \mathrm{PrSO}_{3} \mathrm{H}\right.$ (39) and $\mathrm{SBA}-15 / \mathrm{PrSO}_{3} \mathrm{H}-\mathrm{Pd}-\mathrm{NPs}$ (40) catalysts preparation.

contain well-defined surface of rod-shaped particles. The characterization of the catalyst via HRTEM and XRD exposed that Pd NPs of diameters less than $5 \mathrm{~nm}$ were restrained within the mesoporous of the SBA-15 support. The scope of the heterogeneous $\mathrm{Pd}^{0} / \mathrm{SBA}-15$ catalyst was employed for the coupling of iodo, bromo and chloroarenes with phenylboronic acid to provide good to excellent product (Scheme 53). The reusability of catalysts for four consecutive cycles showed the catalytic activity did not change considerably and no Pd leached out of the support. Comparison of this catalyst with other supported
Pd catalysts showed higher catalytic activity by high values of TOF. ${ }^{95}$

Another catalyst based on SBA-15 has been produced via treatment of the mercaptopropylated SBA- 15 with $\left(\mathrm{CH}_{3} \mathrm{CN}\right)_{2^{-}}$ $\mathrm{PdCl}_{2}$ to yield a heterogeneous Pd-catalyst, SBA-15-SH-Pd (42), with a $0.1 \mathrm{~mol} \%$ Pd loading (Scheme 54 ). ${ }^{96}$

The thiol-functionalized SBA-15 supported Pd-catalyst (42) is highly effective in the S-M cross coupling reaction of aryl iodide, bromide as well as chloride system with phenylboronic acids (yields of $51-97 \%$ ). Reactions were performed in $50 \%$

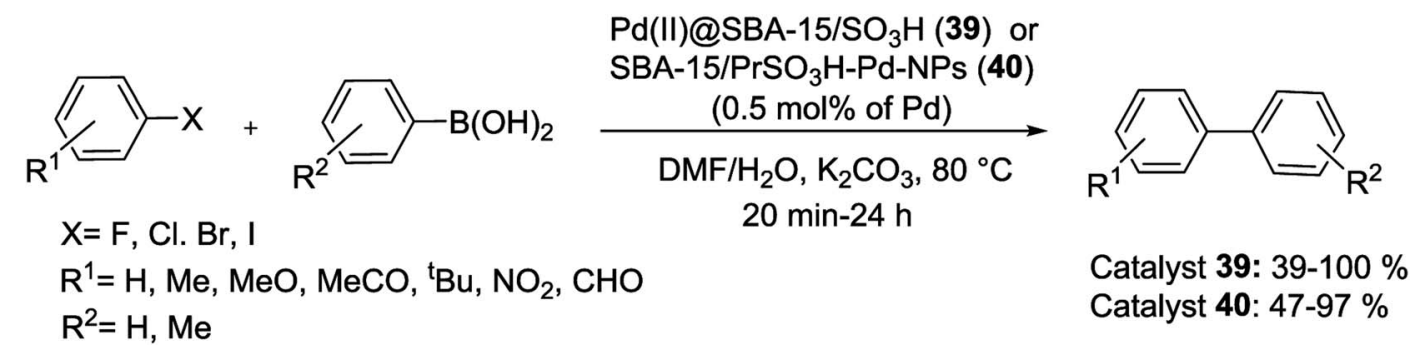

Scheme $52 \mathrm{Pd}(\Perp) @ \mathrm{SBA}-15 / \mathrm{SO}_{3} \mathrm{H}$ (39) or $\mathrm{SBA}-15 / \mathrm{PrSO}_{3} \mathrm{H}-\mathrm{Pd}-\mathrm{NPs}$ (40) catalysis Suzuki reactions under optimized conditions. 


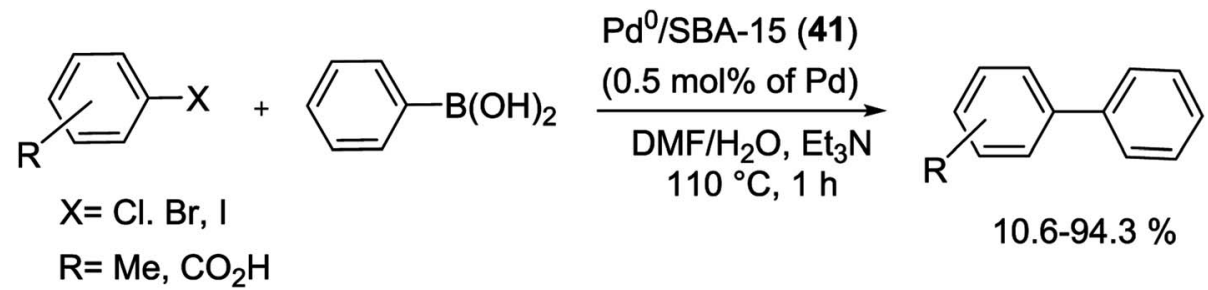

Scheme $53 \mathrm{Pd}^{0} / \mathrm{SBA}-15$ (41) catalyzed Suzuki coupling reaction.
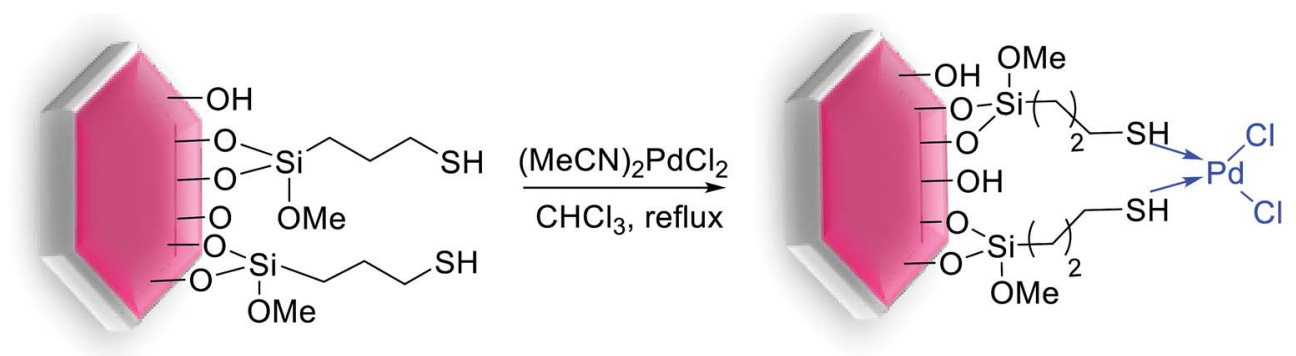

SBA-15-SH-Pd (42)

Scheme 54 Preparation of the SBA-15-SH-Pd (42) catalyst.

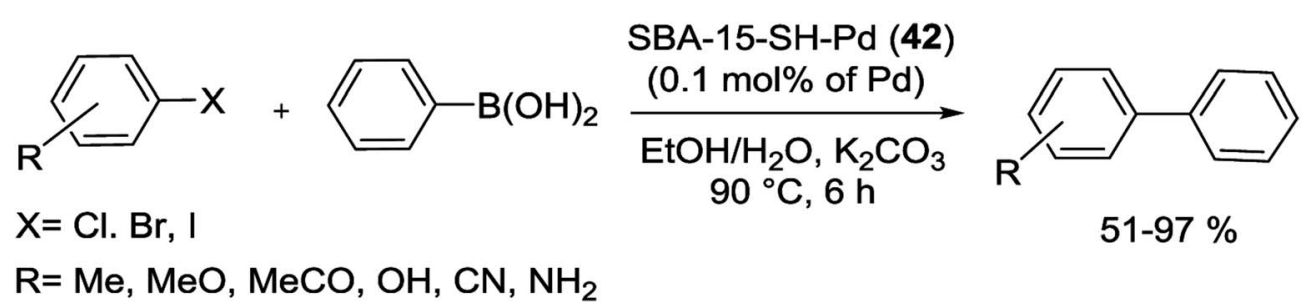

Scheme 55 Suzuki coupling reaction with SBA-15-SH-Pd (42) catalyst.

aqueous ethanol $(1.5 \mathrm{~mL})$ at $90{ }^{\circ} \mathrm{C}$ for $6 \mathrm{~h}$ (Scheme 55). Moreover, the heterogenized Pd-catalyst was recycled five times without significant loss of its catalytic activity. ${ }^{96}$

In 2015, Yamashita et al. showed that the coupling of plasmonic metal (Ag) with catalytically active element (Pd) can generate a heterostructure exhibiting efficient catalytic activity in S-M coupling reaction. Regularly Pd/Ag/SBA-15 catalyst was created by a two-step method. First by MW-assisted alcohol reduction method, $\mathrm{Ag} / \mathrm{SBA}-15$ was produced which gave the color-controlled Ag NPs with different morphologies and particle sizes. Next, under visible light irradiation, deposition of Pd into Ag/SBA-15 through localized surface plasmon resonance (LSPR)-assisted deposition was achieved. Then the LSPRenhanced photocatalytic activity of the Pd/Ag/SBA-15 bimetallic catalyst (43) was tested in the Pd-driven Suzuki reaction of phenylboronic acid and iodobenzene (Scheme 56). Reaction was performed in the presence of $\mathrm{K}_{2} \mathrm{CO}_{3}$ under dark, thermal $\left(35{ }^{\circ} \mathrm{C}\right)$ and light irradiation conditions. The results demonstrated that the catalytic activity was increased under visible light irradiation (54\%). Also in thermal condition moderate yield was obtained (34\%) and under dark conditions no catalytic activity was observed (yield $<1 \%$ ). ${ }^{97}$
At the first time, Jong et al. reported a thiol-immobilized plugged SBA-15 (denoted as P.SBA-15) for confining ultra-fine $(\sim 2 \mathrm{~nm})$ Pd NPs. In this method, Pd NPs have been anchored on P.SBA-15 (were prepared by employing an excess amount of TEOS), using $\mathrm{Pd}(\mathrm{OAc})_{2}$, then reduced with $\mathrm{NaBH}_{4}$ to yield P.SBA15.SH.Pd catalyst (44). The resulting material was studied in the Suzuki reaction of 4-iodoanisole with phenylboronic acid under various conditions (Scheme 57). The results indicated that the stronger alkaline conditions were required for the Suzuki reaction, thus, catalyst based on P.SBA-15 displayed a higher stability and superior catalytic activity than SBA-15 after the first cycle. ${ }^{98}$

In 2016 Pathak and his group successfully synthesized a novel D-2PA-Pd(II)@SBA-15 (45) catalyst via "click chemistry" and employed it for S-M coupling reactions. As shown in Scheme 58, for synthesize of this catalyst, mesoporous silica SBA-15 functionalized with 3-azidopropyltriethoxysilane, followed by its cycloaddition reaction with $\mathrm{N}, \mathrm{N}$-dimethyl-2propynylamine (D-2PA) ligand and further complexation with $\mathrm{PdCl}_{2}$. The synthesized catalyst, has been demonstrated excellent catalytic activities with good yield of biaryl products, also 

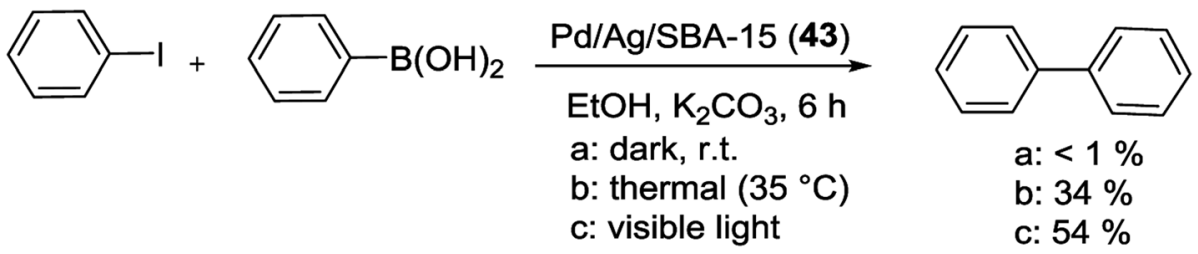

a: $<1 \%$

b: $34 \%$

c: $54 \%$

Scheme 56 The Suzuki reaction catalyzed by Pd/Ag/SBA-15 (43).
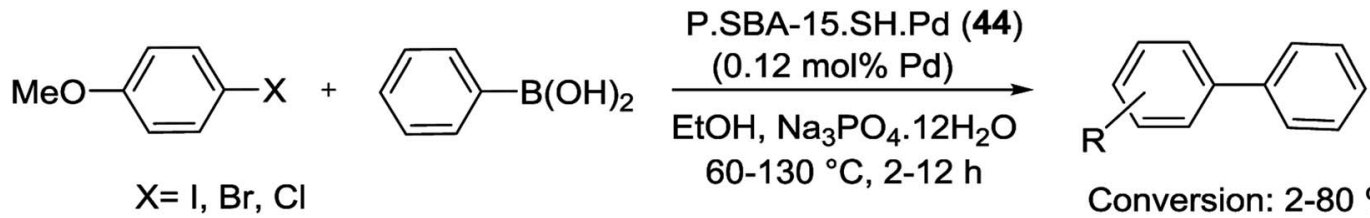

Conversion: $2-80 \%$

Scheme 57 Suzuki coupling reaction catalyzed by P.SBA-15.SH.Pd (44).

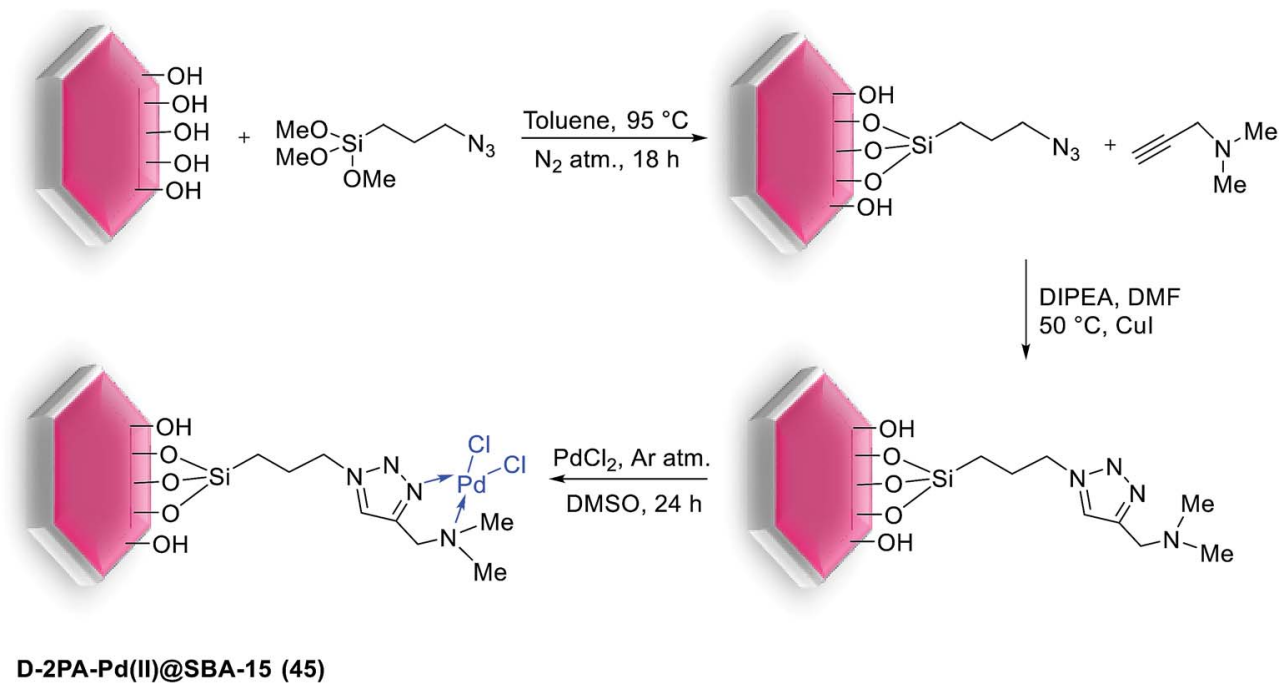

Scheme 58 Synthesis of D-2PA-Pd(॥)@SBA-15 (45) catalyst.

high TON towards coupling reaction of phenylboronic acid and various aromatic halides (Scheme 59). ${ }^{99}$

The reaction results exhibited that aryl halides with electron withdrawing group accelerates the reaction rate whereas aryl halides with electron donating group demonstrated negative effect on yield and results in prolonged reaction time. The authors also investigated the effects of reaction variables such as base, solvent and temperature. Polar solvents such as DMF and inorganic base, $\mathrm{K}_{2} \mathrm{CO}_{3}$, were found as the best solvent and base respectively. Furthermore, performing the reaction at $120{ }^{\circ} \mathrm{C}$ led to the highest yields. Additionally D-2PA-Pd(II)@SBA15 (45) has been exhibited high catalytic stability and reusability for 4 times with no detectable deactivation. ${ }^{99}$

Cao et al. successfully prepared a highly efficient and stable Pd-diimine@SBA-15 (46) catalyst through immobilizing of Pd ions into the pore channels of diimine-functionalized SBA-15. ${ }^{\mathbf{1 0 0}}$ For the synthesis of catalyst, $\mathrm{NH}_{2}$-SBA-15 was reacted with a glyoxal precursor to produce diimine@SBA-15, subsequently reacted with $\mathrm{PdCl}_{2}$ to give Pd-diimine@SBA-15 (46) (Scheme 60).

The scope and limitations of the as-synthesis catalyst 46 with an ultralow amount of Pd $(0.05 \mathrm{~mol} \% \mathrm{Pd})$ were also evaluated for S-M coupling reactions of electronically diverse aryl halides with phenylboronic acid. High yield of corresponding crosscoupling products can be obtained for both electron-donating and -withdrawing bromobenzene (Scheme 61). Compared with the catalytic performances of Pd/SBA-15 and Pd-diimine@ $\mathrm{SiO}_{2}$, the Pd-diimine@SBA-15 (46) catalyst demonstrated higher hydrothermal stability and could be constantly used four times with virtually no evident loss of catalytic performance. These results show that with the help of diimine groups, Pd ions could be attached on the support strongly with high dispersion and stability, hence the catalytic activity and recyclability were greatly enhanced. Therefore, the mesoporous structure and organic functional groups fixed on the SBA-15, consecutively 


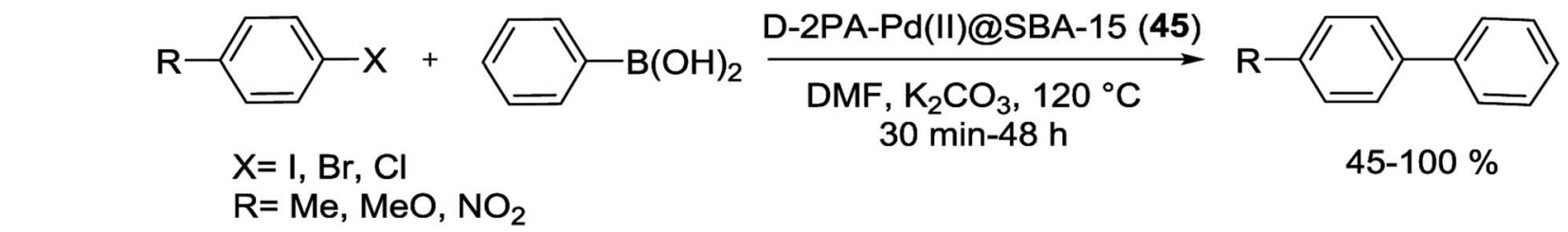

Scheme 59 Reactivity of D-2PA-Pd(॥) (aSBA-15 (45) for Suzuki-coupling reaction.
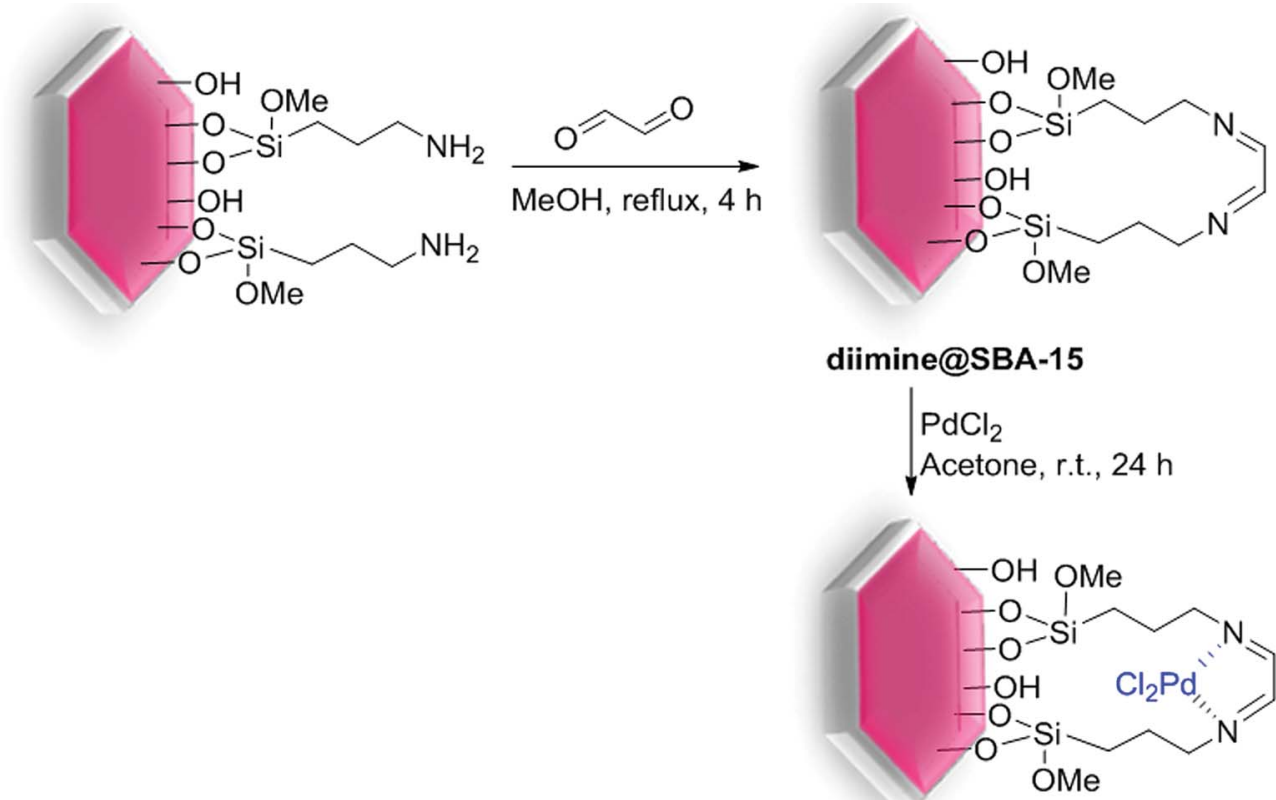

Pd-diimine@SBA-15 (46)

Scheme 60 Schematic diagram of Pd-diimineaSBA-15 (46) fabrication.

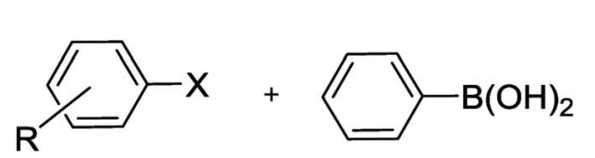

$\mathrm{X}=\mathrm{Br}, \mathrm{Cl}$

$\mathrm{R}=\mathrm{H}, \mathrm{Me}, \mathrm{MeO}, \mathrm{NO}_{2}, 3,5-\left({ }^{\mathrm{t}} \mathrm{Bu}\right)_{2}$,

$3,5-\left(\mathrm{CF}_{3}\right)_{2}, 2,3,4,5-(\mathrm{F})_{4}$, Pyridine
Pd-diimine@SBA-15 (46)

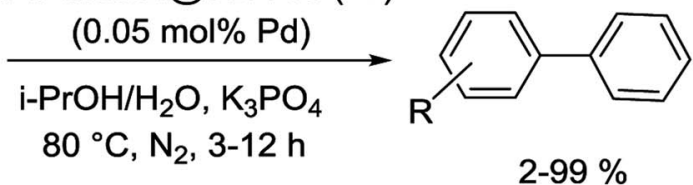

$2-99 \%$

Scheme 61 Suzuki coupling reactions of various aryl halides and phenylboronic acid over Pd-diimine@SBA-15 (46) catalyst.

enhanced the catalytic performance of Pd-diimine@SBA-15 (46). ${ }^{100}$

In 2016, Rostamnia and his group reported the first SBA-15 silica with hydrophobic IL nature which has ability for the immobilization of Pd(II) species. As shown in Scheme 62, for the

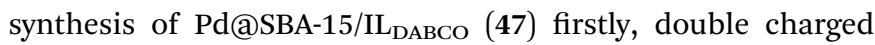
DABCO with 3-chloropropyltrimethoxysilane (CPTMS) was furnished and covalently grafted to the surface of SBA-15 to give lipophilic channels with ionic nature. The SBA-15/IL $\mathrm{IABCO}_{\mathrm{DAB}}(\mathbf{4 7})$ had high ability to support Pd species through converting free $\mathrm{Cl}^{-}$ions to $\left[\mathrm{PdCl}_{4}\right]^{2-}$. 101

This catalyst was used in S-M cross-coupling reaction of aryl halides with arylboronic acids under aqueous conditions at short reaction time (Scheme 63). Good to excellent yields of biaryls were obtained for aryl bromides bearing electronwithdrawing and -donating substituents. Recovery of the catalyst was performed for 9 runs with no significant decrease in activity. In this method, the conversation was $100 \%$ and the TON was $1710[\mathrm{TON}=$ substrate/catalyst $\times$ conversion $(\%)] .{ }^{101}$ 


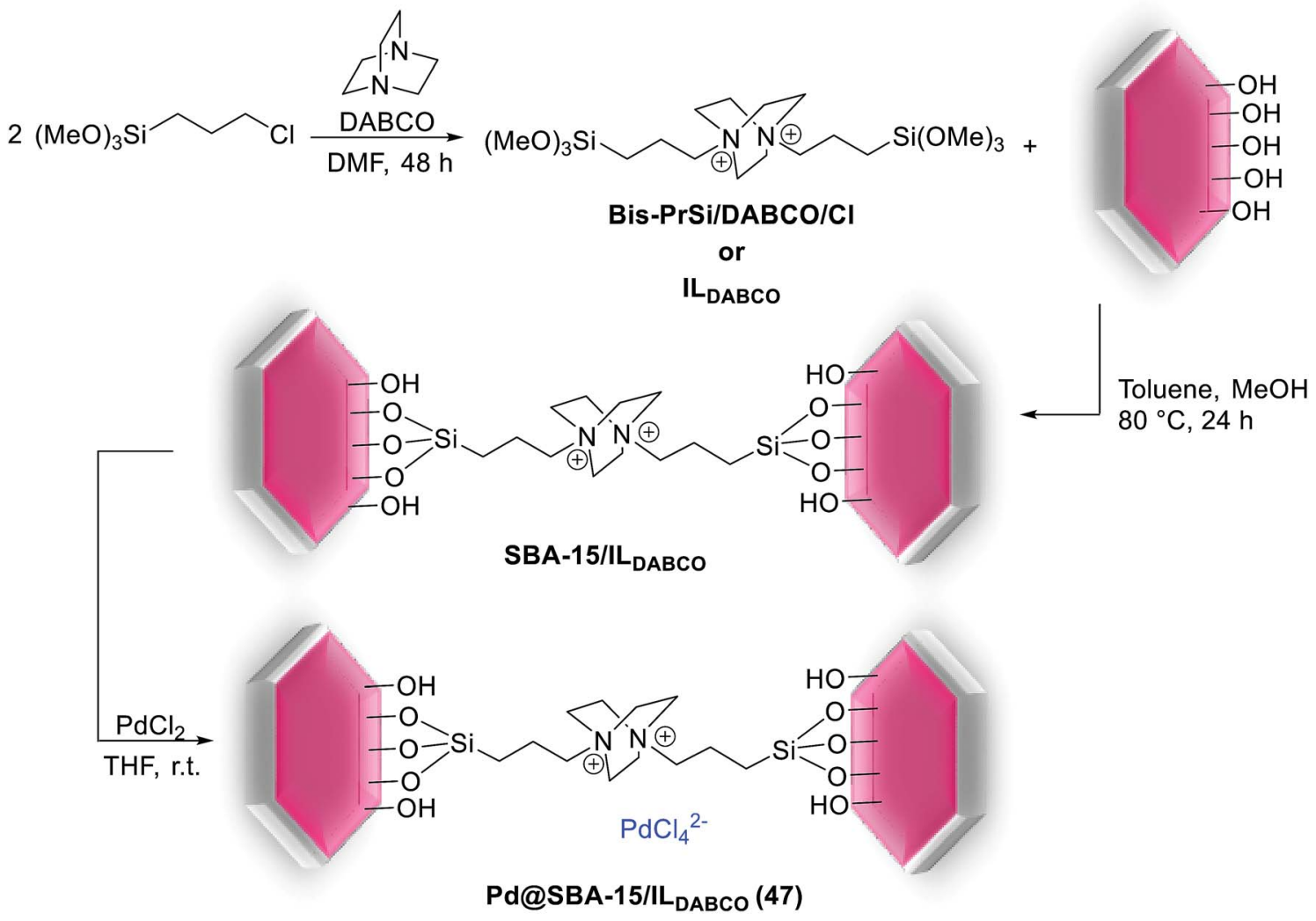

Scheme 62 Schematic synthesis of Pd@SBA-15/IL

In 2017, Rostamnia and co-workers for the first time used a stable ligand, $N$-propyliminodiacetic acid (PIDA), and functionalized it onto the surface of SBA-15 (SBA-15/PIDA) as support of Pd(II) ions to produce a Pd@SBA-15/PIDA (48) catalyst. The general synthesis way of this catalyst started from reaction of SBA-Pr- $\mathrm{NH}_{2}$ with sodium chloroacetate to generate the sodium iminodiacetate supported on SBA-15. By addition of $\mathrm{PdCl}_{2}$ to SBA-PIDA, it seemed that after the release of $\mathrm{NaCl}$ salt from the system, the ratio of $\mathrm{Na}^{+}$and $\mathrm{Cl}^{-}$decreased which referred to a successful formation of Pd(II)-PIDA complex. A schematic pathway of the synthetic process is illustrated in Scheme $64 .{ }^{102}$

The catalytic activity of Pd@SBA-15/PIDA (48) was monitored in $\mathrm{S}-\mathrm{M}$ reaction of aryl halides with a wide various phenylboronic acids using $\mathrm{K}_{2} \mathrm{CO}_{3}$ as the base at $80{ }^{\circ} \mathrm{C}$ under aqueous conditions (Scheme 65). The SEM images of the catalyst confirmed a clear rod-like morphology and TEM spectra also showed the preserved long range order of SBA-15 after functionalization. After 15 runs the TON of the reaction was 1309 that was indicated no noticeable leaching of Pd. ${ }^{102}$

In 2018, Ulusal and her group, introduced a well-dispersed green Pd/SBA-15 (49) nanocatalyst through $\mathrm{scCO}_{2}$ deposition approach by $\mathrm{H}_{2}$-assisted chemical reduction. ${ }^{103}$ For this purpose, $\mathrm{Pd}$ (II) complex of 2,2'-bipyridyl was used as a precursor for preparation of SBA-15-supported Pd NPs. The deposition process was done in 3 steps: (i) dissolution of the precursor in $\mathrm{scCO} 2$ at $80^{\circ} \mathrm{C}$ under 17.2 MPa pressure, (ii) adsorption of the precursor on the SBA-15 surface in same conditions, and (iii) reduction of $\mathrm{Pd}$ complex to $\mathrm{Pd}(0)$ via $\mathrm{H}_{2}$ gas. Homogeneously well-dispersed Pd nanostructure was obtained with an average size of $\sim 13.7 \mathrm{~nm}$ determined by XRD. Furthermore, according to XPS results Pd was in metallic form in the catalyst. The

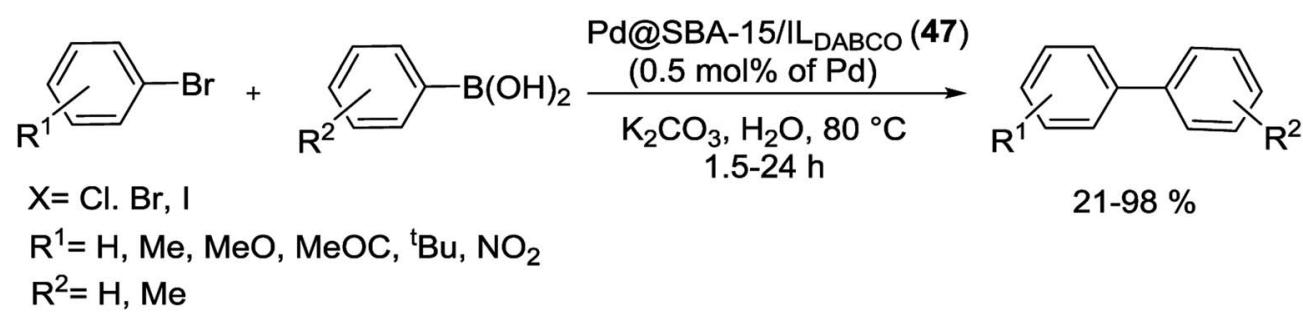

Scheme 63 Synthesis of biaryl derivatives by Suzuki coupling using Pd@SBA-15/IL $\mathrm{L}_{\mathrm{DABCO}}$ (47). 

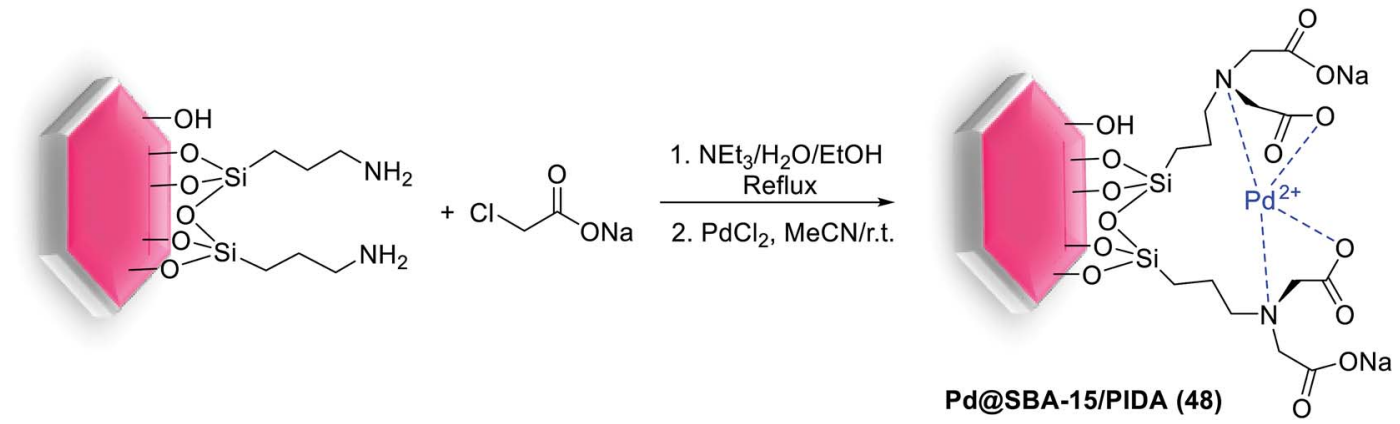

Scheme 64 An overview of the synthesis of Pd@SBA-15/PIDA (48).

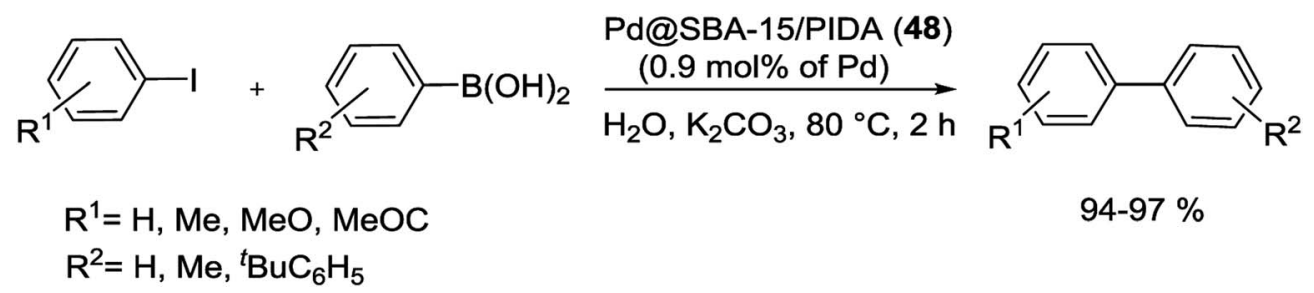

Scheme 65 Synthesis of biphenyl derivatives in the presence of Pd@SBA-15/PIDA (48).

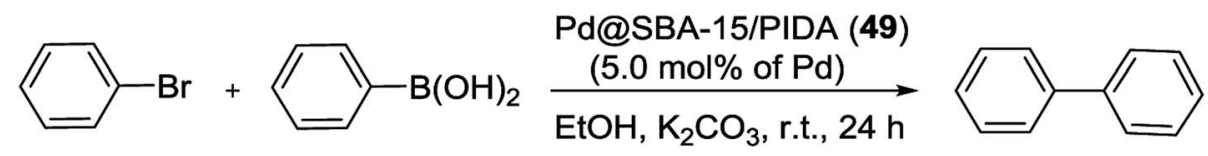

$80.4 \%$

Scheme 66 Synthesis of biphenyl derivatives in the presence of Pd/SBA-15 (49).

amount of total Pd in the nanocatalyst was determined $\sim 5.0 \%$ using ICP-OES measurements. Prepared SBA-15 supported Pd NPs was assessed for Suzuki-Miyaura coupling reaction of bromobenzene and phenylboronic acid at room temperature under atmospheric conditions (Scheme 66). The catalyst reusability was performed at $60{ }^{\circ} \mathrm{C}$ and its activity was found to continue to a significant extent at 4 runs. ${ }^{103}$

In another study, anchored palladium on the surface of organically functionalized silica SBA-15 was successfully prepared by Ghadermazi and co-workers. For the synthesis of SBA-15@adenine-Pd (50) catalyst (Scheme 67), first, the surface of SBA-15/Cl was modified by adenine ligand. Consequently, $\mathrm{Pd}(\mathrm{OAc})_{2}$ was added in a suspension and then reduced with $\mathrm{NaBH}_{4}$ to give present catalyst. Immobilization of Pd complex on silica SBA-15 was confirmed through strong interaction between nitrogen atoms of adenine ligand and Pd metal. The exact amount of Pd loaded on surface of nanocatalyst is found to be $1.34 \mathrm{mmol} \mathrm{g}^{-1}$ using the ICP-AES technique. Moreover, the BET analysis displays the surface area of 643 and 324.17 for SBA15 and SBA-15@adenine-Pd, respectively. Comparison of these results indicated that the functionalized SBA-15 has smaller BET surface area, lower pore volume and narrower pore diameter, hence, the anchoring of Pd complex in the inner pore walls of modified SBA-15 is well verified..$^{\mathbf{1 0}}$
The catalytic performance of this nonstructural material was also investigated in $\mathrm{C}-\mathrm{C}$ bond formation reaction between various aryl halides and phenylboronic acid using polyethylene glycol (PEG) as solvent at $110{ }^{\circ} \mathrm{C}$ (Scheme 68). A wide range of biphenyl products were obtained in high to excellent yields at short reaction times. ${ }^{\mathbf{1 0 4}}$

In another work, the palladium nanorods (PdNRs) into mesoporous channels of silica SBA-15 nanocatalyst, $\operatorname{PdNRs}(x)$ / SBA-15 (51), were prepared through a green ligand and surfactant-free ultrasonic method, by Bia et al. The synthesized procedure did not involve any complex or time consuming chemical modification. As can be seen in Scheme 69, SBA-15 was pre-treated at $200{ }^{\circ} \mathrm{C}$ in the vacuum. Then a certain amount volume of $\mathrm{Na}_{2} \mathrm{PdCl}_{4}$ was added to the pre-treated SBA15 and impregnated over night at room temperature. Next, the dried mixture was mixed with ethylene glycol (EG) in an ultrasonic bath to form $\operatorname{PdNRs}(x) / \mathrm{SBA}-15$ in which $x$ was the theoretical loading of $\mathrm{Pd}(\mathrm{wt} \%)$. In another way, the contrast experiment was performed by stirring instead of ultrasound, which was signed as PdNPs $(x) / \mathrm{SBA}-15$. Dehydration of adjacent hydroxyl groups via simple calcination of silica SBA-15 could result in negatively charged defect site. $\mathrm{Pd}^{2+}$ is adsorbed within the pore channel through electrostatic interaction and subsequently in situ reduced to $\mathrm{Pd}^{0}$ via active radicals produced by 


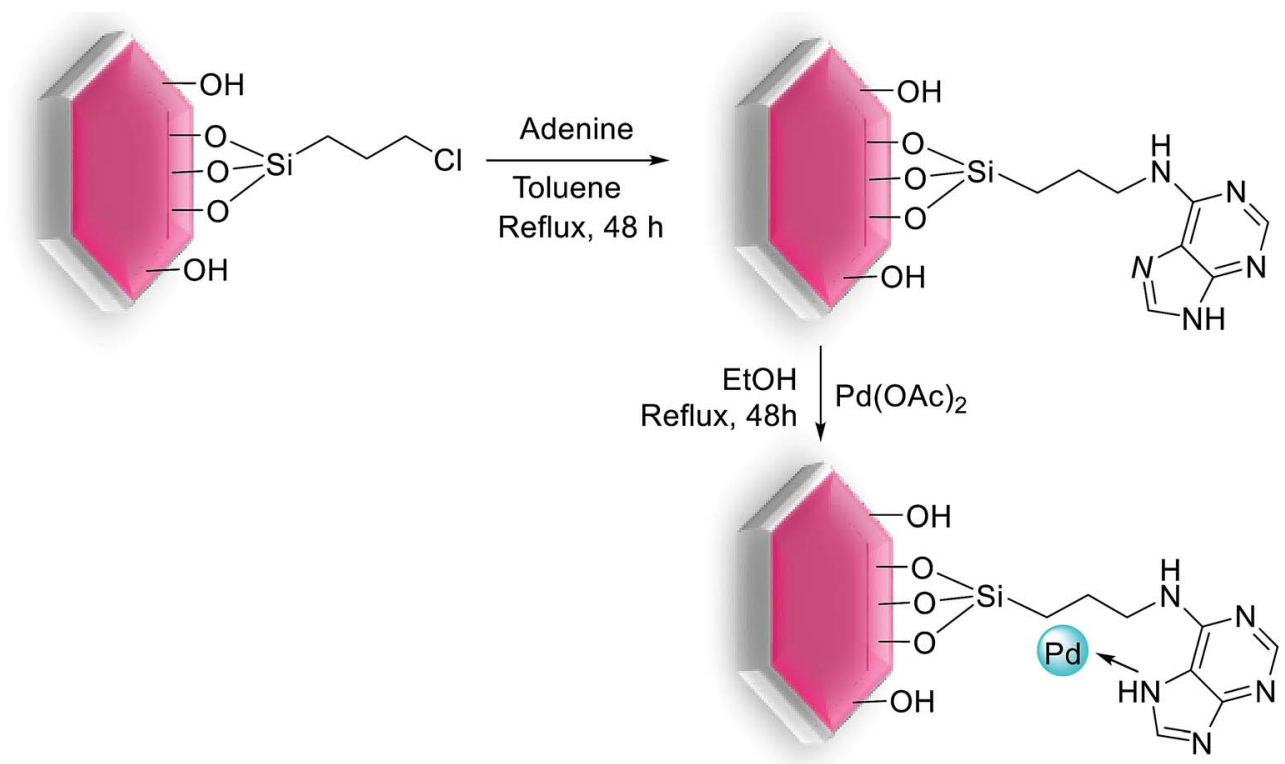

SBA-15@adenine-Pd (50)

Scheme 67 Synthesis of SBA-15@adenine-Pd (50).
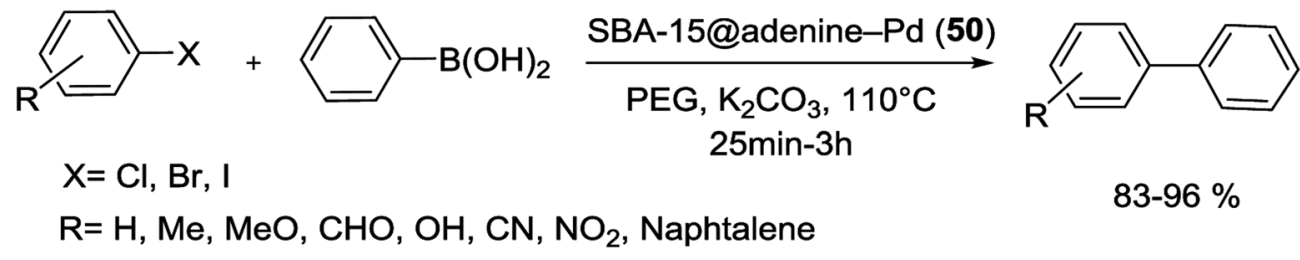

$83-96 \%$

Scheme 68 Suzuki reaction catalyzed by SBA-15@adenine-Pd (50).

ultrasound. Owning to the fast reduction and adequate oscillations of ultrasound, the highly dispersed and uniformly sized Pd species were obtained. ${ }^{105}$

PdNRs(5)/SBA-15 catalyst showed excellent catalytic activity for the S-M coupling and extensive adaptability to different substrates (Scheme 70). The reaction was performed under mild conditions, using $\mathrm{K}_{2} \mathrm{CO}_{3}$ as base and EtOH : $\mathrm{H}_{2} \mathrm{O}(1: 1)$ as solvent at $60^{\circ} \mathrm{C}$ under air atmosphere in the presence of a little amount of nanocatalyst $(0.1 \%)$. The product yield reached $96.4 \%$ at $90 \mathrm{~min}$, more higher than $76.3 \%$ of PdNPs(5)/SBA-15 produced without ultrasound. The excellent catalytic performance can be designed to the open channels filled with uniformly distributed Pd NRs and the close interaction between Pd species and SBA-15 support. It not only facilitates the mass transfer process, but also enables the substrate molecules fully contacting with the well dispersed Pd NRs that beneficial improve the catalytic activity of PdNRs(5)/SBA-15 support. PdNRs(5)/SBA-15 could be recycled five runs with no detectable deactivation owning to the strong chemical interaction and the unblocked pore channel. ${ }^{105}$

In 2018, Nandi et al. found that the pore size and volume of the silica support have enormous effect on the reactivity of the Pd catalysts in S-M coupling reaction. They synthesized two different types of silica support Pd, SBA-Pd (52) and MCM-Pd, which were different from each other in their pore dimension. The silica SBA-15 with $7.6 \mathrm{~nm}$ size was prepared by a non-ionic block-copolymer template (Scheme 71) ${ }^{106}$ Based on this, the SBA-15/ $\mathrm{NH}_{2}$ functionalized with trialdehyde, tris(4formylphenyl)amine, using one of the aldehyde groups. Employing the bulky organic moiety increases hydrophobicity of the silica SBA-15 and checks its hydrolysis in polar solvent. Subsequently, the other two formyl groups are allowed to undergo Schiff-base condensation with two 2-aminothiophenol which lead to introduce the multiple thiol-SH and imine-N groups in the inner pore walls. These electron donor atoms can strongly bind to the Pd species and the soft sulfur centers preferably stabilizes the soft metal. ${ }^{106}$

The BET surface areas for SBA-15 and SBA-Pd are 177 and 129 $\mathrm{m}^{2} \mathrm{~g}^{-1}$, and also the pore volumes are 0.270 and $0.192 \mathrm{~cm}^{3} \mathrm{~g}^{-1}$, respectively. The average pore dimension of the starting SBA-15 silica obtained by non-local density functional theory (NLDFT) model is $7.6 \mathrm{~nm}$. The results indicated the surface area and the pore volumes of the silica support decreases after each stage functionalization. Nevertheless, the TEM images of the SBA-Pd reveal that the basic hexagonal arrangement of pores was retained in the mesoporous silica support after all the 


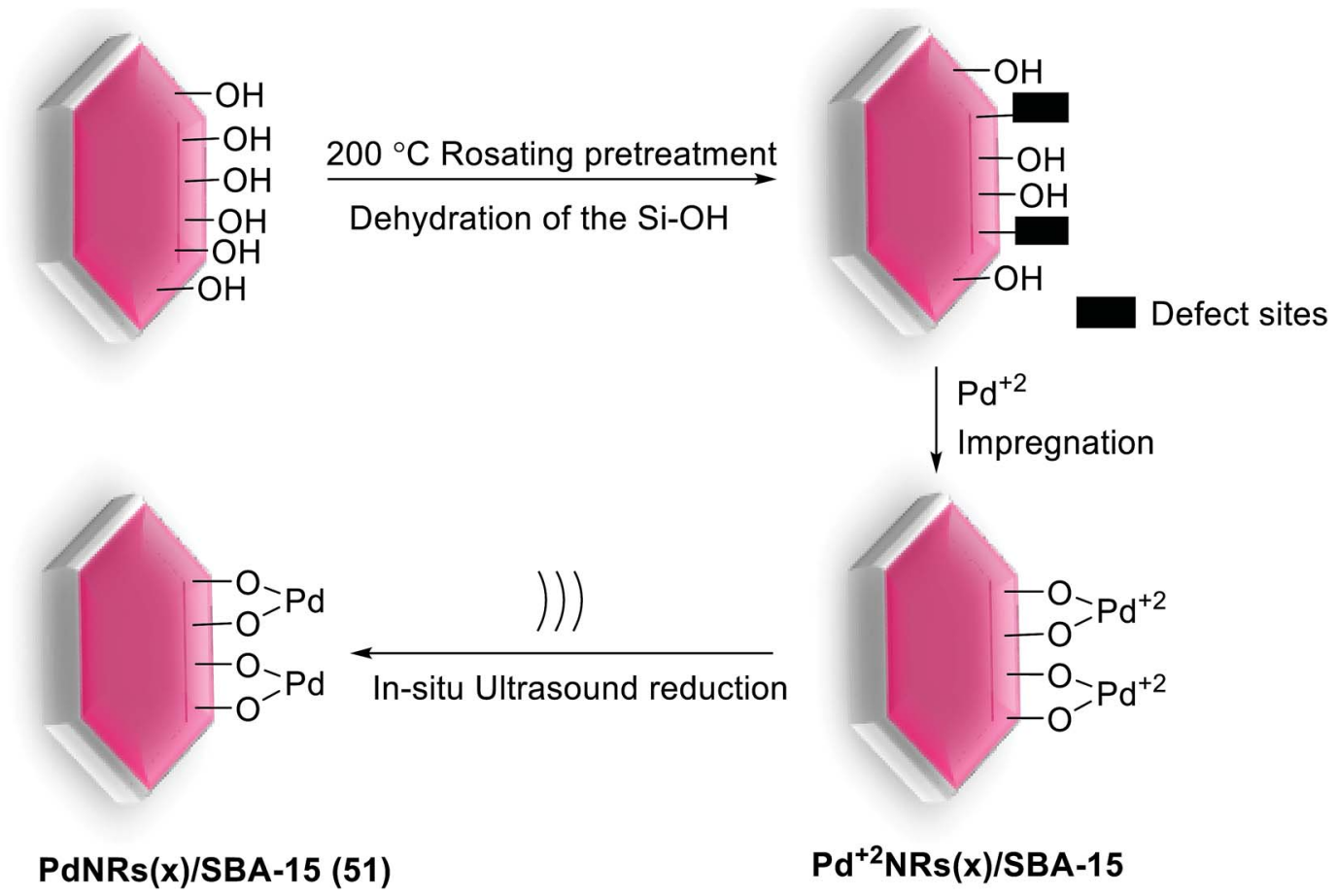

Scheme 69 Ultrasonic synthesis of PdNRs embedded into mesoporous channel of SBA-15 support (PdNRs( $x$ )/SBA-15 (51)).

functionalization and metal loading procedure. The catalytic performance of SBA-Pd was tested in Suzuki coupling of a range of substrates, which contains both electron-withdrawing and electron-donating ones (Scheme 72). According to the results, SBA-Pd displayed better performance compared to MCM-Pd catalyst and yield up to $98 \%$ was obtained in $\mathrm{MeOH}$ within $24 \mathrm{~h}$ of the reactions. This can be attributed to the higher pore size of SBA-Pd that allows better interaction of the substrates with the active centers on the pore surfaces. Besides, reusability of the catalyst indicated three successive reaction cycles without any substantial loss of activity. ${ }^{106}$

In another study in 2018, Luque et al. used cytosine functionalized SBA-15 as a robust anchor for immobilization of Pd to produce Pd-Cyt@SBA-15 (53) nanoreactor. For synthesis of the catalyst (Scheme 73), a suspension of Cyt@SBA-15 and dry acetone was added to $\mathrm{PdCl}_{2}$. The reaction mixture was then stirred at room temperature overnight, all volatiles were removed by vacuum. Finally, the residue was washed with ether and dried in an oven at $50{ }^{\circ} \mathrm{C}$ to give the corresponding PdCyt@SBA-15 catalyst at a loading ca. $0.35 \pm 0.001 \mathrm{mmol} \mathrm{g}^{-1}$.
The nanocatalysis system indicate a surface area of $367 \mathrm{~m}^{2} \mathrm{~g}^{-1}$ with a mean pore size of $3.45 \mathrm{~nm}$. Low angle-XRD measurement confirms that the grafting of Pd inside the pore channels of cytosine immobilized SBA-15 does not seriously disturb the overall mesoporous structure of ordered silica. ${ }^{107}$

The hybrid nanoreactors act as highly efficient catalysts for the $\mathrm{S}-\mathrm{M}$ coupling of different aryl chlorides with boronic acid in mixtures of i-PrOH : $\mathrm{H}_{2} \mathrm{O}$ under mild reaction conditions (Scheme 74). Good to excellent yield of products were obtained for electron-withdrawing as well as electron-donating substituents with high TON as 6650. Moreover, the catalysts exhibited excellent reusability over seven successive cycles and no significant leaching of the Pd was detected in the nanoreactors. ${ }^{107}$

Recently, our group published the synthesis of SBA-15/diurea/Pd (54) catalyst which was used in Suzuki coupling reaction. For preparation of the present catalyst, firstly, orthophenylene diamine was reacted with 3isocyanatopropyltriethoxysilane through formation of $\mathrm{C}-\mathrm{N}$ bond between isocyanate and amine parts to yield 1,1'-(1,2-<smiles>[R]c1ccc(Br)cc1</smiles>

$\mathrm{R}=\mathrm{H}, \mathrm{Me}, \mathrm{MeO}, \mathrm{MeCO}, \mathrm{CN}, \mathrm{NO}_{2}$

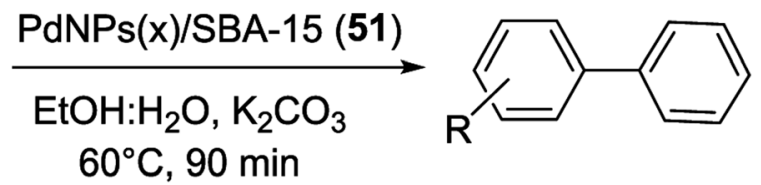

$32.7-92.2 \%$

Scheme 70 Suzuki reaction catalyzed by $\operatorname{PdNRs}(x) /$ SBA-15 (51). 

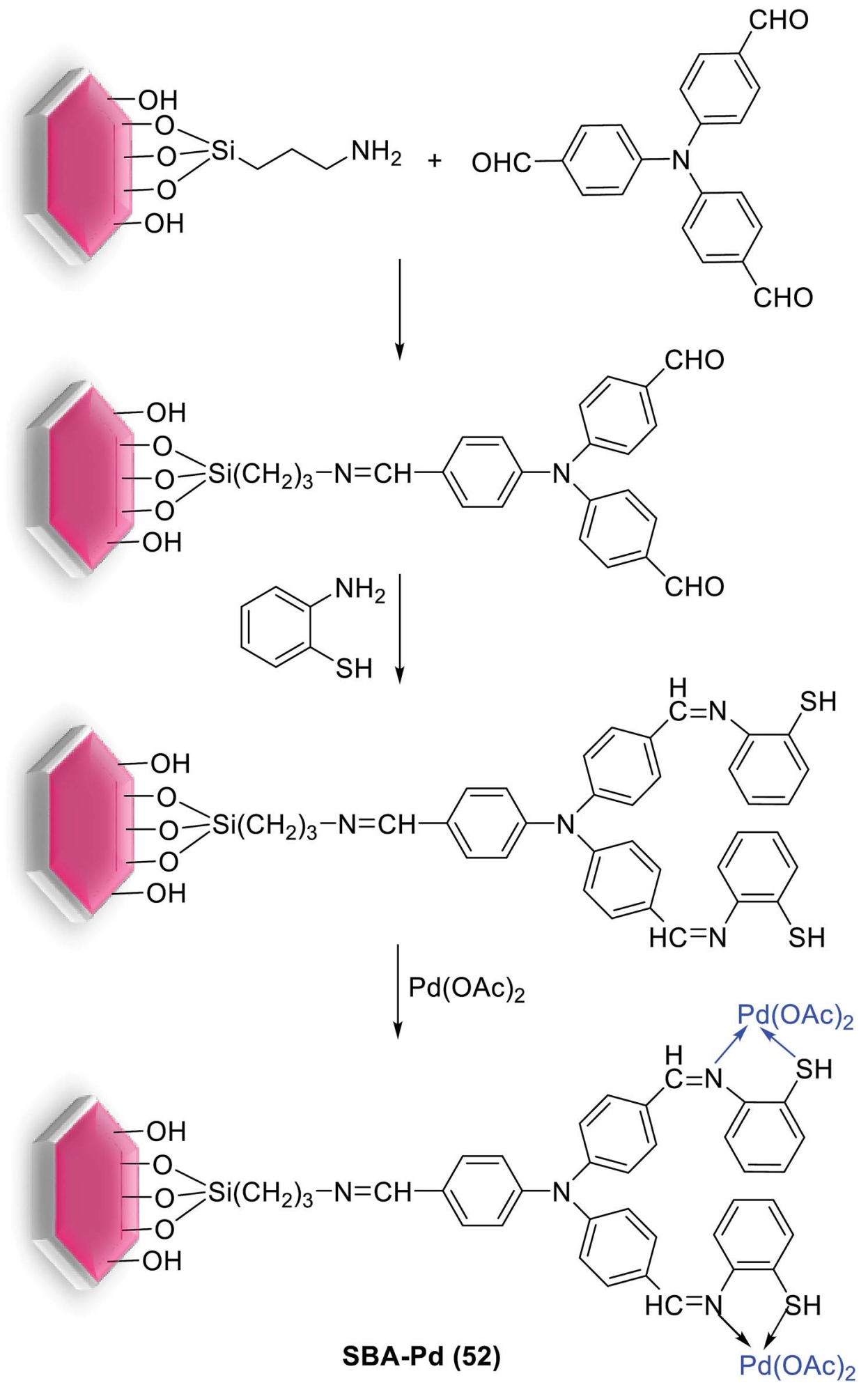

Scheme 71 Grafting of tris(4-formyl phenyl) amine on 3-aminopropyl triethoxy silane functionalized silica and synthesis of SBA-Pd (52).

phenylene)bis(3-(3-(triethoxysilyl)propyl)urea). In the next step, this di-urea based ligand was reacted with silica SBA-15 to form the di-urea functionalized SBA-15. Finally, the SBA-15/di-urea/ Pd nanocatalyst was achieved by the reaction of $\mathrm{Pd}(\mathrm{OAc})_{2}$ with SBA-15/di-urea (Scheme 75). ${ }^{54}$
Typical SEM image of SBA-15/di-urea/Pd reveals rod-shaped morphology aggregated into bundles (Fig. 2a). The TEM image of the nanocatalyst also demonstrations that the material is organized in ordered arrays of 2D hexagonal SBA-15 mesoporous silica and the attachment of organic components inner 

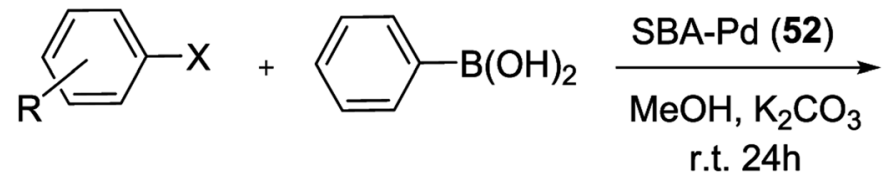

$\mathrm{X}=\mathrm{Br}, \mathrm{I}$
$\mathrm{R}=\mathrm{H}, \mathrm{Me}, \mathrm{MeO}, \mathrm{MeCO}, \mathrm{CO}_{2} \mathrm{H}, \mathrm{NO}_{2}, \mathrm{Cl}$

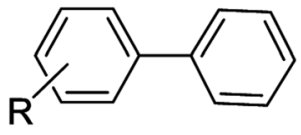

$32.7-92.2 \%$

Scheme 72 Suzuki reaction catalyzed by SBA-Pd (52).

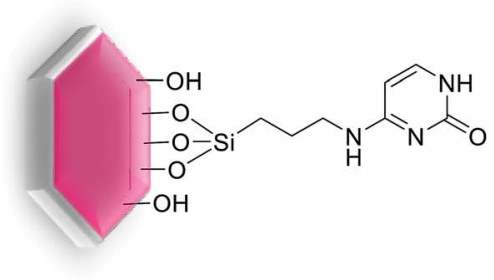

Pd-Cyt@SBA-15
Dry acetone, r.t., $24 \mathrm{~h}$

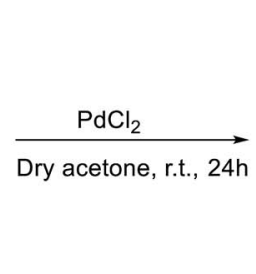

Pd-Cyt@SBA-15 (53)

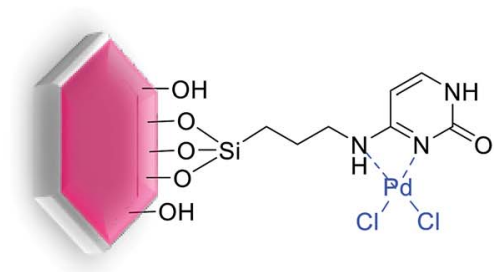

Scheme 73 Schematic representation of the synthesis of Pd-Cyt@SBA-15 (53) nanocatalyst.

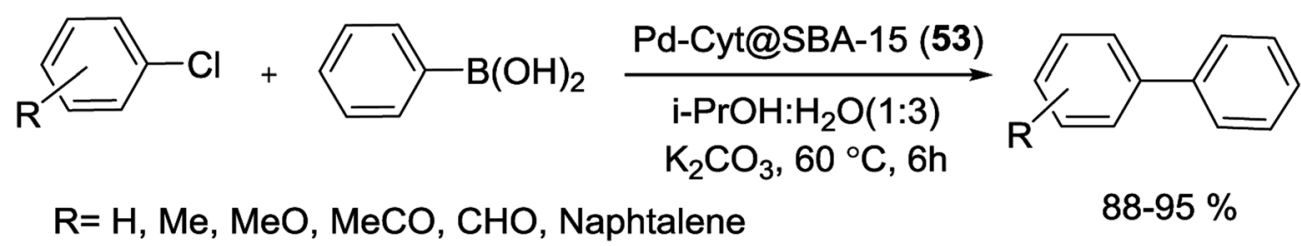

Scheme 74 Suzuki coupling reaction of aryl chloride and phenylboronic acid by Pd-CytaSBA-15 (53) nanoreactor.

pore walls of SBA-15 has no distinct effect on the morphology of composition (Fig. 2b). Furthermore, the dark spots in TEM are the Pd NPs with diameter $\sim 3 \mathrm{~nm}$ which clearly obvious. ${ }^{54}$

The theoretical calculations was also performed that indicated each Pd ion was strongly grafted with one nitrogen and two oxygen atoms from multidentate di-urea ligand and these interactions were retained during catalytic process. The results are in good agreement with hot filtration result that demonstrates the Pd ions have very high stability against leaching. The catalytic activity of SBA-15/di-urea/Pd nanostructure was tested for the Suzuki coupling (Scheme 76) of electronically diverse aryl halides with phenylboronic acid under mild reaction conditions with a minimal amount of Pd loading ( $0.26 \mathrm{~mol} \%)$. This protocol gave some advantages such as high yields of products, short reaction times, easy catalyst recovery, stability of catalyst without leaching and preserving catalytic performance for at least six successive runs. ${ }^{54}$

\subsection{Mizoroki-Heck reaction}

Another example of important $\mathrm{C}-\mathrm{C}$ cross coupling is Heck or Mizoroki-Heck reaction (denoted as $\mathrm{M}-\mathrm{H}$ reaction) involving an interaction between olefins with aryl or vinyl halides to form a substituted alkene using Pd as a catalyst and a base (Scheme 77). ${ }^{108} \mathrm{M}-\mathrm{H}$ reaction was first reported by Heck and Mizoroki in the late 1960s. ${ }^{109,110}$ Because of mild reaction conditions, high reactivity and selectivity, and moderate toxicity of this protocol, it has been used in a wide variety of fields such as natural product synthesis, bioorganic chemistry and also employed in medical, pharmaceutical, electronics, and material science. ${ }^{111-113} \mathrm{~A}$ heterogeneous mechanism, similar to that of the Suzuki reaction, was proposed for the Heck coupling reaction (Scheme 78). ${ }^{114}$ The reaction begins through oxidative addition of the aryl halide with $\operatorname{Pd}(0)$ species to form $\operatorname{Pd}(\mathrm{II})$ halide intermediate which is followed by coordination and migratory insertion of the olefin to the Pd to form a $\pi$-complex. Next, bond rotation places the two groups in trans to each other to remove the steric strain and consequent $\beta$-hydride elimination results in a trans final product. In the last step, reductive elimination gave the product species with regeneration of $\operatorname{Pd}(0)$ catalyst. ${ }^{115}$ As expected, rather similar to other $\mathrm{C}-\mathrm{C}$ coupling reactions, efficient anchorage of Pd NPs into mesoporous SBA15 , beside other parameters, has received considerable attention for the easy and efficient product separation and catalyst recycling in the Heck coupling.

Mercaptopropyl-functionalized SBA-15 supported Pd material (denoted as SBA-15-SH-Pd) (3), as mentioned previously, was also employed by Crudden $e t$ al. as a catalyst for the $\mathrm{M}-\mathrm{H}$ reaction, with virtually no leaching of Pd (Scheme 79). Even 


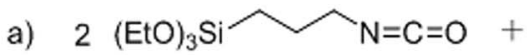

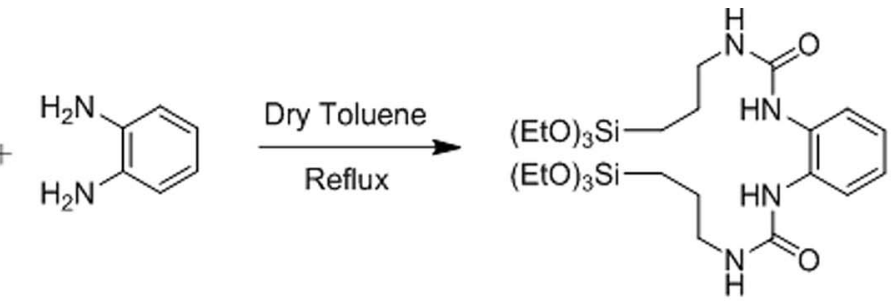

di-urea based ligand

b)

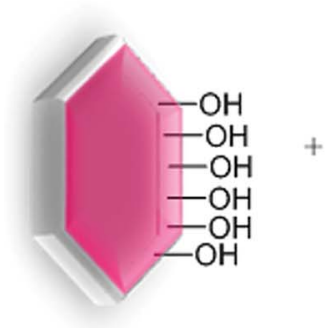

SBA-15

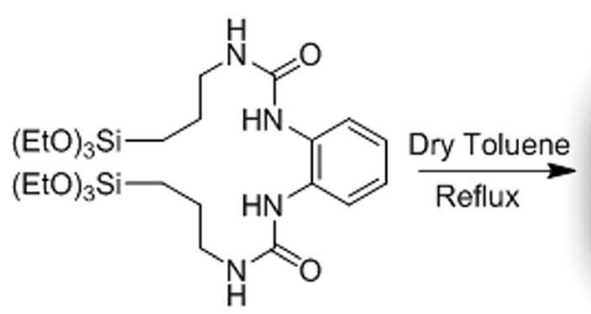

di-urea based ligand<smiles>C[Si](O)(O)OCCCNC(=O)Nc1ccccc1NC(=O)NCCC[Si](O)(O)O</smiles>

SBA-15/di-urea

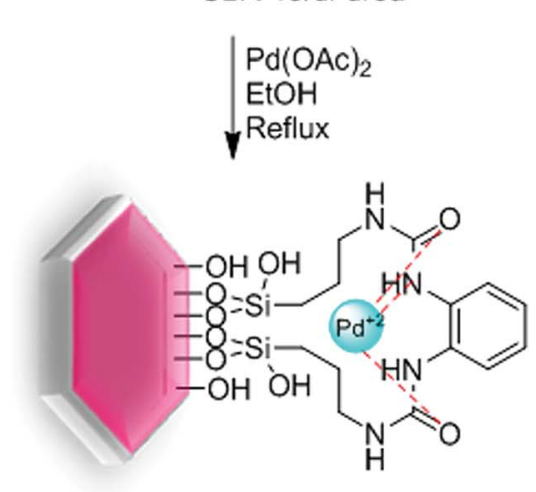

SBA-15/di-urea/Pd (54)

Scheme 75 Schematic diagram of SBA-15/di-urea/Pd (54) fabrications.

after using loadings as high as $2 \%$, only $3 \mathrm{ppb}$ of Pd were detected in solution, accounting for only $0.001 \%$ of the added catalyst. Interestingly, various heterogeneity tests such as three- phase tests and hot filtration experiments have displayed that the reaction was predominantly occurred on the surface-bound Pd. ${ }^{65}$
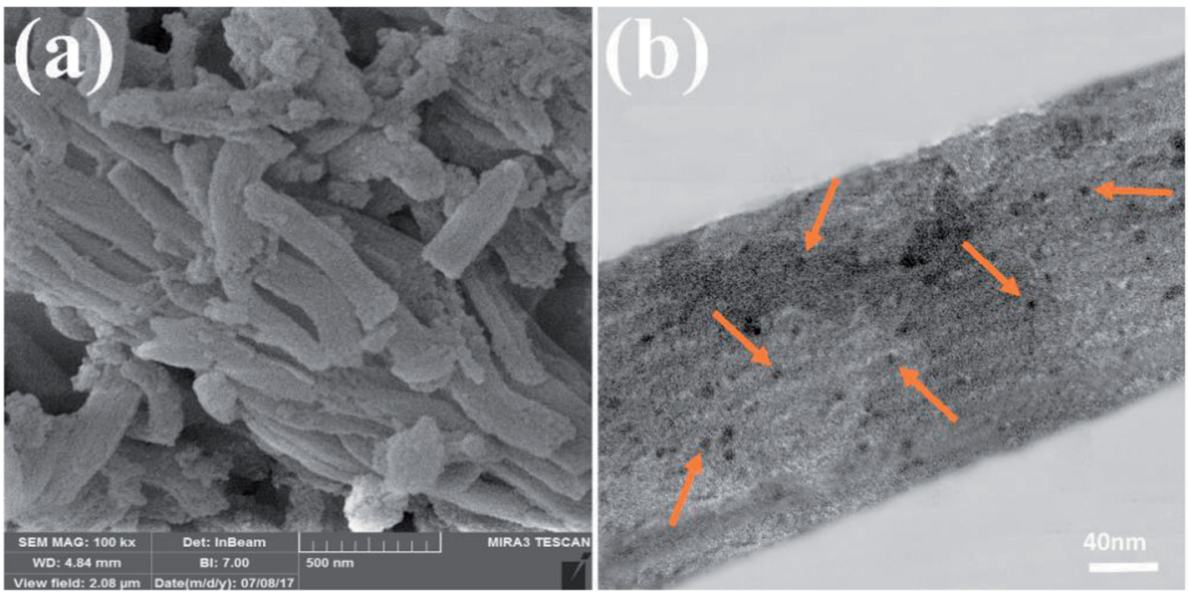

Fig. 2 (a) SEM and (b) TEM images of SBA-15/di-urea/Pd (54). The arrows in (b) indicate Pd NPs. 

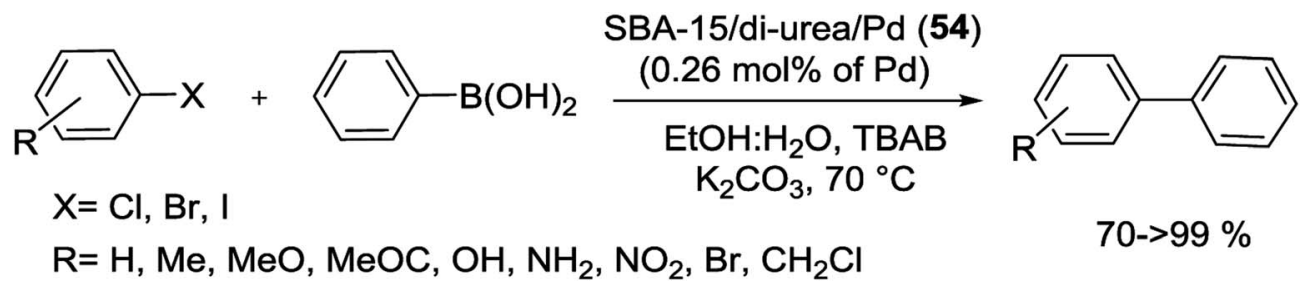

$70->99 \%$

Scheme 76 Suzuki coupling using SBA-15/di-urea/Pd (54).

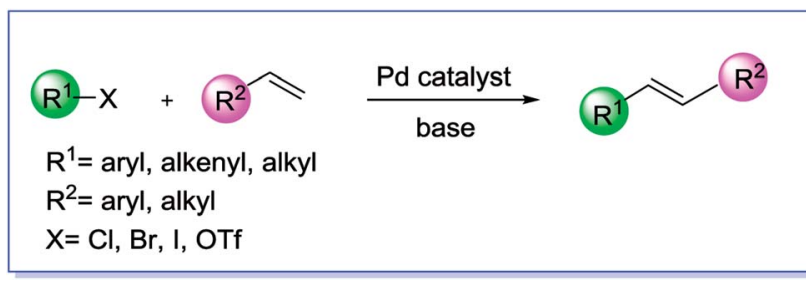

Scheme 77 The Heck coupling reaction.

In the recent literature, Pd colloid layers decorated SBA-15 functionalized with $\mathrm{Si}-\mathrm{H}$ groups (Pd-SBA-15) (55) by a selective and in situ reduction method were described by Shi et al. In the preparation of this catalyst, the $\mathrm{Si}-\mathrm{H}$ groups were introduced by reaction with TMS. This modified surface with hydrosilane is capable for in situ reducing Pd ions on the pore channels of SBA15. The material is the most active heterogeneous catalysts for $\mathrm{M}-\mathrm{H}$ coupling reactions in air at temperatures between 120 and
$170{ }^{\circ} \mathrm{C}$ (Scheme 80). High yields of products were obtained in the coupling of bromo- and iodo arenes with methyl acrylate or styrene, even while low amounts of catalyst were employed. The catalyst could be separated via simple filtration and reused for at least five recycles with no detectable deactivation. Compared with the analogous Pd-grafted mesoporous MCM-41 material (Pd-TMS11), which was prepared by CVD method, ${ }^{116}$ Pd-SBA-15 (55) composite relatively demonstrated high catalytic activity in Heck reactions. It is due to the high dispersion of Pd colloid layers on the pore walls of the supporting material and absence of big Pd clusters on the outer surfaces of Pd-SBA-15. The other advantages of the using catalyst were simple synthesis, the ultrahigh specific area, large pore opening, high efficiency and reusability, and low Pd leaching. ${ }^{117}$

The Pd/SBA-15 (6) catalyst, discussed above in Suzuki coupling, has been tested in the Heck coupling as well (Scheme 81). Coupling of aryl halide with olefin was performed under optimal conditions. The results exhibit high conversion (90-

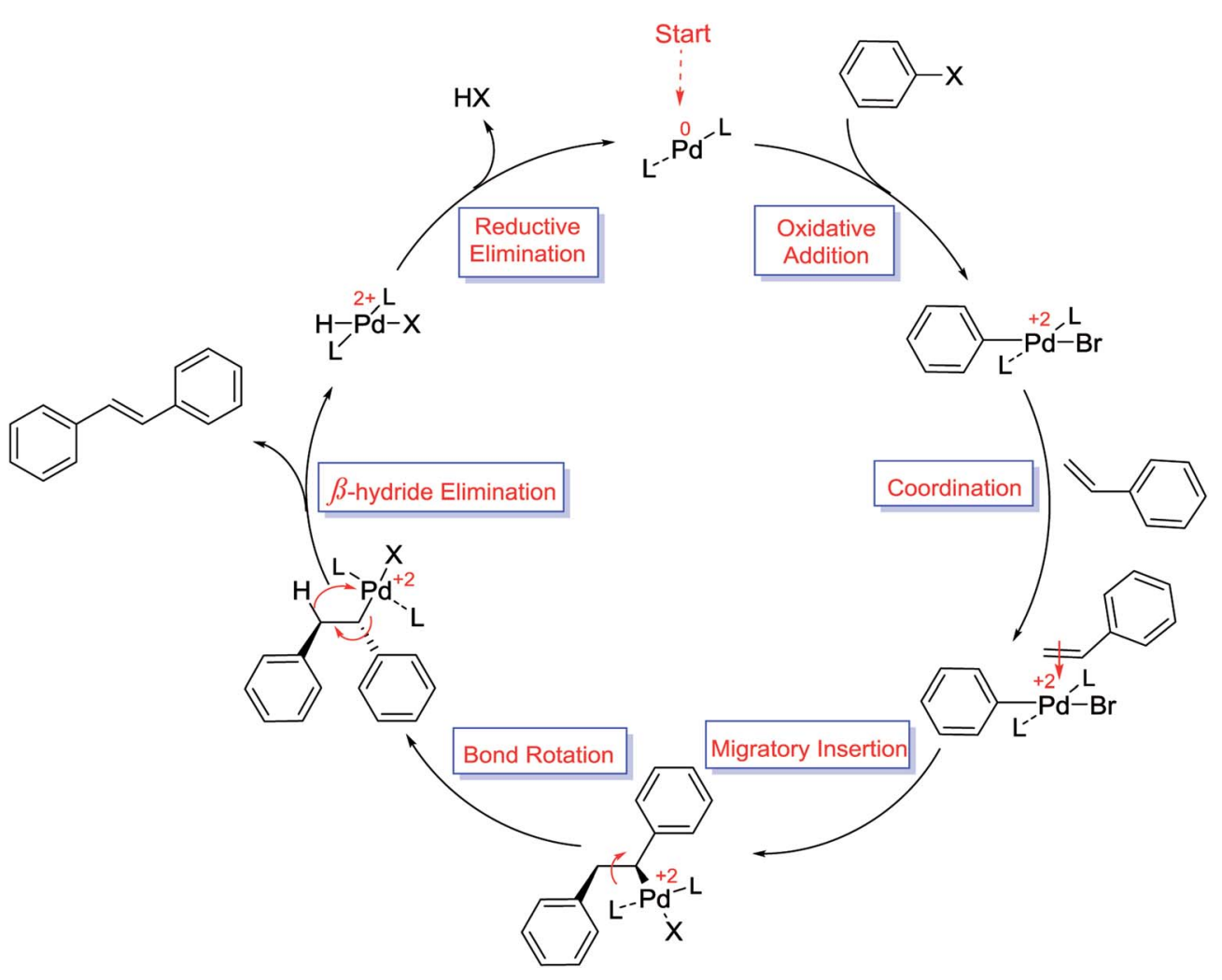

Scheme 78 The proposed mechanism of Heck coupling reaction. ${ }^{115}$ 
<smiles>[R]c1ccc([X])cc1</smiles>

$\mathrm{X}=\mathrm{I}, \mathrm{Br}$

$\mathrm{R}=\mathrm{H}, \mathrm{MeCO}$<smiles>C=Cc1ccccc1</smiles>

SBA-15-SH-Pd (3)

(1 $\mathrm{mol} \% \mathrm{Pd}$ )

DMF, NaOAc, $120^{\circ} \mathrm{C}, 15 \mathrm{~h}$<smiles>[R]c1ccc(/C=C/c2ccccc2)cc1</smiles>

Conversion $=98-99 \%$

Scheme 79 SBA-15-SH-Pd (3) catalyst for the $\mathrm{M}-\mathrm{H}$ reaction.

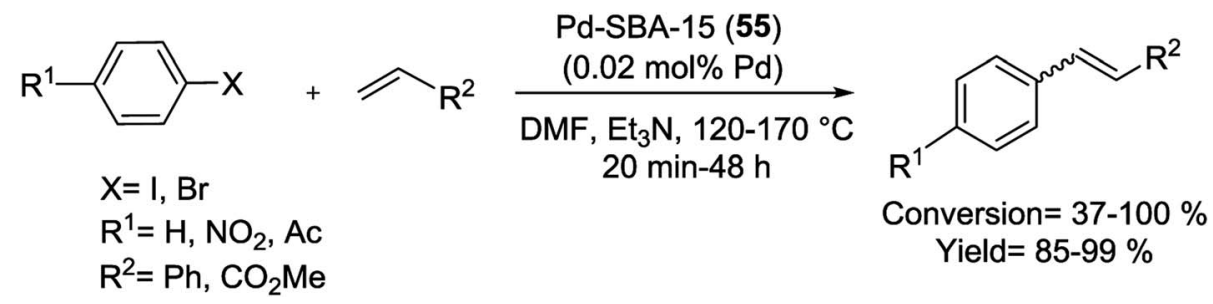

Scheme 80 Heck olefination of aryl halide over Pd-SBA-15 (55) catalyst.

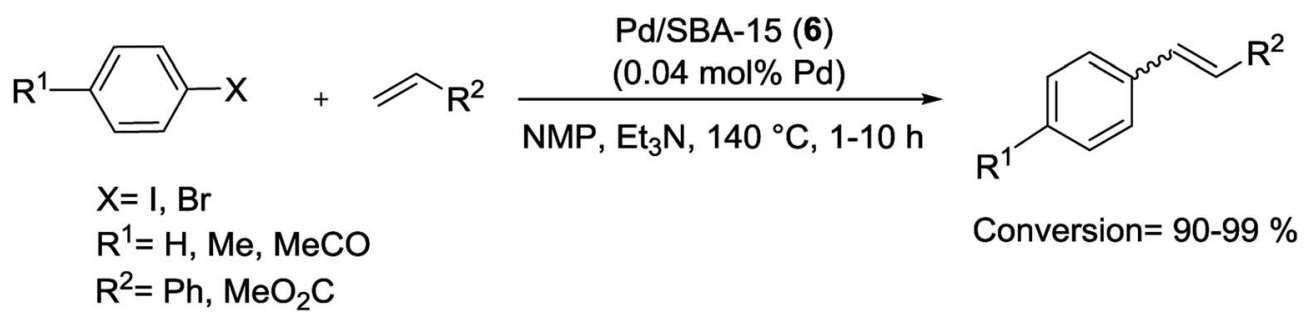

Scheme 81 Heck coupling reaction catalyzed by Pd/SBA-15 (6) nanocomposite.

99\%) and good TON (450-2500). Recycling test for $\mathrm{M}-\mathrm{H}$ coupling reactions showed excellent yield at least up to $90 \%$ until fifth reusing usage. But the yield decrease to $70 \%$ in the sixth recycling which probably due to fell off Pd NPs from SBA15 channels. ${ }^{68}$

Heck arylation of olefins by aryl halides was applied under solvent-free conditions using 1.06\% SBA-TMG-Pd (56) as catalyst. The synthesis of catalyst started from the reaction of IL 1,1,3,3-tetramethylguanidinium lactate (TMGL) and $\mathrm{Pd}(\mathrm{OAc})_{2}$ in the presence of SBA-15 following reduced with $\mathrm{H}_{2}$ and then heated up to $220^{\circ} \mathrm{C}$ to remove the anion of the IL (Scheme 82). The coupling product were obtained in moderate to excellent yields (33-94\%). It is easy to isolate the supported catalyst from the reaction mixture and this catalyst can be facilely recycled at least 6 times with no detectable deactivation. SBA-TMG-Pd (56) was much more active and stable than a Pd catalyst decorated on pristine SBA-15 without IL (denoted as SBA-Pd). ${ }^{118}$

Recently, $\mathrm{Pd}(\mathrm{OAc})_{2}$ with IL was successfully confined onto immobilized SBA-15 silica by Jin and co-workers. ${ }^{119}$ As shown in Scheme 83, for modification the surface of SBA-15, firstly, the $N$ methylimidazole was reacted with (3-chloropropyl)triethoxysilane following treatment with SBA-15 silica. Next, Pd(OAc) was immobilized into the channels of modified SBA-15 through absorbed IL to give SBA-15-IL-Pd (57).
The SBA-15-IL-Pd (52) system was exhibited high catalytic activity in the coupling of acrylates with activated aryl halides and in the presence of $\mathrm{Bu}_{3} \mathrm{~N}$ as a base at $120{ }^{\circ} \mathrm{C}$ (Scheme 84). Furthermore, it could be recycled six runs without any apparent decrease in activity. ${ }^{119}$

Pd/SBA-15 (58) can be prepared by a two-step synthesis route via the Pd NPs copolymer unit as template. Pd NPs with narrow size-distribution $(\sim 6-10 \mathrm{~nm})$ have been prepared by formalin reduction approach and encapsulated within mesoporous SBA15 channels through hydrothermal synthesis without agglomeration. Hence using this method, the pore size increases and the surface area decreases. The Pd/SBA-15 (53) nanocomposite is an efficient heterogeneous catalyst for $\mathrm{M}-\mathrm{H}$ reaction (Scheme 85) because demonstrated a high activity, a minimal amount of Pd leaching, and reusability of at least five times in air for the Heck coupling reaction. ${ }^{\mathbf{1 2 0}}$

In another study, Wang's group synthesized the Pd-SBA-15 (59) catalyst using an in situ approach. In this method, molecular assembly template was used as a hydrophobic carrier to afford the compatible environment for the hydrophobic compounds. The hydrophobic solvent $\left(\mathrm{CHCl}_{3}\right)$ was employed as a transport medium to inject the $\operatorname{Pd}(\mathrm{II})$ acetylacetonate $\left[\operatorname{Pd}(\text { acac })_{2}\right]$ inside the core of the surfactant micelles. Finally a $1.46 \mathrm{wt} \%$ Pd loading was achieved without the loss of pore 


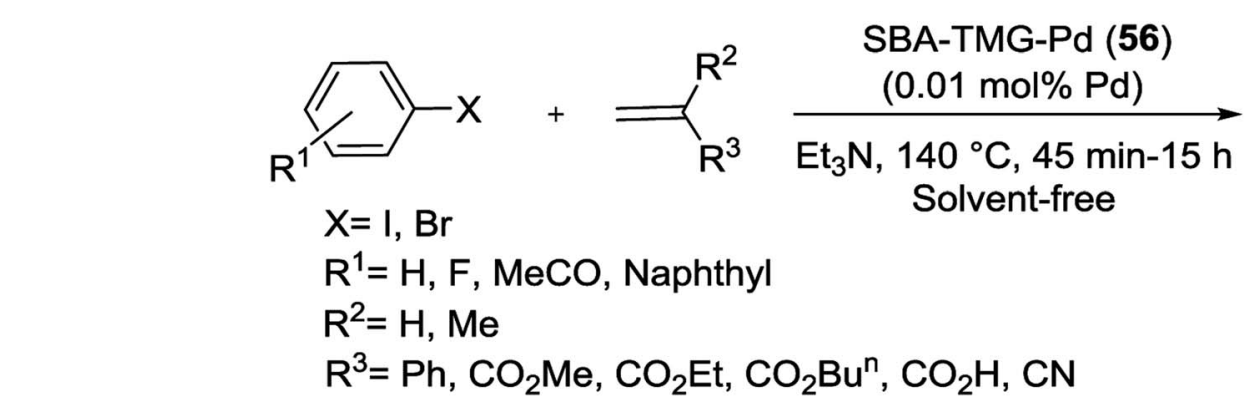<smiles>[R]C([R])=Cc1ccc([R])cc1</smiles>

$33-94 \%$

Scheme 82 Heck reactions of aryl halides with olefins in presence of SBA-TMG-Pd (56).
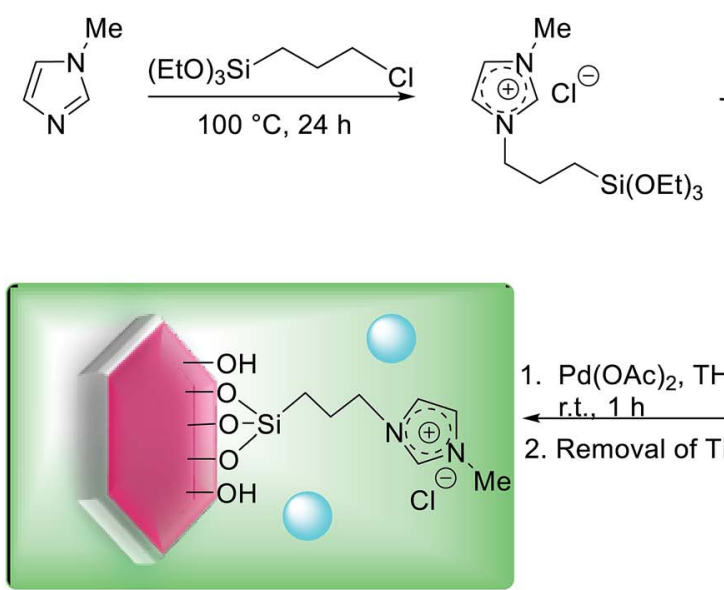

1. $\mathrm{Pd}(\mathrm{OAc})_{2}, \mathrm{THF}$ r.t., $1 \mathrm{~h}$ 2. Removal of THF

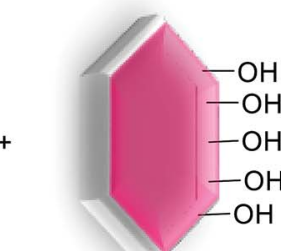

Toluene, reflux $\mathrm{OH}$
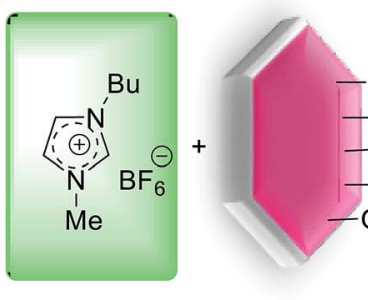

$$
=\operatorname{Pd}(\mathrm{OAc})_{2}
$$

SBA-15-IL-Pd (57)

Scheme 83 Schematic synthesis of SBA-15-IL-Pd (57).

ordering. The SBA-15-Pd (59) nanocomposite showed excellent catalytic activities and high reusability for the $\mathrm{M}-\mathrm{H}$ coupling reactions (Scheme 86). ${ }^{121}$

The same group, was prepared Pd-SBA-15 (60) nanocomposite with high Pd loading and dispersion following investigated for the $\mathrm{M}-\mathrm{H}$ reaction (Scheme 87 ). Firstly, mesoporous SBA-15 was modified using [3-(2-aminoethyl aminopropyl)] trimethoxysilane. Subsequently, Pd(II) ions were anchored to the organo-functionalized SBA-15, following reduced by hydrazine hydrate to yield Pd supported on SBA-15 with $4.30 \%$ Pd loading and average diameter of $7.3 \mathrm{~nm}$. Activated bromobenzenes and iodobenzenes reacted with acrylic acid, styrene, and butyl acrylate to give high yields of products. Even though the catalyst showed a minimal amount of Pd<smiles>[X]c1cccc([R])c1</smiles>

$\mathrm{X}=\mathrm{I}, \mathrm{Br}, \mathrm{Cl}$

$\mathrm{R}^{1}=\mathrm{H}, \mathrm{Me}, \mathrm{MeO}, \mathrm{NO}_{2}, \mathrm{OH}$

$\mathrm{R}^{2}=\mathrm{Me}, \mathrm{Et}, \mathrm{Bu}$
SBA-15-IL-Pd (57)

(1 $\mathrm{mol} \% \mathrm{Pd})$

Dodecane, $\mathrm{Bu}_{3} \mathrm{~N}, 120^{\circ} \mathrm{C}, 2-12 \mathrm{~h}$

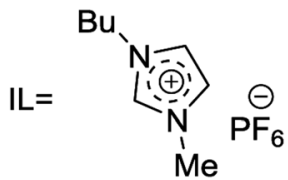<smiles>[R]OC(=O)/C=C/c1ccc([R])cc1</smiles>

$21-100 \%$

Scheme 84 Heck reaction of aryl halides with acrylates in the presence of SBA-15-IL-Pd (57) catalyst. 


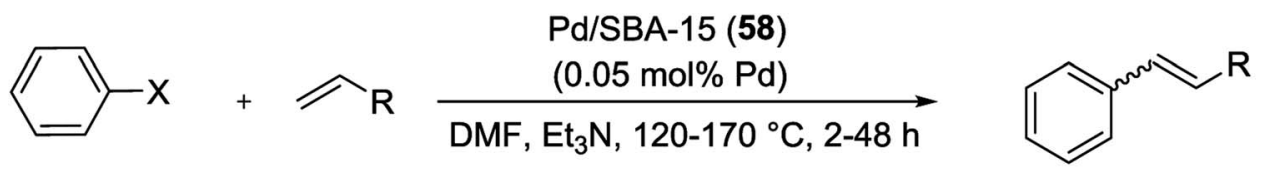

$$
\begin{aligned}
& \mathrm{X}=\mathrm{I}, \mathrm{Br} \\
& \mathrm{R}=\mathrm{Ph}, \mathrm{CO}_{2} \mathrm{Bu}^{\mathrm{n}}
\end{aligned}
$$

Conversion $=40-100 \%$

Selectivity $=88-98.5 \%$

Scheme 85 Heck cross-coupling reaction of various substrates catalyzed by Pd/SBA-15 (58).
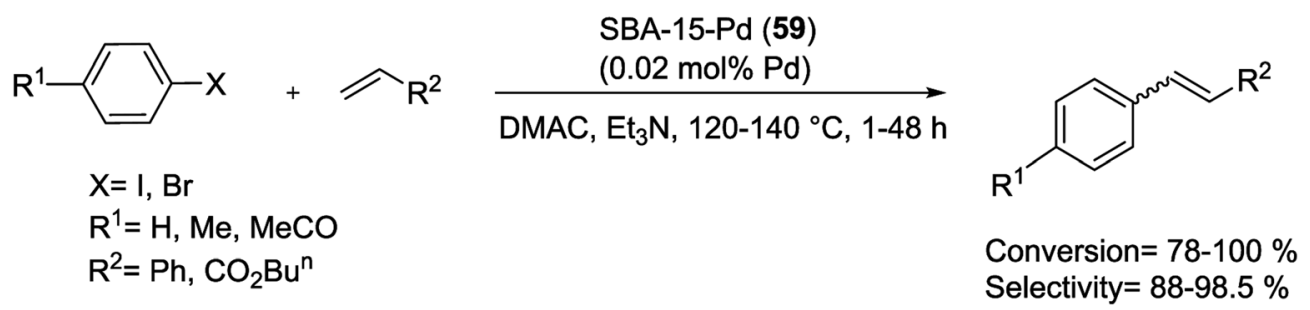

Scheme 86 Heck olefination of aryl halide by the SBA-15-Pd (59) catalyst.
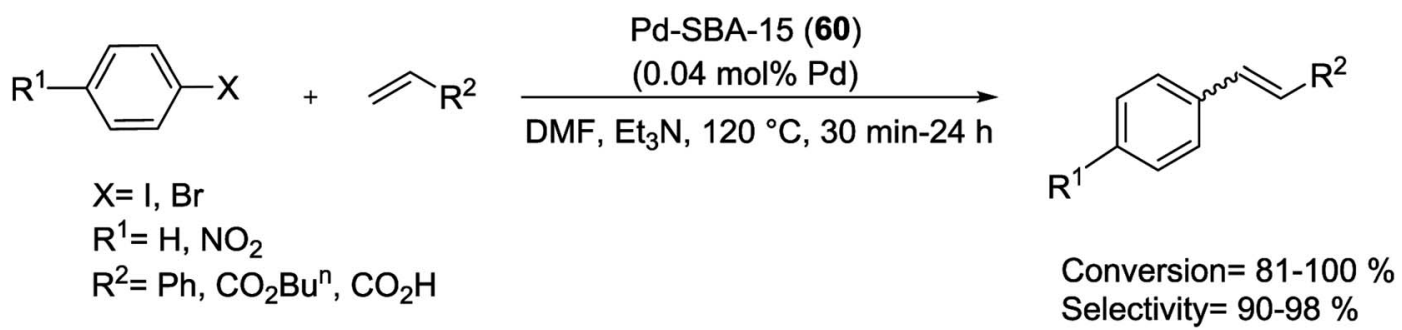

Scheme 87 Heck olefination of aryl halide by the Pd-SBA-15 (60) catalyst.

leaching accompanied by the decreasing Pd dispersion during reaction, it could be reused with only a minor decrease of activity in six runs. ${ }^{122}$

A Pd colloid grafted heterogeneous catalyst (Pd/SBA-15) (61), with extremely low loading amount of Pd $(0.1 \mathrm{~mol} \%)$ in SBA-15 matrix had been successfully synthesized via directly in situ reduction technique. In this nanocomposite, after modified with $\mathrm{Si}-\mathrm{H}$ groups, much less Pd ions were reduced to Pd colloids which were evenly dispersed on both the outer and inner surfaces as isolated islands or even isolated single atoms. The as-prepared catalyst with extremely low amounts of $\mathrm{Pd}$ (0.002 mol\%) demonstrated high catalytic efficiency and TOF values for $\mathrm{M}-\mathrm{H}$ coupling reactions. The large and open pore channels, highly dispersed catalyst species, facile catalyst recovery, very high specific surface area and ultrahigh stability against leaching were other benefits of this heterogeneous catalyst (Scheme 88). ${ }^{123}$

The Pd-porphyrin immobilized IL could be covalently grafted into the pore channels of SBA-15 silica via ion-pair electrostatic interaction between Pd-porphyrin-anionic and imidazolium-cationic moieties. Such functionalized SBA-15 material was successfully prepared using a one-pot sol-gel technique or a post-synthesis (surface sol-gel polymerization) method. According to the process in Scheme 89, the

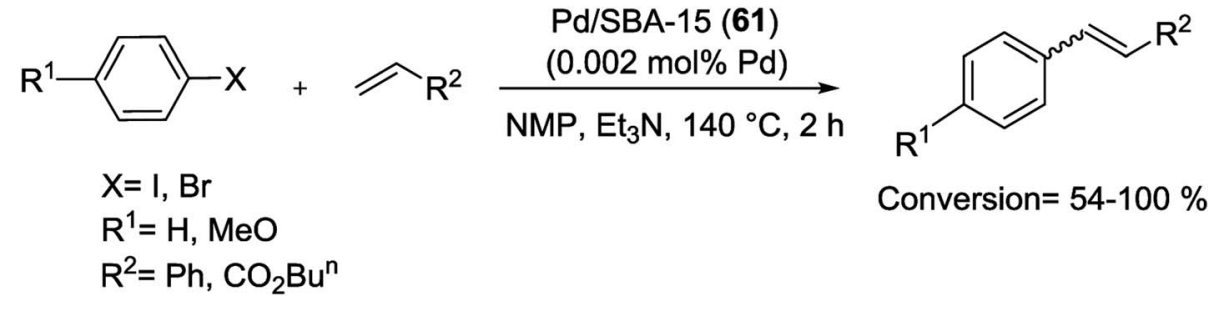

Scheme 88 Catalytic properties of the prepared Pd/SBA-15 (61) for $\mathrm{M}-\mathrm{H}$ reaction. 


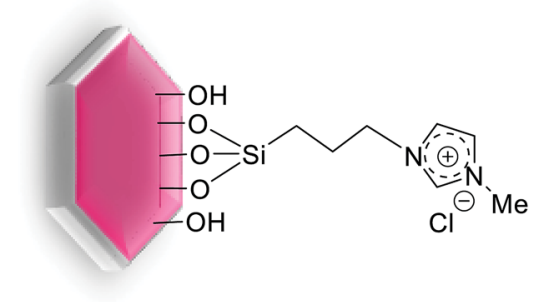

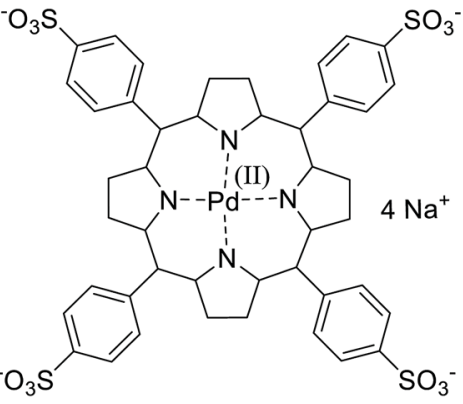

Pd-PMIM-SBA-15

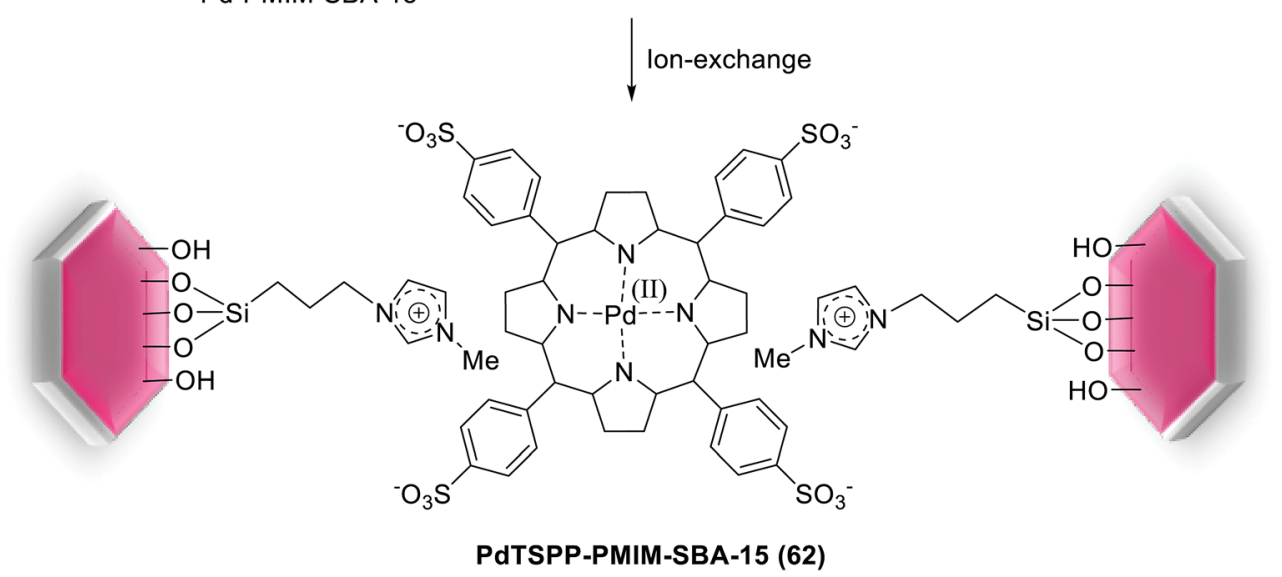

Scheme 89 Strategy for synthesizing of the post-PdTSPP-PMIM-SBA-15 (62).

imidazolium-based IL anchored mesoporous silica, PMIM-SBA15 , was produced via attaching of quaternizing $N$-methylimidazole group into the channels of SBA-15. Consequently ionexchange by (meso-tetra-( $p$-sulfonatophenyl)-porphyrinato) palladium sodium, [PdTSPP] $\mathrm{Na}_{4}$, in water gave the postPdTSPP-PMIM-SBA-15 (62). ${ }^{124}$

It became clear that the materials produced via postsynthesis protected better mesophase structure of SBA-15 than those formed by one-pot sol-gel method. The catalysis investigation demonstrated that the post-PdTSPP-PMIM-SBA-15 material was an effective and recyclable heterogeneous catalyst towards solvent-free Heck coupling of ethylacrylate and iodides/bromides aryl (Scheme 90), which could be recovered and reused 9 runs without SBA-15 structural collapse, leaching of $\mathrm{Pd}$, and considerable deactivation.

As another technique worth mentioning, Pd NPs encapsulated in silica SBA-15 were synthesized via ion-exchange with cationic Pd precursor in an alkaline solution using an uncalcined SBA-15. Then the resulting was reduced by formalin. The high Pd loading in these nanocomposites can be obtained up to $5.21 \mathrm{wt} \%$ via adjusting the $\mathrm{pH}$ value of the solution. The Pd NPs (equal or less than $6 \mathrm{~nm}$ in size) are well distributed within the mesoporous channels without agglomeration. The Pd/SBA-15 (63) nanocomposite was a simple and efficient catalyst for the $\mathrm{M}-\mathrm{H}$ coupling reactions (Scheme 91). The simple catalyst synthesis, facile recovery, high reusability in air and low Pd leaching can be mentioned as other benefits of this catalyst. ${ }^{125}$

Catalyst $\mathrm{Ph}-\mathrm{SBA}-15-\mathrm{PPh}_{3}-\mathrm{Pd}(\mathbf{1 2})$, used in the Suzuki reaction, proved also to be a highly active and stable catalyst in the $\mathrm{M}-\mathrm{H}$ coupling reaction for the first time. As shown in Scheme 92, the reaction of 4-nitrobromobenzene with methyl acrylate was occurred smoothly using $\mathrm{scCO}_{2}$ to give the desired product in high yield. This newly designed SBA-15-supported Pd catalyst acts as expected as a nanoreactor, in which catalysis can occur. Even if the Pd species cut off from one phosphine ligand, they

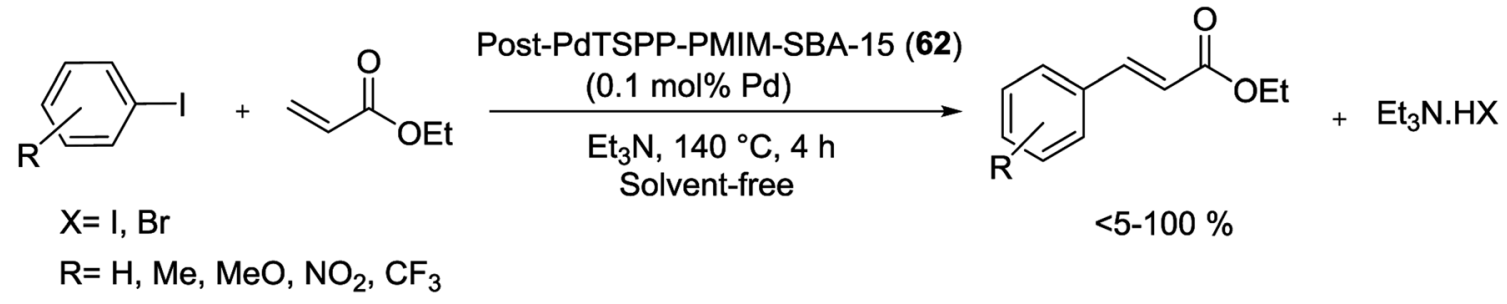

Scheme 90 Heck reaction of aryl halides with ethyl acrylate catalyzed by post-PdTSPP-PMIMSBA-15 (62). 


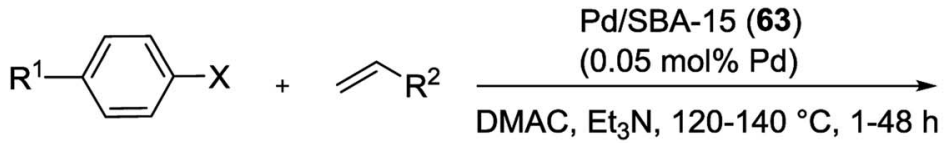

$$
\begin{aligned}
& \mathrm{X}=\mathrm{I}, \mathrm{Br} \\
& \mathrm{R}^{1}=\mathrm{H}, \mathrm{NO}_{2} \\
& \mathrm{R}^{2}=\mathrm{Ph}, \mathrm{CO}_{2} \mathrm{Bu}^{\mathrm{n}}
\end{aligned}
$$<smiles>[R]C=Cc1ccc([R])cc1</smiles>

Conversion $=79-100 \%$ Yield $=76-97 \%$

Scheme 91 Heck olefination of aryl halide by the Pd/SBA-15 (63) catalyst.

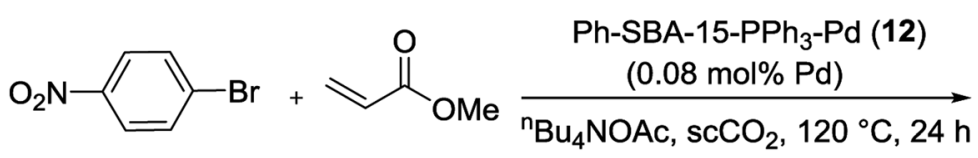<smiles>COC(=O)/C=C/c1ccc([N+](=O)[O-])cc1</smiles>

Scheme 92 Heck reaction of 4-nitrobromobenzene with methyl acrylate catalyzed by Ph-SBA-15-PPh $-\mathrm{Pd}(12)$.

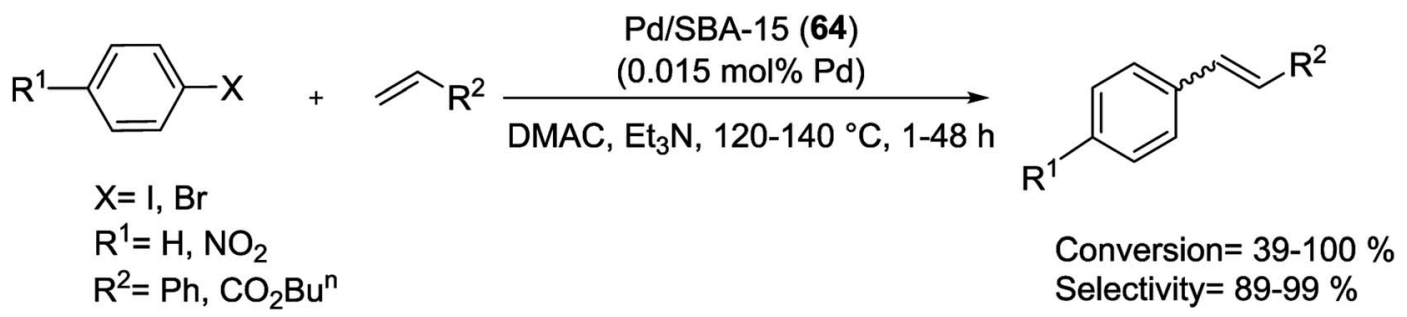

Scheme 93 Heck olefination of aryl halide by the Pd/SBA-15 (64) catalyst.

may graft to another phosphine ligand within the channels of SBA-15. Hence, this catalyst was very stable and can be reused several times without any obvious loss of the activity. ${ }^{126}$

In 2012, Wang et al. developed a novel strategy called twosolvent method (containing hydrophobic and hydrophilic solvents) to prepare Pd NPs encapsulated inside the pore channels of SBA-15. The catalytic performance of the assynthesized Pd/SBA-15 (64) with $3.01 \mathrm{wt} \%$ Pd loading was tested in $\mathrm{M}-\mathrm{H}$ coupling of activated and non-activated aryl substrates with $n$-butyl acrylate or styrene (Scheme 93). The reactions take place in a reactor in air using triethylamine $\left(\mathrm{Et}_{3} \mathrm{~N}\right)$ as base. In all the cases the obtained products, cis- and trans-isomers, were in good yields. Excellent catalytic activities as well as high reusability and low Pd leaching were the benefits of this catalyst. ${ }^{127}$

In 2014, veisi and his group were successfully developed an efficient synthetic process for preparation of basic amine denderon on SBA-15 silica and related Pd(II) complex as a novel heterogeneous catalyst for Heck coupling reaction. For synthesis of catalyst, metformin was added to the $\mathrm{NH}_{2}$-SBA- 15 immobilized by CC. Then for immobilization of Pd(II) ions on the surface of the SBA-15/CCMet, $\mathrm{PdCl}_{2}$ was added to the mixture and hybrid material SBA-15/CCMet/Pd(II) (65) was obtained (Scheme 94). ${ }^{128}$
The SBA-15/CCMet/Pd(II) (65) catalyzed M-H coupling was carried out using aryl halide and styrene to afford the corresponding coupling products in good yields (Scheme 95). After any reaction, the catalyst was washed by fresh ethanol, acetone and ethylacetate, dried at $110^{\circ} \mathrm{C}$ for $3 \mathrm{~h}$ and reused for next run. The advantages of this catalyst are simple and cheaper synthetic pathway, milder and more efficient applications for $\mathrm{C}-\mathrm{C}$ coupling reactions. Notably, the simple recovery of the very stable hybrid material catalyst without any Pd leaching and five times reusing with a little loss of activity are good characteristics. ${ }^{128}$

Pd NPs supported on thiol-functionalized SBA-15 were synthesized in 2014. The resulting Pd/SBA-15-SH (66) with Pd particle size of approximately $2 \mathrm{~nm}$, was able to catalyze the Heck coupling reaction. Various electron-deficient, electronrich, and electron-neutral aryl iodides reacted with butylacrylate to give substituted alkenes in good selectivity without formation of byproducts (Scheme 96). Furthermore, the combination of thiol groups attached on SBA-15 and a mixed solvent (toluene/DMF) was very effective to decrease the particle growth and Pd leaching, which permitted this catalyst to be reused ten times without any obvious loss of the activity. Based on comparison, it was clearly realized that the immobilized catalysts were more stable than the non-immobilized catalysts, 


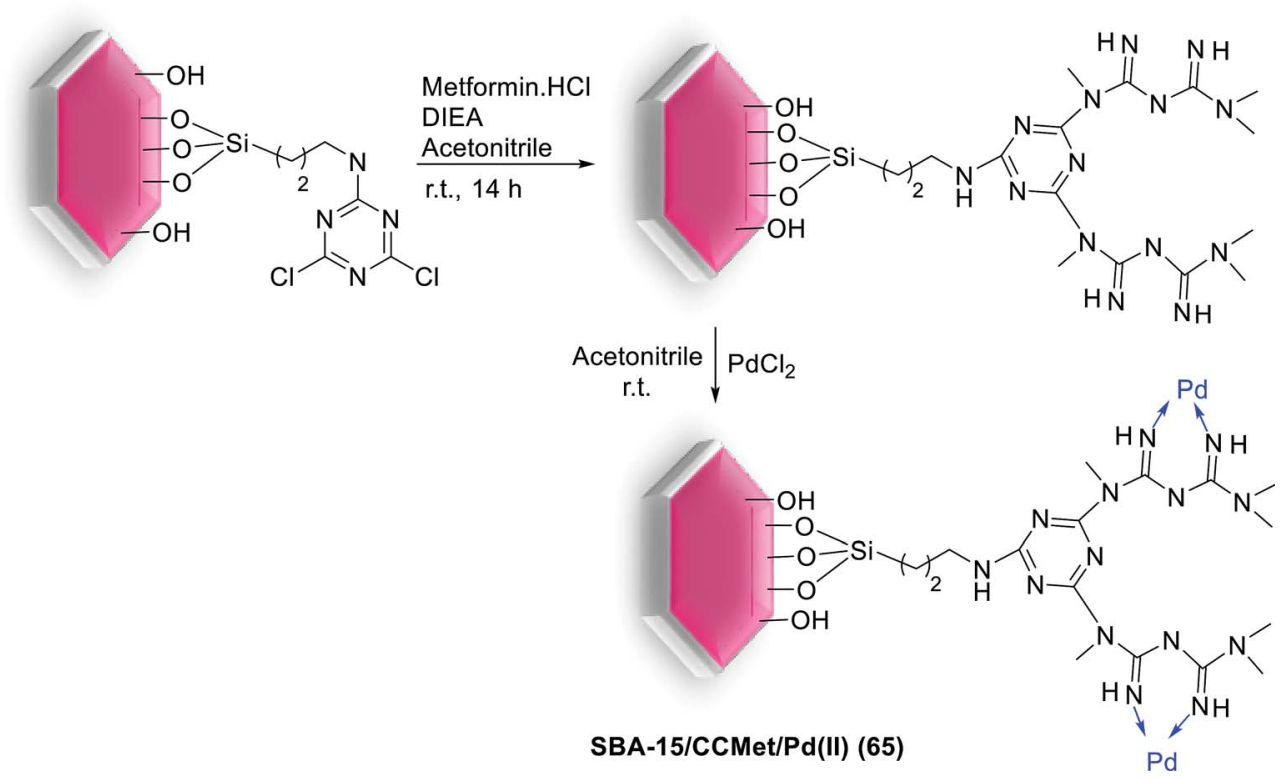

Scheme 94 The pathways of SBA-15/CCMet/Pd(॥) (65) fabrication.

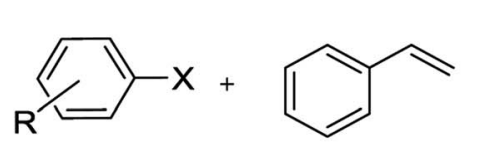

$\mathrm{X}=\mathrm{I}, \mathrm{Br}, \mathrm{Cl}$

$\mathrm{R}=\mathrm{H}, \mathrm{Me}, \mathrm{MeO}, \mathrm{MeCO}, \mathrm{Cl}$
SBA-15/CCMet/Pd(II) (65)

(1 $\mathrm{mol} \% \mathrm{Pd}$ )

DMF, $\mathrm{Et}_{3} \mathrm{~N}, 110^{\circ} \mathrm{C}, 2-10 \mathrm{~h}$<smiles>[R]c1ccc(/C=C/c2ccccc2)cc1</smiles>

Conversion $=80-98 \%$

Scheme 95 Heck reaction of aromatic aryl halides and styrene catalyzed by SBA-15/CCMet/Pd(॥) (65).

which gradually lost their activity due to the metal leaching and Pd particle growth. ${ }^{129}$

The Pd(OAc) $)_{2} @ S B A-15 / \operatorname{PrEn}(26)$ nanoreactor, as mentioned above, was also studied as a phosphine-free and highly efficient pre-catalyst for $\mathrm{M}-\mathrm{H}$ coupling of aryl halides with alkene in a mixture of DMF : $\mathrm{H}_{2} \mathrm{O}$. Consequently corresponding arylolefins was obtained in good to excellent yields without homocoupling by-products (Scheme 97). There was no important difference in the yield of product between electron-rich and electron-deficient substrates. The catalyst also recovery and reused for 9 time with no detectable deactivation and low Pd leaching. ${ }^{\mathbf{1 3 0}}$

SBA-15/ $\mathrm{PrSO}_{3} \mathrm{H}-\mathrm{Pd}-\mathrm{NPs}$ (40) catalyst, as described above synthesized by Rostamnia et al., also investigated for the Heck arylation reaction of aryl halides with conjugate alkenes, to yield corresponding unsymmetric biaryls in high to excellent yields under phosphine-free aerobic conditions (Scheme 98). ${ }^{\mathbf{1 3 1}}$ This heterogeneous catalyst could be separated easily from reaction mixture and reused several times, displaying superiority over homogeneous catalysts for chemical and industrial applications. Hot filtration test for the catalyst in middle of the reactions demonstrated a minor of Pd leaching. ${ }^{131}$

Catalyst Pd@thiazolidine-modified SBA-15 (38) discussed earlier in the Suzuki reaction, proved also to be a highly efficient and stable catalyst in the Heck coupling between aryl iodides and methyl acrylate or styrenes with a similar amount of Pd loading (Scheme 99). Yields of alkene products were excellent or high, except in the reaction of methyl acrylate and 2-

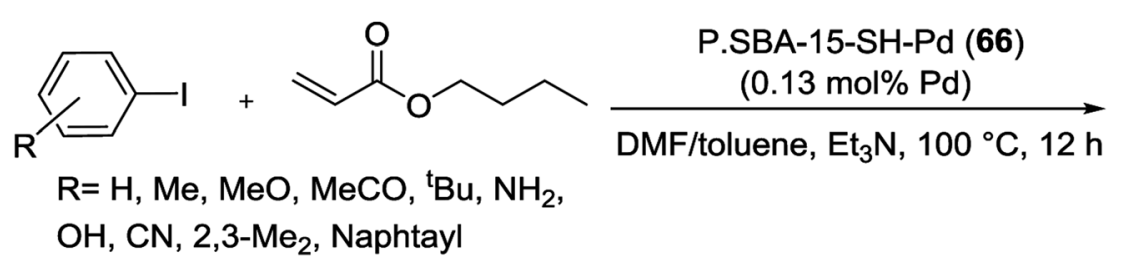<smiles>[R]c1ccc(/C=C/C(=O)OCCCC)cc1</smiles>

Conversion $=41-100 \%$

Scheme 96 Heck reaction of aryl iodides with butyl acrylate promoted by Pd/SBA-15-SH (66). 


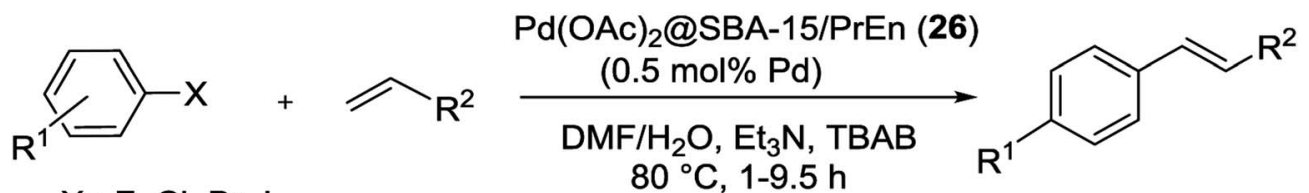

$X=\mathrm{F}, \mathrm{Cl}, \mathrm{Br}, \mathrm{I}$
$\mathrm{R}^{1}=\mathrm{H}, \mathrm{Me}, \mathrm{MeCO}$
$\mathrm{R}^{2}=\mathrm{Ph}, \mathrm{MeO}, \mathrm{MeCO}, \mathrm{CO}_{2} \mathrm{Me}, \mathrm{CO}_{2} \mathrm{Et}, \mathrm{CO}_{2} \mathrm{Bu}^{\mathrm{t}}$

$58-98 \%$

Scheme 97 Heck cross-coupling reaction of various substrates catalyzed by Pd(OAc) 2 (aSBA-15/PrEn (26).
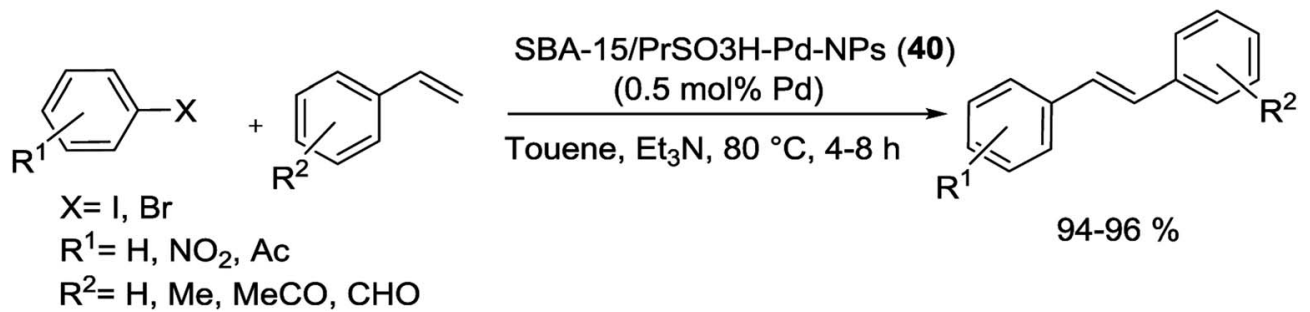

Scheme 98 The SBA-15/PrSO 3 H-Pd-NPs (40) catalysed Heck reaction.

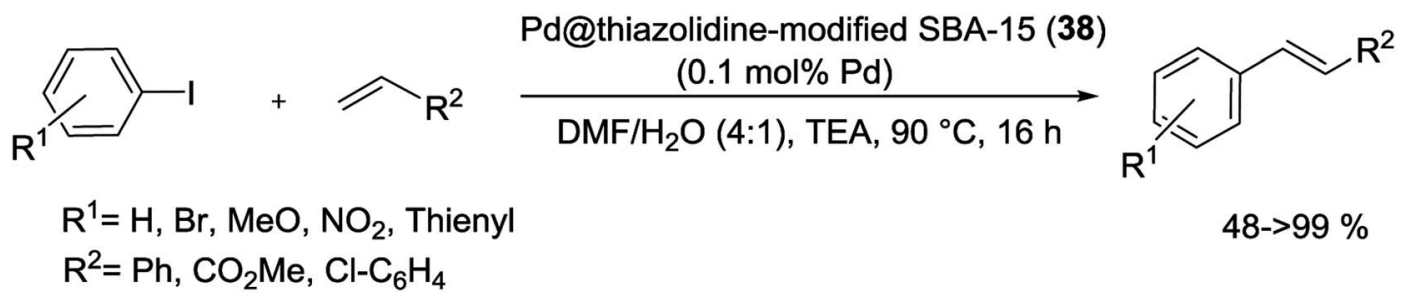

Scheme 99 Heck reaction between methyl acrylateorstyrenes and aryl iodides in the presence of catalyst Pdathiazolidine-modified SBA-15 (38).

iodothiophene. Likewise good conversions were detected with styrene derivatives. ${ }^{93}$

The SBA-15-EDTA-Pd(II) (67) catalyst with 0.87 mol\% Pd loading was synthesized via covalent anchoring Pd-EDTA complex on the organo-modified surface of SBA-15. ${ }^{132}$ The catalyst was found to exhibit excellent catalytic performance in appreciable yield for $\mathrm{M}-\mathrm{H}$ coupling reactions of olefins with aryl halide, in the presence of $\mathrm{Et}_{3} \mathrm{~N}$ as base, yielding the corresponding products in good to excellent yields (Scheme 100). Another important features of the covalently anchored heterogeneous catalyst were stability, easily separation, phosphinefree method and simple to handle. ${ }^{132}$

\subsection{Sonogashira reaction}

The Sonogashira coupling reaction (also called the Sonogashira-Hagihara reaction) was first reported by Kenkich Sonogashira, Yasuo Tohda, and Nobue Hagihara in $1975 .{ }^{133}$ The reaction is a highly demanding process in organic synthesis, as it results in the $\mathrm{C}\left(\mathrm{sp}^{2}\right)-\mathrm{C}(\mathrm{sp})$ bond-forming reactions catalyzed by Pd, with or without copper(I) co-catalyst (Scheme 101). ${ }^{134}$ The produced arylalkynes and conjugated enynes can be widely used as precursors for preparation of several natural products, dendrimeric and polymeric materials, nonlinear optical materials and molecular electronics, biologically active molecules, macrocycles with acetylene links, pharmaceuticals and polyalkynylated molecules. ${ }^{135}$ Instead of using Pd metal directly, Pdanchored on the mesoporous silica SBA-15, is highly stable and reusable catalyst for Sonogashira reaction. However most catalysts, have been developed recently, are active without $\mathrm{Cu}$ to avoid the formation of the homocoupling products. The catalytic mechanism of the Sonogashira reaction is quite similar to that of the Pd-catalyzed Suzuki and Heck reaction (Scheme 102). ${ }^{136}$

Heterogeneous copper-free Pd-modified mesoporous catalyst (Pd/SBA-15) (68) have been prepared, through condensation of surface silanol of the oxide support with the alkoxysilane groups of precursor. The Pd/SBA-15 nanocomposite had potential application for Sonogashira coupling reaction of various terminal alkynes with aryl halides giving generally complete conversion within few hours (Scheme 103). In comparison with homogeneous catalysts (i.e. $\left\{\mathrm{Pd}\left[\mathrm{P}\left(\mathrm{O}-\mathrm{C}_{6} \mathrm{H}_{4}-\right.\right.\right.$ $\left.\left.\left.\mathrm{CH}_{3}\right)_{2}\left(\mathrm{C}_{6} \mathrm{H}_{4} \mathrm{CH}_{2}\right)\left[\mathrm{CO}_{2} \mathrm{CH}_{3}\right]\right]\right\}_{2}$ and $\left.\operatorname{PdCl}_{2}\left(\mathrm{PPh}_{3}\right)_{2}\right)$ this catalysts also showed remarkable catalytic activity and selectivity, also displayed excellent stability towards leaching. ${ }^{137}$ 

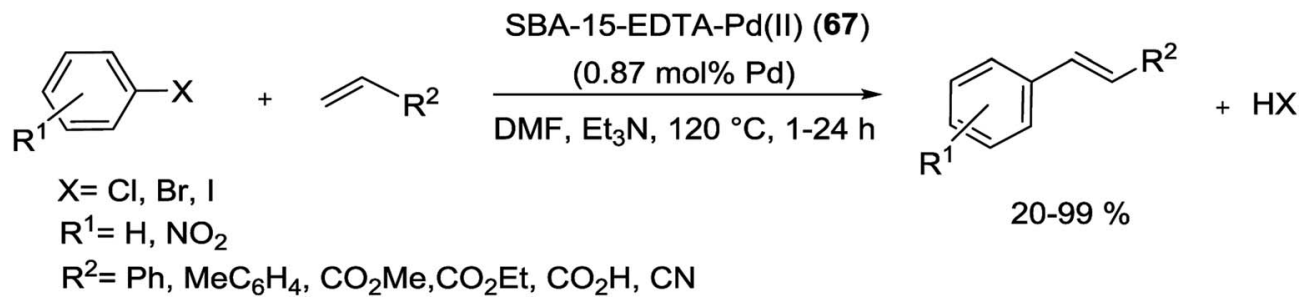

$20-99 \%$

Scheme 100 Reactivity of SBA-15-EDTA-Pd(I) (67) catalyst for Heck reaction.

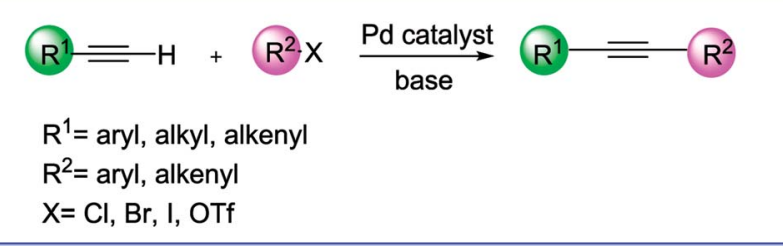

Scheme 101 The Sonogashira coupling reaction.

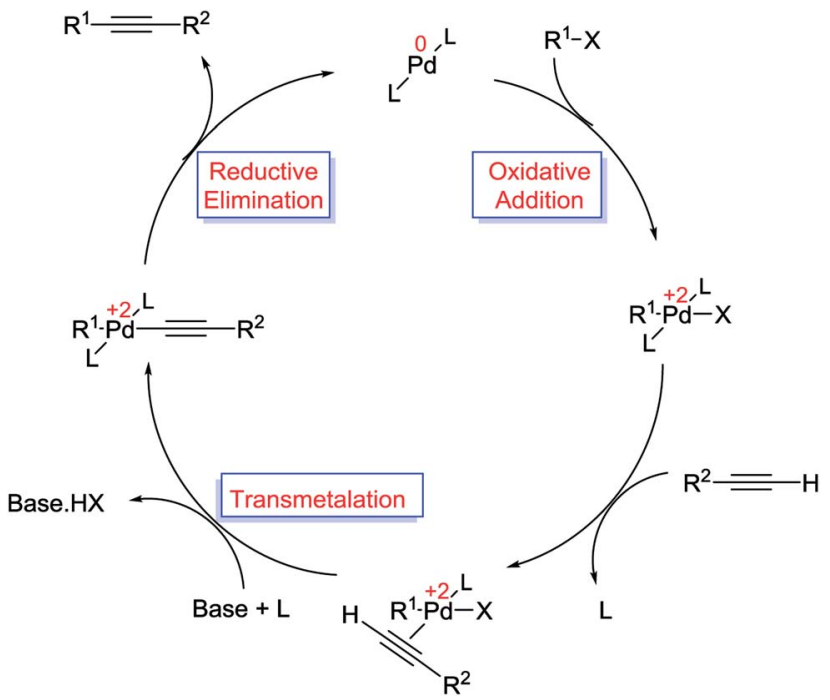

Scheme 102 The proposed mechanism for copper-free Sonogashira coupling reaction. ${ }^{137}$

In recent work, SBA-15-(1/8-KCl)-Pd (16), SBA-15-G-Pd (17) and SBA-15-SH-Pd (18) catalysts, found to afford high yields in the Suzuki reaction, has also been efficient in Sonogashira coupling under copper-free conditions (Scheme 104). The desired products were selectively obtained in high yield (up to 93\%) without side reactions. Moreover, for compared in Sonogashira coupling the Pd leaching was higher than S-M reaction. ${ }^{76}$

The heterogeneous catalyst SBA-15-SH-Pd (15), which is also used in the in the Suzuki reaction, was employed in Sonogashira coupling reaction and the products were obtained selectively in high yields (Scheme 105). Unlike in the case of the S-M coupling, which gave products with approximately $10 \mathrm{ppm} \mathrm{Pd}$ content without additional scavenging, herein, the products from the Sonogashira reaction would require further scavenging to meet regulatory hurdles. ${ }^{75}$

Catalyst SBA-15-EDTA-Pd(II) (37), displaying excellent robustness in the Suzuki coupling, also exhibited similar performance in phosphine and copper-free Sonogashira reactions. Therefore, various haloarenes were coupled with phenylacetylene using SBA-15-EDTA-Pd(II) (37) in the presence of $\mathrm{Et}_{3} \mathrm{~N}$ as a base and DMF as a solvent at $120{ }^{\circ} \mathrm{C}$ to give their corresponding products in good to excellent yields (Scheme 106). The catalyst can be reused a number of times without a major loss in the reactivity and selectivity. Likewise, hot filtration test indicated that Pd was not leached out from the heterogeneous catalyst during the coupling reactions. ${ }^{91}$

The SBA-15-SH-Pd (42) developed by Sarkar et al. and discussed in connection with the Suzuki reaction, also exhibited high efficiency in copper and solvent-free Sonogashira crosscoupling reaction (Scheme 107). Various aryl halide and phenylacetylene, reacted smoothly with each other to afford the corresponding coupling products in up to $98 \%$ yield. Furthermore, the heterogenized Pd-catalyst was recovered by a simple filtration from the reaction mixture and reused without losing its activity to a greater extent. ${ }^{96}$

\subsection{Stille reaction}

The Pd-catalyzed cross-coupling reaction of $\mathrm{sp}^{2}$-hybridized organic halides with organostannanes (also known as

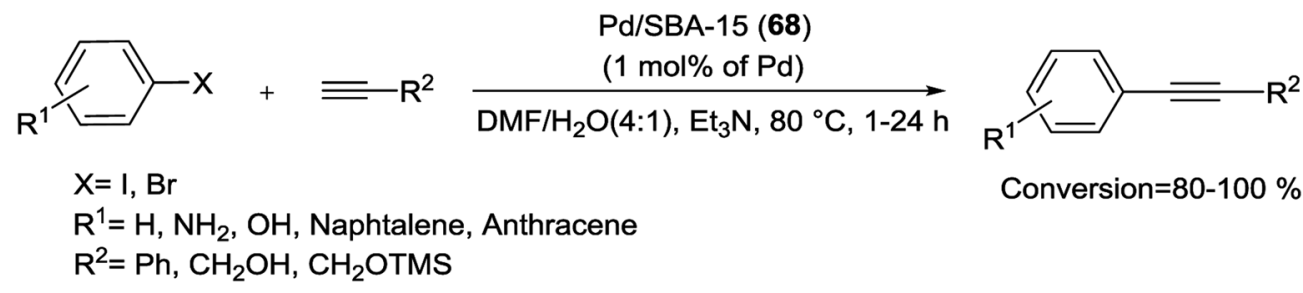

Scheme 103 Sonogashira coupling reaction catalyzed by Pd/SBA-15 (68) applied to the synthesis of target organic molecules. 


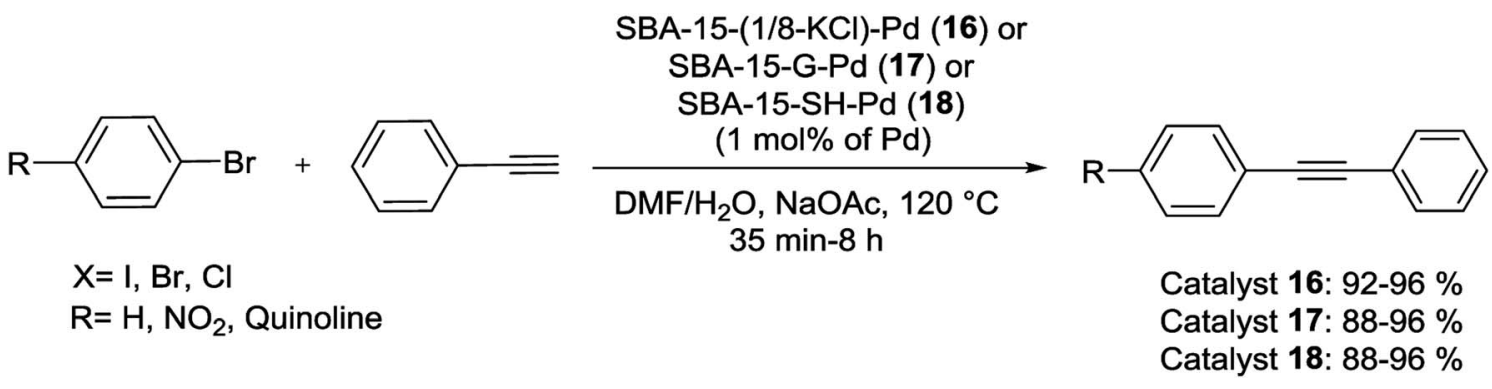

Scheme 104 Catalytic results in Sonogashira-coupling reactions by Pd-containing materials SBA-15-(1/8-KCl)-Pd (16), SBA-15-G-Pd (17) and SBA-15-SH-Pd (18).

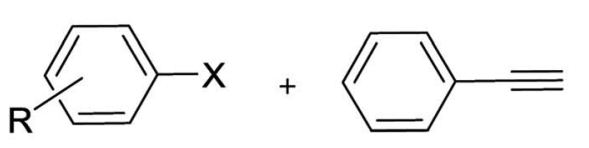

$\mathrm{X}=\mathrm{I}, \mathrm{Br}, \mathrm{Cl}$

$\mathrm{R}=\mathrm{NO}_{2}$, Thiophene

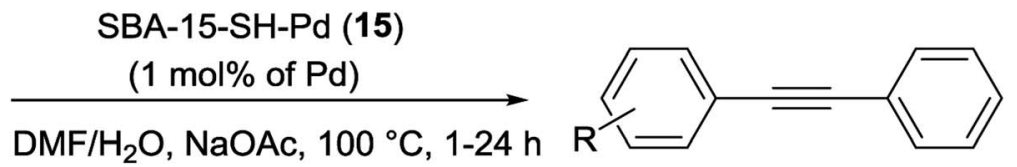

$89-98 \%$

Scheme 105 Sonogashira reaction catalyzed by SBA-15-SH-Pd (15).

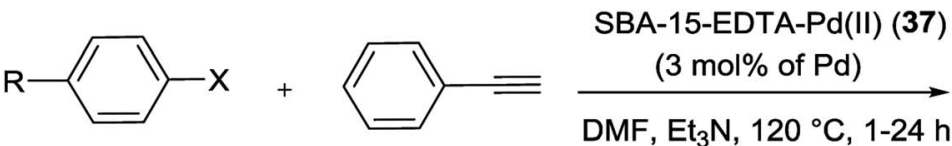

$\mathrm{X}=\mathrm{I}, \mathrm{Br}, \mathrm{Cl}$

$\mathrm{R}=\mathrm{H}, \mathrm{Me}, \mathrm{NO}_{2}$

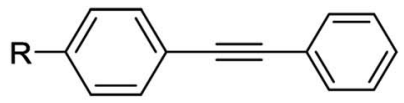

$75-100 \%$

Scheme 106 Reactivity of SBA-15-EDTA-Pd(॥) (37) catalyst for Sonogashira reaction.

organotins) traditionally known as the Stille or Migita-KosugiStille reaction has extensively employed in organic synthesis (Scheme 108). ${ }^{138,139}$ This is owing to the growing availability of the organostannanes, their stability to air and moisture, and excellent adaptability with numerous functional groups. Moreover the Stille reaction has played an essential role in total synthesis of several important pharmaceutical compounds such as dynemicin and rapamycin. ${ }^{10,141}$ The proposed mechanism for stille reaction, as well as other major $\mathrm{C}-\mathrm{C}$ coupling reactions discussed above, was carried out in four-sequential steps (Scheme 109). ${ }^{138,142}$

Pd NPs deposited over mesoporous molecular sieve SBA-15 bearing N-donor groups at the surface, Pd/SBA-15 (69), can be employed as catalyst for coupling of aryl bromides with phenyltributyltin (Scheme 111). For synthesis of catalyst firstly, allsiliceous SBA-15 functionalized with 3-chloropropyl groups, were reacted with $N, N$-diethyl-1,2-diaminoethane $\left(\mathrm{Et}_{2} \mathrm{~N}\left(\mathrm{CH}_{2}\right)_{2^{-}}\right.$ $\mathrm{NH}_{2}$ ). Then, Pd NPs anchored in the aminated support using $\mathrm{Pd}(\mathrm{OAc})_{2}$ (Scheme 110)..$^{143}$

The desired heterocoupling product was obtained in moderate to high yields. The catalyst recovered studies indicated that the catalyst lost its activity during the catalytic run, probably owing to blocking of the support surface or aggregation of the Pd NPs. ${ }^{143}$

An environmentally friendly SBA-15@adenine-Pd (50) catalyst, as mentioned previously, was also used in Stille coupling

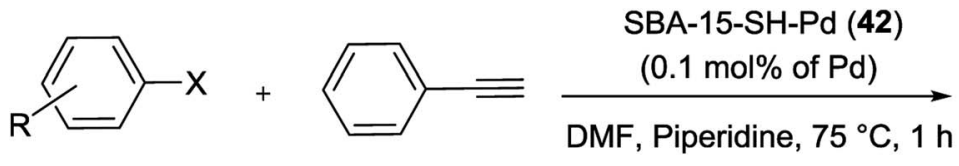

$\mathrm{X}=\mathrm{I}, \mathrm{Br}$

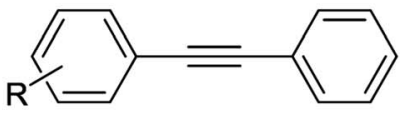

$89-98 \%$

$\mathrm{R}=\mathrm{H}, \mathrm{Me}, \mathrm{MeO}, \mathrm{MeCO}, \mathrm{NO}_{2}, \mathrm{NC}, \mathrm{CF}_{3}$

Scheme 107 Sonogashira coupling reaction with SBA-15-SH-Pd (42) catalyst. 


$$
\begin{aligned}
& \mathrm{R}^{1}-\mathrm{X}+\mathrm{R}^{2}-\mathrm{SnR}_{3} \stackrel{\text { Pd catalyst }}{\longrightarrow} \mathrm{R}^{1}-\mathrm{R}^{2}+\mathrm{X}-\mathrm{SnR} \mathrm{R}_{3} \\
& \mathrm{R}^{1}=\text { aryl, alkenyl, allyl } \quad \mathrm{R}^{2}=\text { aryl, alkenyl, acyl } \\
& \mathrm{R}=\text { alkyl } \mathrm{X}=\mathrm{Cl}, \mathrm{Br}, \mathrm{I}, \mathrm{OTf}
\end{aligned}
$$

Scheme 108 Stille coupling reaction.

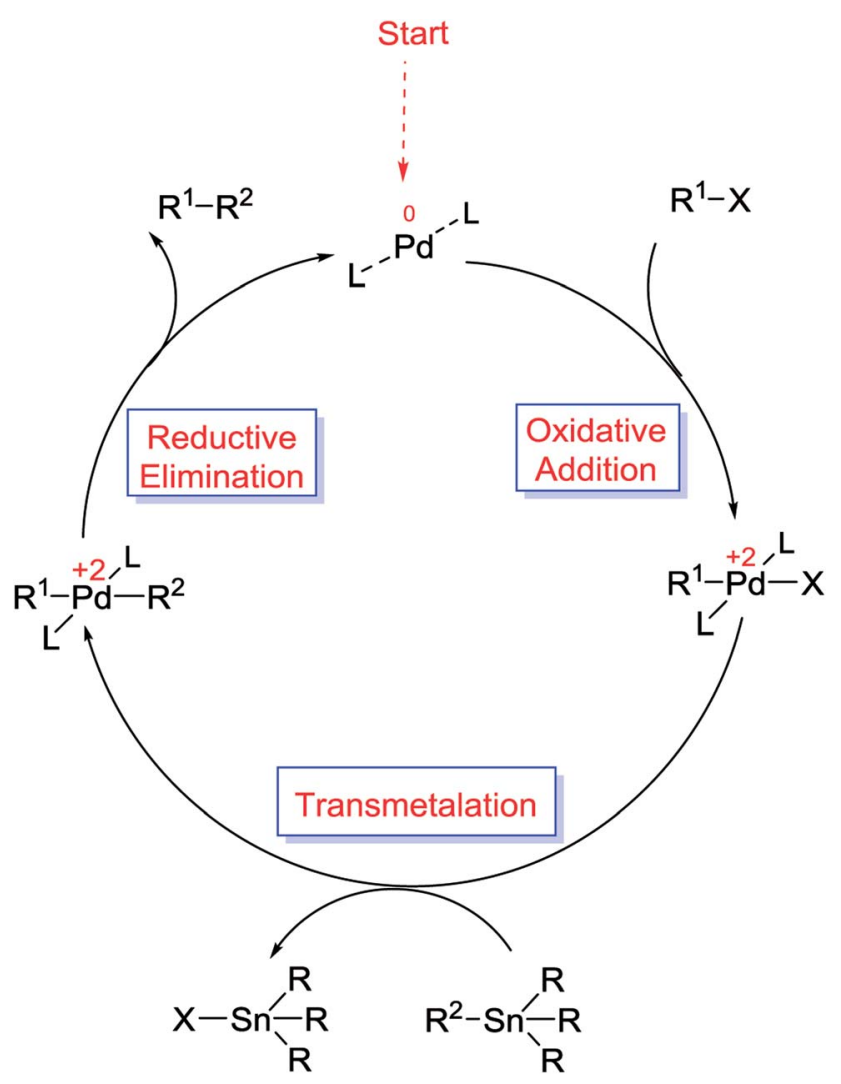

Scheme 109 The proposed mechanism of Stille coupling reaction. ${ }^{142}$

reaction (Scheme 112) of different aryl halides with triphenyltin chloride $\left(\mathrm{Ph}_{3} \mathrm{SnCl}\right)$. Excellent yields of products (87-97\%) were obtained and the catalyst can be reused several consecutive times without significant decrease of its catalytic activity. Use of green medium, high efficiency, low cost, well dispersed in the reaction medium, short reaction time, easy separation and use of a commercially available reagents are other advantages of this method.

After successful catalytic performance of SBA-15-EDTA-Pd(II) (67) in Heck reaction, Stille coupling reaction of phenyltributyltin with various aryl halides was also proceeded in presence of this catalyst with $0.87 \mathrm{mmol} \% \mathrm{Pd}$ at $120{ }^{\circ} \mathrm{C}$ under mild reaction conditions (Scheme 113). The desired products were obtained in good to excellent yields $(76-94 \%) .{ }^{132}$

\subsection{Hiyama coupling}

Another Pd-catalyzed cross-coupling reaction, involves reaction of an organosilanes with organic halides (Scheme 114), is Hiyama coupling that was used in synthesis of various organic natural products. This reaction was discovered in 1988 by Tamejiro Hiyama and Yasuo Hatanaka as a method to form C-C bond formations with chemo- and regioselectivity. ${ }^{144,145}$ In comparison of Suzuki reaction with problems in purifying the boron reagents, and Stille coupling via toxic tin reagents, the Hiyama coupling uses partly stable, easy preparation of organosilane reagents, low toxicity and the fact that, after reaction, may simply convert to moderately harmless silica waste, made the coupling reactions more attractive for environmental purposes. Because of low reactivity of organosilanes, the reaction need activating agent such as fluoride ion or a base to cleave the $\mathrm{C}-\mathrm{Si}$ bond. The mechanism for the Hiyama coupling corresponding of other organometallic reactions (e.g. Suzuki, Heck and Stille) follows a catalytic cycle (Scheme 115). ${ }^{144,146}$

Nevertheless, there are only two reports on the application of silica SBA-15 supported Pd catalysts for the Stille coupling.

The first example of the Hiyama reaction catalyzed by modified SBA-15-supported Pd, Pd@M-SBA-15 (70), was reported by Yang et al. in $2014 .{ }^{147}$ As shown in Scheme 116, mesoporous silica SBA-15 was reacted with trimethylchlorosilane to yield TMS functionalized SBA-15. Subsequently, Pd NPs preferentially incorporate to the latter using a solution of $\mathrm{PdCl}_{2}(\mathrm{MeCN})_{2}$ following reduced by hydrogen flow at $573 \mathrm{~K}$ to form Pd@M-SBA-15 (70) catalyst. ${ }^{147}$

The nanocomposite catalysts exhibited excellent activity for the cross-coupling of various aryl halides with aryltriethoxysilanes in the mixture of tetra- $n$-butylammonium fluoride trihydrate $\left(\mathrm{TBAF} \cdot 3 \mathrm{H}_{2} \mathrm{O}\right)$ under moderately mild reaction conditions to form different biphenyl derivatives in good to excellent yields (Scheme 117). Moreover, the catalysts could be recycled, and the decreased catalytic activity was ascribed to a little level of Pd-leaching and slow collapse of mesoporous of host silica after sequential catalytic runs. ${ }^{147}$

Synthesis of homoleptic chelating N-heterocyclic carbene complexes of Pd decorated into the pore channels of SBA-15/IL (NHC-Pd/SBA-15/IL) (71) was successfully achieved by Rostamnia and his group in $2015 .{ }^{148}$ For synthesis of this catalyst, firstly the $N$-methylimidazole (NMI) reacted with CPTMS to yield imidazolium chloride-based IL. Subsequently Pd(II) ions (from $\mathrm{PdCl}_{2}$ ) were coordinated to $\mathrm{N}$-heterocyclic carbene (NHC) bearing IL. Then as-prepared NHC-Pd/IL mixture was supported on SBA-15 to produce NHC-Pd/SBA-15/IL catalyst (71) (Scheme 118)..$^{148}$

This heterogeneous system with $0.8 \mathrm{~mol} \%$ of Pd, had chemoselectivity towards Hiyama products using TBAF and $\mathrm{Cs}_{2} \mathrm{CO}_{3}$ (to generate a small amount of $\mathrm{OH}^{-}$for activation of C-Si bond) at $80{ }^{\circ} \mathrm{C}$ in the mixture of dioxane : $\mathrm{H}_{2} \mathrm{O}(2: 1)$ (Scheme 119). Moreover, the NHC-Pd/SBA-15/IL (71) catalyst could successfully be recycled for 5 times without negligible decrease in the yields. ${ }^{148}$ 


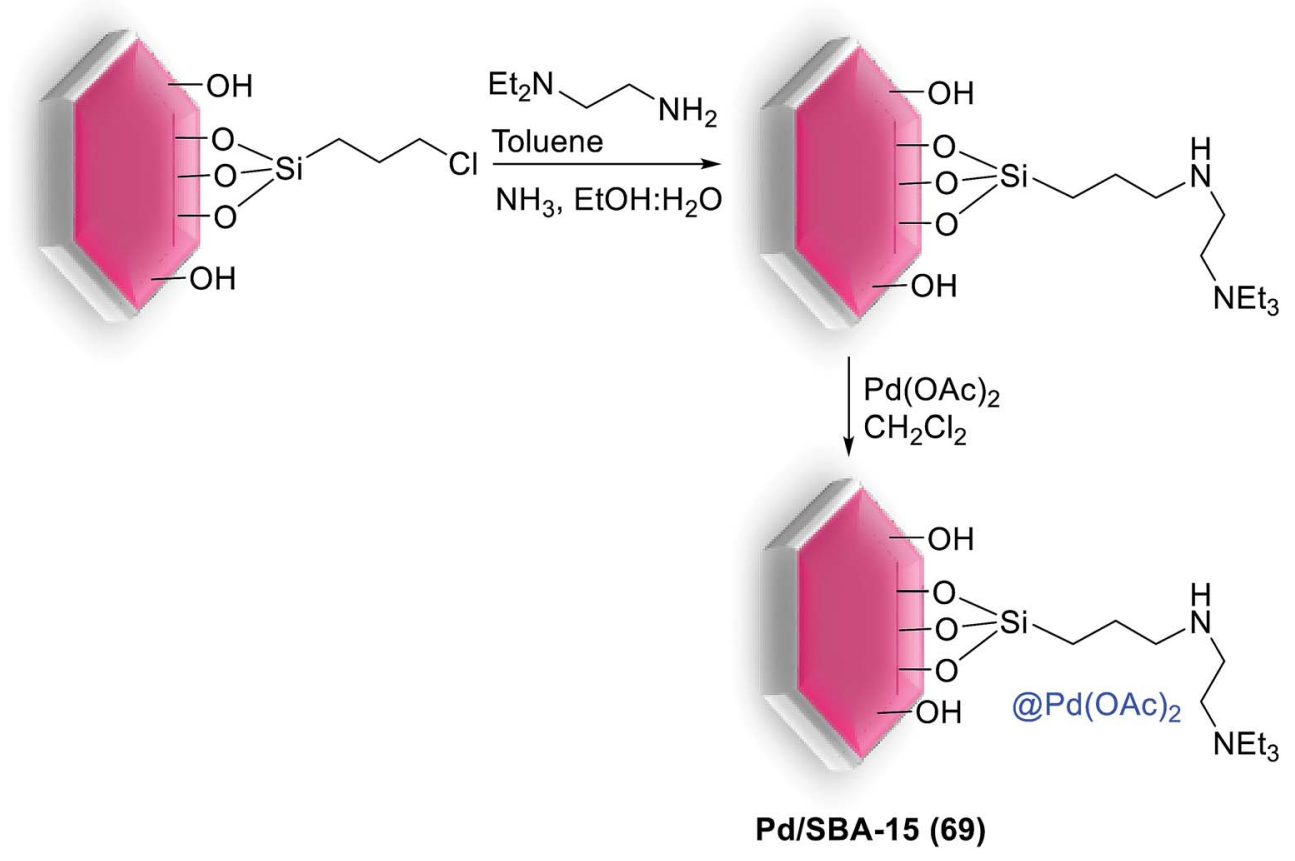

Scheme 110 Preparation of Pd/SBA-15 (69)

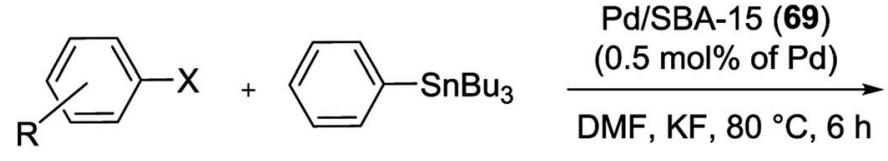

$\mathrm{X}=\mathrm{Cl} . \mathrm{Br}, \mathrm{I}$

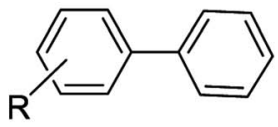

$14-63 \%$

$$
\mathrm{R}=\mathrm{H}, \mathrm{Me}, \mathrm{MeO}
$$

Scheme 111 The model Stille coupling of aryl bromides with phenyltributyltin catalyzed by Pd/SBA-15 (69).

\subsection{Miscellaneous coupling reactions}

The following coupling reactions are all exclusive examples because they are often less studied and less applied particularly considering catalyst recycling.

2.6.1 Homocoupling reactions. One of the important methods for the preparation of symmetrical biaryl derivatives is the homocoupling of aryl halides. Whereas considerable progress in this area has been achieved via a broad range of $\mathrm{Cu}_{-}^{-}$, Pd-, and Ni-based homogeneous catalysts, recently, the use of heterogeneous catalysts for the homocoupling reaction has received increasing attention from both an economic and industry point of view. In this section, recent applications of
SBA-15 supported Pd as heterogeneous catalyst for homocoupling reactions are summarized. ${ }^{\mathbf{1 4 9}}$

2.6.2 Ullmann-type coupling reactions. The Ullmann-type reaction named after scientist Frietz Ullmann, is a homocoupling of aryl halides to construct symmetric biaryl units. ${ }^{\mathbf{1 5 0 , 1 5 1}}$

In recent study, a Pd catalyst deposited on a phenylfunctionalized SBA-15 support (Pd/Ph-SBA-15) (72) was prepared by $\mathrm{Li}$ and co-workers. ${ }^{152}$ This heterogeneous catalyst was synthesized through impregnating the as-prepared Ph-SBA15 series supports with a solution of $\mathrm{PdCl}_{2}$. This catalysts demonstrated higher selectivity and activity to biphenyl than $\mathrm{Pd} / \mathrm{MCM}-41$, Pd/Ph-MCM-41, $\mathrm{Pd} / \mathrm{SiO}_{2}$ and Pd/SBA-15 in a water-

$$
\begin{aligned}
& \text { X } \mathrm{X}+\mathrm{Ph}_{3} \mathrm{SnCl} \frac{\mathrm{SBA}-15 @ \text { adenine-Pd (50) }}{\mathrm{PEG}, \mathrm{K}_{2} \mathrm{CO}_{3}, 110^{\circ} \mathrm{C}} \\
& \begin{array}{l}
30 \mathrm{~min}-3.5 \mathrm{~h} \\
\mathrm{R}=\mathrm{Cl}, \mathrm{Br}, \mathrm{I}
\end{array} \\
& \mathrm{R}, \mathrm{Me}, \mathrm{MeO}, \mathrm{CHO}, \mathrm{OH}, \mathrm{CN}, \mathrm{NO}_{2}, \text { Naphtalene }
\end{aligned}
$$

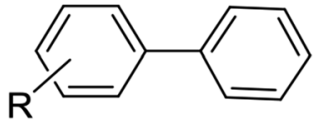

$87-98 \%$

Scheme 112 The Stille reaction catalyzed by SBA-15@adenine-Pd (50). 


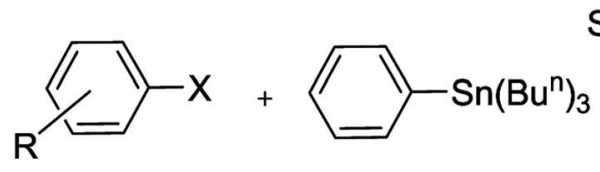

$\mathrm{X}=\mathrm{Cl} . \mathrm{Br}, \mathrm{I}$

$\mathrm{R}=\mathrm{H}, \mathrm{F}, \mathrm{Me}, \mathrm{MeO}, \mathrm{NO}_{2}$
SBA-15-EDTA-Pd (II) (67)

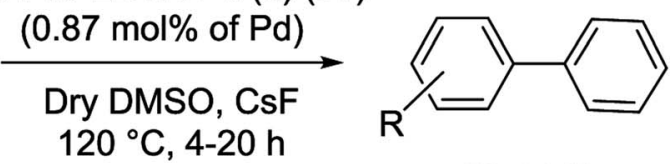

$76-94 \%$

Scheme 113 Reactivity of SBA-15-EDTA-Pd(॥) (67) catalyst for the Stille coupling reaction.

$$
\begin{aligned}
& R^{1}-X+R^{2}-S i\left(R^{3}\right)_{3} \underset{F \text { or base }}{\stackrel{P d \text { catalyst }}{\ominus}} R^{1}-R^{2} \\
& R^{1}=\text { aryl, alkenyl, alkynyl, alkyl } \quad R^{2}=\text { aryl, alkenyl, alkynyl } \\
& R^{3}=C l, F \text {, alkyl } \quad X=C l, B r, I, \text { OTf }
\end{aligned}
$$

Scheme 114 Hiyama coupling reaction.

medium iodobenzene participated Ullmann reaction due to high distribution of Pd active sites, the large pore size (4-5 nm) and strong surface hydrophobicity. So the reaction was carried out using iodobenzene, $\mathrm{HCO}_{2} \mathrm{Na}$ as a reducing agent and $\mathrm{KOH}$ with $6.0 \mathrm{wt} \% \mathrm{Pd} / \mathrm{Ph}-\mathrm{SBA}-15$ (72) for $10 \mathrm{~h}$ (Scheme 120). ${ }^{152}$

During the reaction process, only two products were obtained. One is the goal product biaryl, obtaining from the coupling reaction of iodobenzene. Another is the by-product benzene $(\mathrm{Ar}-\mathrm{H})$, obtaining from dehalogenation of

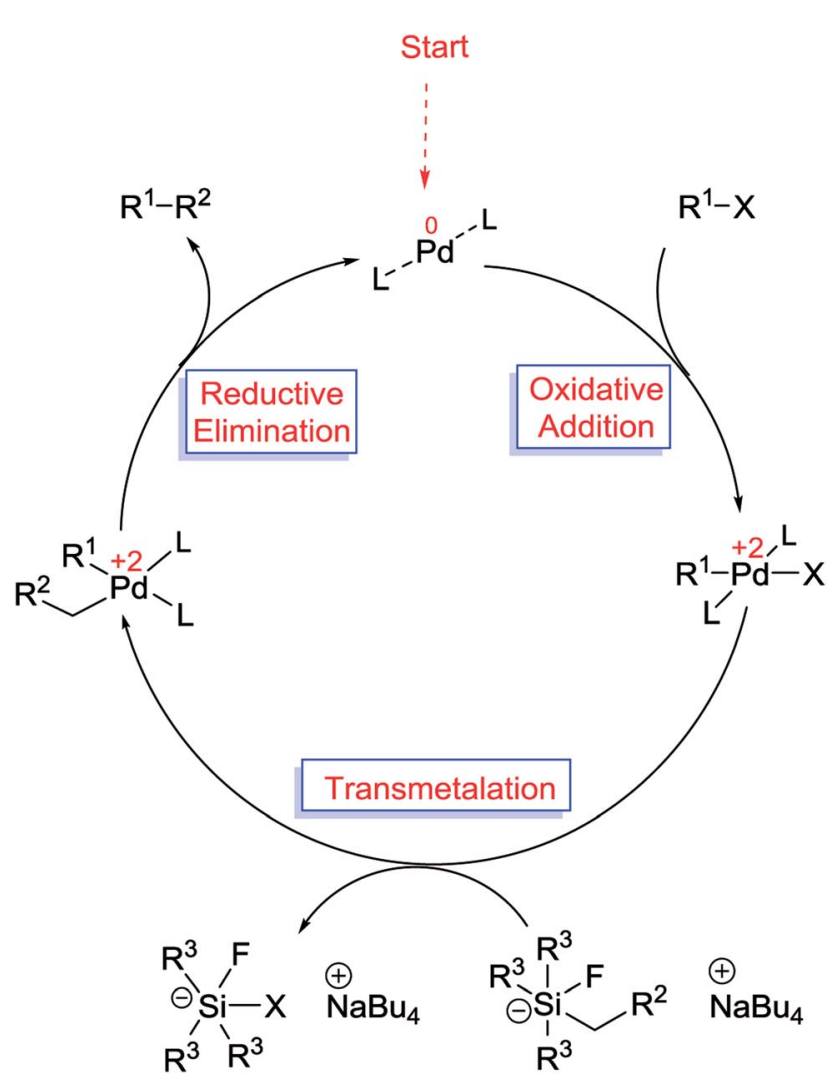

Scheme 115 The proposed mechanism of Hiyama coupling. ${ }^{144}$ iodobenzene. Therefore, the present reaction followed the mechanism designated in Scheme 121. ${ }^{152}$

Moreover, the as-prepared Pd-based catalyst could be separated simply from reaction products and recycled frequently several times. ${ }^{152}$

In 2011 Zhang et al. were produced the multifunctional mesoporous SBA-15 supported PdNPs (signified as $\mathrm{Pd} / \mathrm{NH}_{2} \& \mathrm{Ph}-$ SBA-15) (73) as illustrated in Scheme $122 .{ }^{153}$ First via cocondensation of tetraethyl orthosilicate, phenyl-silane and amine-silane, mesoporous silica with binary aminopropyl $\left(\mathrm{NH}_{2}\right)$ and phenyl (Ph) groups was obtained. Next, the Pd(II) ions were introduced within the mesoporous pore channels via the isometric impregnation method. Then, the hydrogen reduction procedure offered the final catalyst. ${ }^{153}$

In comparison with Pd NPs modified the parent SBA-15 or monofunctionalized mesoporous materials, the $\mathrm{NH}_{2} \& \mathrm{Ph}-\mathrm{SBA}$ 15 (73) catalyst demonstrated high reactivity and selectivity toward the water-medium Ullmann reaction (Scheme 123). ${ }^{153}$

This could be ascribed to the cooperative synergic promoting effect because of binary organic functional groups. The $\mathrm{NH}_{2}$ groups guaranteed the high dispersion of $\mathrm{Pd}(\mathrm{II})$ ions inside the pore channels via coordination whereas the Ph-groups around the active sites could greatly enhance the surface hydrophobicity that decreased the diffusion limitation of organic molecules into the pore channels in water. Moreover, these functional groups also provided the excellent catalyst durability, which could be recycled six times with only a minor decrease of catalytic activity. ${ }^{\mathbf{1 5 3}}$

2.6.3 Glaser reaction. Glaser reaction is another type of homocoupling reactions that was reported by Carl Andreas Glaser in 1869. ${ }^{154}$ It is based on coupling of two sp carbon atoms to form 1,3-diyne derivatives which was used in a wide variety of fields such as pharmaceuticals, natural products and optical materials. In addition to haloarenes, terminal alkynes also undergo homocoupling under appropriate reaction conditions to give corresponding conjugated 1,3-diynes at room temperature. ${ }^{154}$

The SBA-15@DABCO-Pd catalyst (24) that was shown high activity in Suzuki reaction with $0.3 \mathrm{~mol} \%$ of $\mathrm{Pd}$, has also been successfully used for the catalytic dimerization of a variety of alkynes carrying various substitution groups with $1.0 \mathrm{~mol} \%$ of Pd. High to excellent yield of product was obtained (ranging from $62 \%$ to $94 \%$ ) and the catalyst could be easily recovered through simple filtration and reused at least five times without any apparent decrease in its catalytic activity (Scheme 124). ${ }^{82}$ 

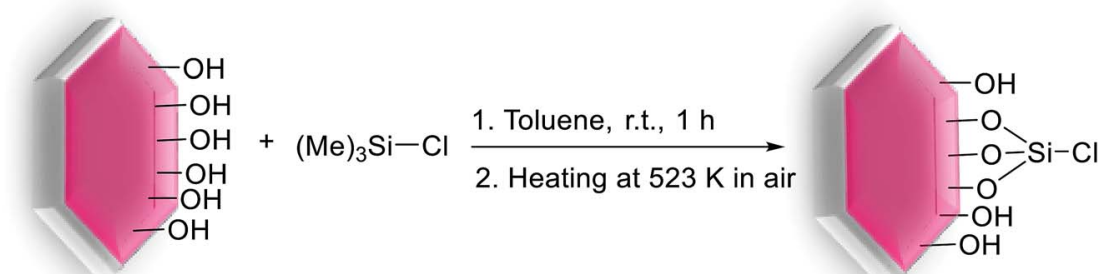

\begin{tabular}{c|c}
$\mathrm{H}_{2}$ flow & $(\mathrm{MeCN})_{2} \mathrm{PdCl}_{2}$ \\
$573 \mathrm{~K}$ & $\downarrow$ Acetone
\end{tabular}

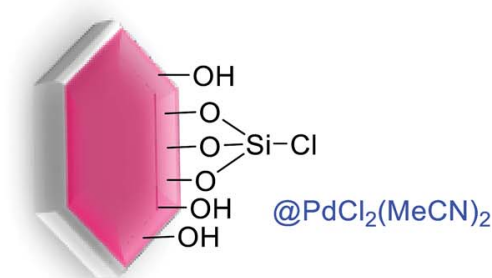

Pd@M-SBA-15 (70)

Scheme 116 Schematic synthesis of Pd@M-SBA-15 (70) catalyst.

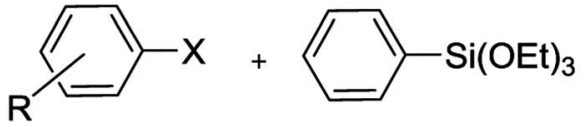

$\mathrm{X}=\mathrm{Cl}, \mathrm{Br}$

$\mathrm{R}=\mathrm{Me}, \mathrm{MeO}, \mathrm{MeCO}, \mathrm{CHO}$, $\mathrm{NO}_{2}, \mathrm{CN}, \mathrm{Cl}$, Naphthyl
Pd@M-SBA-15 (70)

$\underset{\text { TBAF. } 3 \mathrm{H}_{2} \mathrm{O}, \mathrm{AcOH} \text {, }}{\stackrel{(0.5 \mathrm{~mol} \% \text { of } \mathrm{Pd})}{\longrightarrow}}$

Toluene, $100^{\circ} \mathrm{C}, 24 \mathrm{~h}$

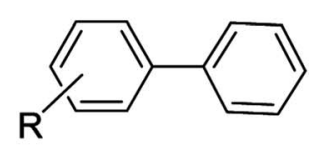

$13-92 \%$

Scheme 117 The Hiyama cross-coupling of various aryl halides and phenyltriethoxysilane catalyzed Pd@M-SBA-15 (70).

\section{Challenges and limitations}

As demonstrated throughout this review, significant efforts were done for employing of various hybrid catalysts based on SBA-15 for promoting various coupling reactions. Thanks to recent efforts by researchers in related fields, different strategies have been developed for increasing the stability and reactivity of these catalysts. However, some factors should be taken into account for a successful synthesis of the SBA-15 based catalysts. The pore volume size of the SBA-15 must be

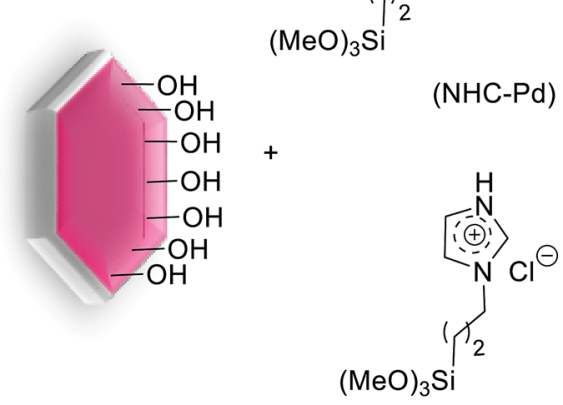

(IL)

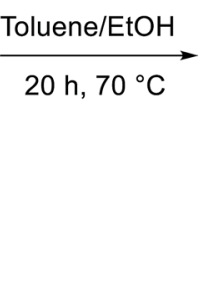

$\frac{\text { Toluene/EtOH }}{20 \mathrm{~h}, 70^{\circ} \mathrm{C}}$

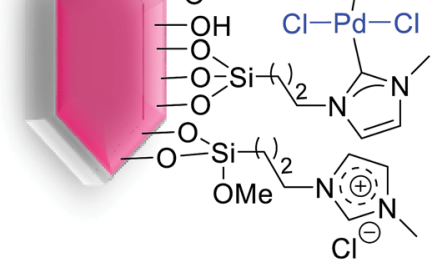

NHC-Pd/SBA-15/L (71)

Scheme 118 Schematic synthesis pathway of NHC-Pd/SBA-15/IL (71). 
<smiles>[R]c1cccc([X])c1</smiles>

$\mathrm{X}=\mathrm{I}, \mathrm{Br}$

$\mathrm{R}=\mathrm{Me}, \mathrm{MeO}, \mathrm{MeCO}, \mathrm{NO}_{2}$
NHC-Pd/SBA-15/IL (71)

(0.8 mol\% of Pd)

TBAF, $\mathrm{Cs}_{2} \mathrm{CO}_{3}$

$\mathrm{H}_{2} \mathrm{O} /$ Dioxane(1:2), $80^{\circ} \mathrm{C}, 5-8 \mathrm{~h}$

$\mathrm{R}$<smiles>[R]c1cccc(-c2ccccc2)c1</smiles>

$82-95 \%$

Scheme 119 Synthesis of biaryls over Hiyama reaction catalyzed by NHC-Pd/SBA-15/IL (71).

2

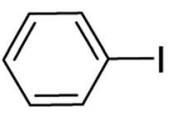

Pd/Ph-SBA-15 (72)

$\mathrm{HCO}_{2} \mathrm{Na}, \mathrm{KOH}, \mathrm{H}_{2} \mathrm{O}, 100^{\circ} \mathrm{C}, 10 \mathrm{~h}$

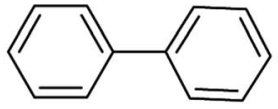

Conversion $=49-78 \%$

Selectivity $=87-97 \%$

Yield $=42-75 \%$

Scheme 120 The Ullmann reaction catalyzed by Pd/Ph-SBA-15 (72).

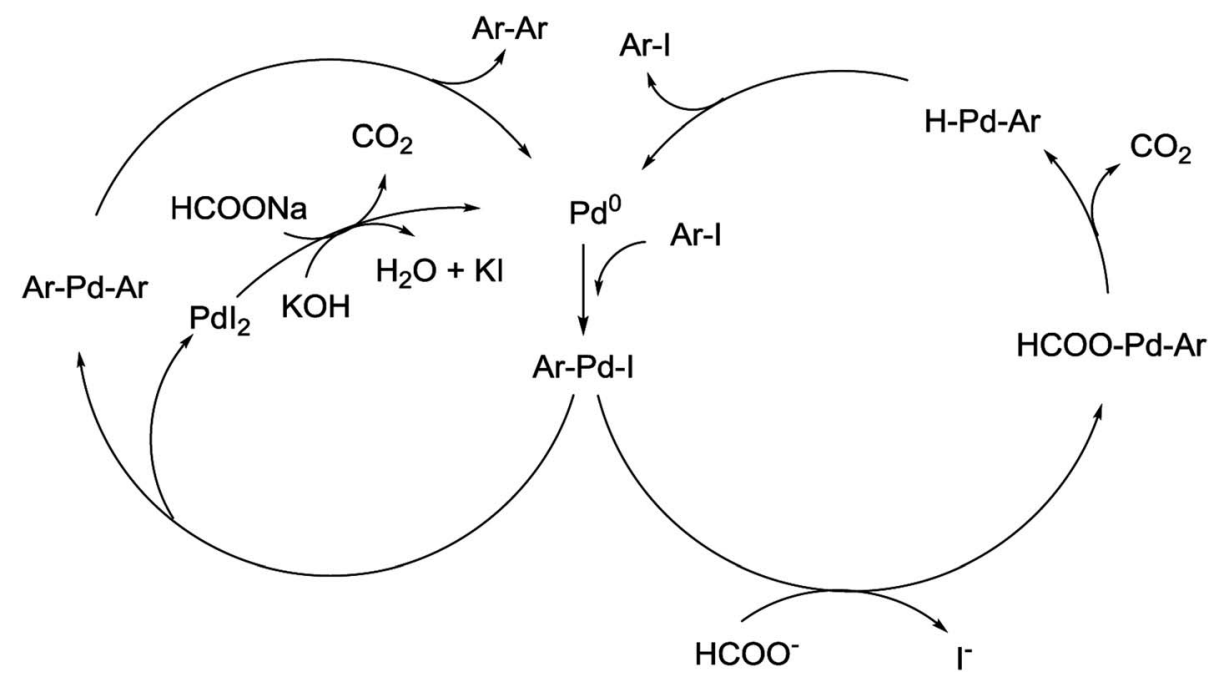

Scheme 121 A plausible mechanism for the Ar-I Ullmann reaction. ${ }^{152}$

appropriate and large enough to accommodate a definite catalytic species. This issue can be controlled by incorporation of specific functionalities. Moreover, for functionalization of SBA-
15, a method must be chosen that does not lead to the collapse of silica structure and block the pores of SBA-15. Additionally, engross and ingress of the substrates and products through the

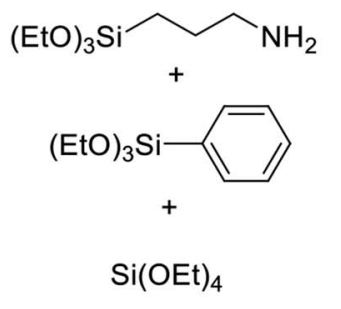

$\mathrm{Si}(\mathrm{OEt})_{4}$

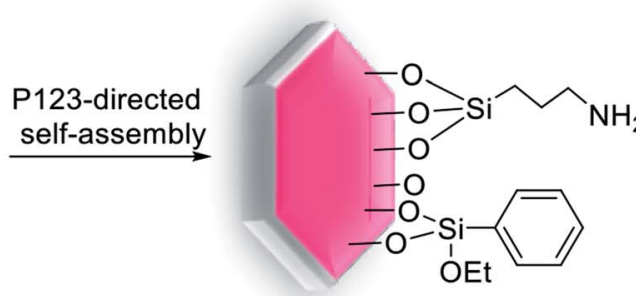

$\underset{\text { Reduction }}{\stackrel{\mathrm{PdCl}_{2}}{\longrightarrow}}$

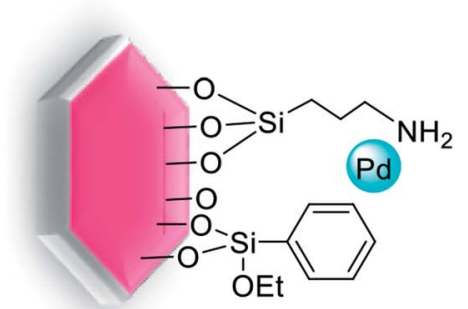

$\mathrm{Pd} / \mathrm{NH}_{2} \& \mathrm{Ph}-\mathrm{SBA}-15$ (73)

Scheme 122 Schematic illustration of the preparation of $\mathrm{Pd} / \mathrm{NH}_{2} \& \mathrm{Ph}-\mathrm{SBA}-15$ (73). 
2

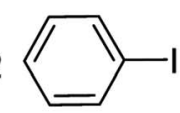

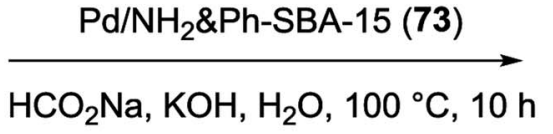

$\mathrm{HCO}_{2} \mathrm{Na}, \mathrm{KOH}, \mathrm{H}_{2} \mathrm{O}, 100^{\circ} \mathrm{C}, 10 \mathrm{~h}$

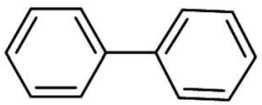

Conversion $=40.8-89.5 \%$

Selectivity $=92.5-95.8 \%$

Yield $=38.2-82.3 \%$

Scheme 123 Ullmann reaction of iodobenzene catalyzed by $\mathrm{Pd} / \mathrm{NH}_{2} \& \mathrm{Ph}-\mathrm{SBA}-15$ (73).

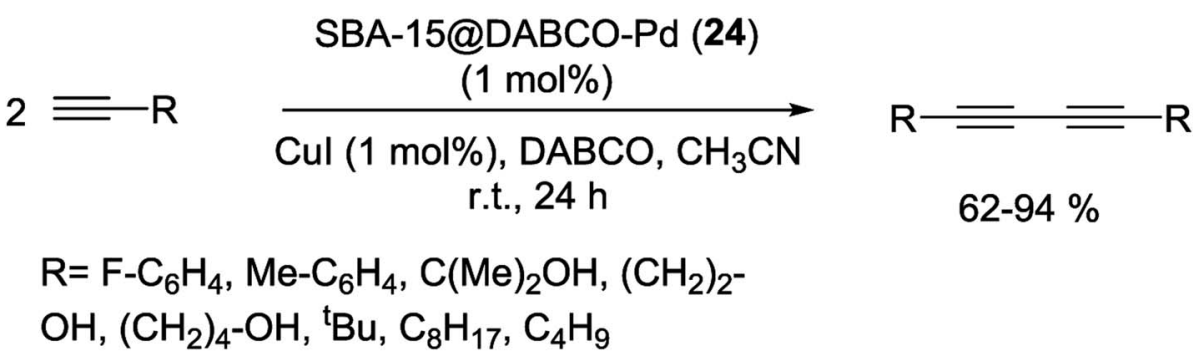

Scheme 124 SBA-15(ADABCO-Pd (24) as catalyst for homocoupling reaction of terminal alkynes.

cavities of silica SBA-15 must be feasible. Remarkably, the functionalities should be efficient enough for high anchoring of Pd and reducing Pd leaching.

Nevertheless, several drawbacks to the present heterogeneous SBA-15 catalysts are still continuing in $\mathrm{C}-\mathrm{C}$ bond formation reactions. Although the performance of $\mathrm{Pd}$ nanocatalysts strongly depends on the particle shape, size and interaction with this support, but the relationship between such parameters and relativities is less understood and requires to be investigated in more detail. Another drawback is that most of authors do not try to prove the generality of mol ppm/ppb level of Pd loading in their system. The trend in order to decreasing the catalyst loading in versatile coupling reactions continues to gain much attention from the scientific community. Through shifting from mol\% levels to mol ppm levels, the cost of the catalyst is removed and also problems of toxicity are degreased. Moreover, by decreasing catalyst loadings below $10 \mathrm{~mol} \mathrm{ppm}$, the toxicity problems are completely eliminated, since the catalyst loading is previously below the needed levels for metal impurities in pharmaceuticals. The other missing point in approximately all the publications reported here is the application of the catalytic systems to the chemical industry. Sometimes, the functionalization of SBA should be performed through a multi-step process. This may make the synthetic method timeconsuming and costly. Furthermore, the purification must be done in each step. Moreover, most of the Pd catalyzed coupling reactions are conducted under inert atmospheres since they are sensitive to oxygen or moisture. Several catalysts need higher catalyst loadings, higher reaction temperatures, and have limitations in stereoselective coupling reactions. Only a few Pd-catalysts are capable of activating aryl chlorides. Some Pd NPs immobilized on SBA-15 supports suffer from Pd aggregation and leaching during reactions, resulting in limited reusability. These problems may be overcome for large-scale applications of heterogeneous systems.

\section{Conclusion and future perspective}

The aim of this perspective is to afford readers the important developments of Pd-based mesoporous silica SBA-15 as catalyst in $\mathrm{C}-\mathrm{C}$ coupling reactions. Among ordered mesoporous materials, SBA-15 support has attracted much attention due to their noteworthy and desirable characteristics for catalytic applications such as easy functionalization, high specific surface area, available pore volume, tunable pore size and high thermal stability. The heterogeneous transition metals, particularly Pd supported on SBA-15, have many benefits, including (a) the well-ordered mesopore channels present in silica SBA-15 have shown significant advantages for capturing of the Pd species (b) the cavities of SBA-15 can act as nanoreactor for embedding Pd species that not only feasible ingress/egress of the substrates and products through the meso-channels, but also enhance the interaction between substrates and active Pd species embedding in pore walls (c) the inorganic SBA-15 can physically protect the captured Pd complex and also can improved the catalytic activity through synergistic effects between the Pd complex and mesoporous structure (d) a large specific surface area containing highly ordered mesopores of SBA can affect on the uniformly distribution of Pd species that can help to overcome the problems of aggregation and leaching of Pd in the solution.

As above mentioned, significant efforts were done for employing these catalysts to overcome the problems regarding separation, recovery, stability and the possibility of using broad range of ligands instead of homogeneous catalyst systems. To date, different strategies have been developed for increasing the 
stability and reactivity of these catalysts such as functionalized with P-ligands, N-ligands, S-ligands, as well as NHC ligands. Another development is the shift from quite toxic and harsh reaction conditions toward milder and greener ones. A point is that if the majority of reactions still need a reaction temperature above $100{ }^{\circ} \mathrm{C}$, many publications now describe the usage of lower temperature, and a few report reactions conducted at room temperature. With respect to the solvent, the use of water as a solvent for the Suzuki reaction is important to develop greener manufacturing protocols for improving truly green processes. Hence, silica SBA-15 is modified with some ligands to provide more suitable catalytic sites for reactions in aqueous media. Besides, the coupling reactions under solvent-free conditions using thermal and MW techniques revealed excellent activity over some cycles. One of the other advantages of mesoporous silica SBA-15 is the possibility of tuning their properties such as hydrophobicity/hydrophilicity, surface polarity and electrostatic features. Using surface functionalization, the hydrophilicity and hydrophobicity of the SBA-based catalysts can be adjusted. This is particularly important when the catalyst is water-sensitive and may be poisoned by water. The improvement of water-tolerant SBA-based catalyst with excellent mass transport can be achieved through appropriate immobilization of SBA-15 by functional groups with hydrophobic features. These catalysts demonstrated high performance in different organic transformations under mild and green conditions.

Since the functionalization of the organics and grafting of the metal centers occur inside the pore channels of the mesoporous framework, the remaining pore space plays an important role in the catalytic activity. It is known that catalytic performance improves with larger surface exposure of the substrates toward the active centers and their accessibility into the porous structure. Therefore, the pore size and volume have a huge effect on the catalytic performance of SBA-15 support. To the best of our knowledge, there are no systematic studies reported which deal with the influence of the volume and pore size of the mesoporous silica SBA-15 support on the activity of Pd-catalysts in coupling reactions (only investigated in ref. 106). This provides a perspective for additional development of other Pd-catalyzed coupling reactions. Even though, SBA-15 supported Pd catalyst has a significant role in coupling reactions, at present, the number of reports about Pd supported on SBA-15 is much less compared to other supports. Hence, this provides an outlook for further advances of other Pd-catalyzed coupling reactions. To date, different heterogeneous catalysts by utilities for promoting asymmetric reactions have been advanced. One of the biggest challenges in modification of chiral catalysts is preserving their activity and enantioselectivity. In this regards, SBA-15 can be considered as an efficient nanoreactor for encapsulation of this class of catalyst. The chiral ligands can be incorporated within the cavities of silica SBA-15 and then used for immobilization of Pd species. These chiral catalysts/ligands within SBA structure can be used for doing asymmetric reactions with high enantioand diastereoselectivity. Future researches in this field is expected to develop such chiral SBA-15 supports containing new chiral ligands with high catalytic activity and better enantioselectivity. In general, to achieve a high catalytic performance while minimizing the price of catalysts and impurity of the products, researchers should improve high-TON Pd catalysts that leach a low level of Pd contents. Additionally, durability, stability, and cost are all the topics that need to be addressed, if such systems are to revel extensive usage in industries for commercial purposes. Therefore, according to the unique properties of SBA-15 and also considering the proposals and future prospects for improving the applications of this silica support, it can be expected that the silica SBA-15 supported catalysts will still continue to be a fast-moving topic in future.

\section{Conflicts of interest}

There are no conflicts to declare.

\section{Abbreviations}

\begin{tabular}{|c|c|}
\hline AIBN & Azobisisobutyronitrile \\
\hline APTES & (3-Aminopropyl)triethoxysilane \\
\hline [BMIm] & 1-Butyl-3-methylimidazolium \\
\hline$\left[\mathrm{PF}_{6}\right]$ & hexafluorophosphate \\
\hline $\mathrm{CC}$ & Cyanuric chloride \\
\hline CPTMS & 3-Chloropropyltrimethoxysilane \\
\hline DMF & $N, N^{\prime}$-Dimethylformamide \\
\hline D-2PA & $N, N$-Dimethyl-2-propynylamine \\
\hline DIEA & Diisopropylethylamine \\
\hline DABCO & 1,4-Diaza-bicyclo[2.2.2]octane \\
\hline EG & Ethylene glycol \\
\hline IL & Ionic liquid \\
\hline ICP-AES & $\begin{array}{l}\text { Inductive coupled plasma-atomic emission } \\
\text { spectroscopy }\end{array}$ \\
\hline $\mathrm{K}_{2} \mathrm{CO}_{3}$ & Potassium carbonate \\
\hline LSPR & Localized surface plasmon resonance \\
\hline $\mathrm{M}-\mathrm{H}$ & Mizoroki-Heck \\
\hline MW & Microwave \\
\hline MPTES & (3-Mercaptopropyl)triethoxysilane \\
\hline MPTMS & Mercaptopropyltrimethoxysilane \\
\hline NHC & $\mathrm{N}$-Heterocyclic carbine \\
\hline NMP & $N$-Methylpyrrolidone \\
\hline NLDFT & Non-local density functional theory \\
\hline OMS & Ordered mesoporous silica \\
\hline Pd NPs & Palladium nanoparticles \\
\hline PdNRs & Palladium nanorods \\
\hline PrEn & Propyl ethylenediamine \\
\hline $\mathrm{PrNH}_{2}$ & Propylamine \\
\hline PAMAM & Poly(amido-amine) \\
\hline$[\mathrm{PdTSPP}]$ & (meso-tetra-( $p$-Sulfonatophenyl)-porphyrinat \\
\hline $\mathrm{Na}_{4}$ & palladium sodium \\
\hline PhBpin & Phenyl boronic acid pinacol ester \\
\hline PIDA & $N$-Propyliminodiacetic acid \\
\hline PEG & Polyethylene glycol \\
\hline S-M & Suzuki-Miyaura \\
\hline $\mathrm{scCO}_{2}$ & Supercritical carbon dioxide \\
\hline TOF & Turn-over frequency \\
\hline TON & Turn-over number \\
\hline TEOS & Tetraethyl orthosilicate \\
\hline
\end{tabular}


TBAB Tetrabutyl ammonium bromide

TMS Trimethylsilyl

TMGL 1,1,3,3-Tetramethylguanidinium lactate

\section{Acknowledgements}

We gratefully acknowledge for the financial support from the Research Council of Alzahra University and University of Tehran.

\section{References}

1 S. H. Petrosko, R. Johnson, H. White and C. A. Mirkin, Nanoreactors: small spaces, big implications in chemistry, J. Am. Chem. Soc., 2016, 138, 7443-7445.

2 V. Fathi Vavsari, G. Mohammadi Ziarani, A. Badiei and S. Balalaie, J. Iran. Chem. Soc., 2016, 13, 1037-1043.

3 D. A. Gomez-Gualdron, S. T. Dix, R. B. Getman and R. Q. Snurr, Phys. Chem. Chem. Phys., 2015, 17, 2759627608.

4 C. Deraedt, L. Salmon and D. Astruc, Adv. Synth. Catal., 2014, 356, 2525-2538.

5 T. Mitsudome, K. Nose, K. Mori, T. Mizugaki, K. Ebitani, K. Jitsukawa and K. Kaneda, Angew. Chem., 2007, 119, 3352-3354.

6 S. Lee, C. Jo and R. Ryoo, J. Mater. Chem. A, 2017, 5, 1108611093.

7 P. Serp and E. Castillejos, ChemCatChem, 2010, 2, 41-47.

8 G. Mohammadi Ziarani, N. Lashgari and A. Badiei, Curr. Org. Chem., 2017, 21, 674-687.

9 H. Vojoudi, A. Badiei, S. Bahar, G. Mohammadi Ziarani, F. Faridbod and M. R. Ganjali, Powder Technol., 2017, 319, 271-278.

10 V. Fathi Vavsari, G. Mohammadi Ziarani and A. Badiei, RSC Adv., 2015, 5, 91686-91707.

11 D. H. Hwang, D. Lee, H. Lee, D. Choe, S. H. Lee and K. Lee, Korean J. Chem. Eng., 2010, 27, 1087-1092.

12 E. I. Basaldella and M. S. Legnoverde, J. Sol-Gel Sci. Technol., 2010, 56, 191-196.

13 S.-W. Song, K. Hidajat and S. Kawi, Langmuir, 2005, 21, 9568-9575.

14 F. Sevimli and A. Yllmaz, Microporous Mesoporous Mater., 2012, 158, 281-291.

15 V. Fathi Vavsari, G. Mohammadi Ziarani, S. Balalaie, A. Latifi, M. Karimi and A. Badiei, Tetrahedron, 2016, 72, 5420-5426.

16 J. Afshani, A. Badiei, N. Lashgari and G. Mohammadi Ziarani, RSC Adv., 2016, 6, 5957-5964.

17 N. Lashgari, A. Badiei and G. Mohammadi Ziarani, Nanochem. Res., 2016, 1, 127-141.

18 D. Margolese, J. Melero, S. Christiansen, B. Chmelka and G. Stucky, Chem. Mater., 2000, 12, 2448-2459.

19 Z. Bahrami, A. Badiei and F. Atyabi, Chem. Eng. Res. Des., 2014, 92, 1296-1303.

20 M. Karimi, A. Badiei and G. Mohammadi Ziarani, RSC Adv., 2015, 5, 36530-36539.
21 G. Mohammadi Ziarani, P. Gholamzadeh, A. Badiei and V. Fathi Vavsari, Res. Chem. Intermed., 2018, 44, 277-288.

22 V. Fathi Vavsari, G. Mohammadi Ziarani, S. Balalaie, A. Badiei, F. Golmohammadi, S. Ramezanpour and F. Rominger, ChemistrySelect, 2017, 2, 3496-3499.

23 G. Mohammadi Ziarani, N. Lashgari and A. Badiei, J. Mol. Catal. A: Chem., 2015, 397, 166-191.

24 A. Badiei, H. Goldooz, G. Mohammadi Ziarani and A. Abbasi, J. Colloid Interface Sci., 2011, 357, 63-69.

25 Y. Yang and R. M. Rioux, Chem. Commun., 2011, 47, 65576559.

26 Y. Yang and R. M. Rioux, Green Chem., 2014, 16, 3916-3925. 27 M. A. Smith, A. Zoelle, Y. Yang, R. M. Rioux, N. G. Hamilton, K. Amakawa, P. K. Nielsen and A. Trunschke, J. Catal., 2014, 312, 170-178.

28 Y. Yang, J. W. Chang and R. M. Rioux, J. Catal., 2018, 365, 43-54.

29 B. Karimi, F. Mansouri and M. Khorasani, Curr. Org. Chem., 2016, 20, 349-380.

30 R. Jahanshahi and B. Akhlaghinia, New J. Chem., 2017, 41, 7203-7219.

31 B. Karimi, M. R. Marefat, M. Hasannia, P. F. Akhavan, F. Mansouri, Z. Artelli, F. Mohammadi and H. Vali, ChemCatChem, 2016, 8, 2508-2515.

32 P. Veerakumar, P. Thanasekaran, K.-L. Lu, S.-B. Liu and S. Rajagopal, ACS Sustainable Chem. Eng., 2017, 5, 63576376.

$33 \mathrm{~K}$. Manabe, Palladium catalysts for cross-coupling reaction, Catalysts, 2015, 5, 38-39.

34 A. r. d. Molnár, Chem. Rev., 2011, 111, 2251-2320.

35 L. Pu, Chem. Rev., 1998, 98, 2405-2494.

36 J. Hassan, M. Sevignon, C. Gozzi, E. Schulz and M. Lemaire, Chem. Rev., 2002, 102, 1359-1470.

37 B. Karimi, H. Behzadnia, E. Farhangi, E. Jafari and A. Zamani, Curr. Org. Synth., 2010, 7, 543-567.

38 R. Huirache-Acuña, R. Nava, C. L. Peza-Ledesma, J. LaraRomero, G. Alonso-Núez, B. Pawelec and E. M. RiveraMuñoz, Materials, 2013, 6, 4139-4167.

39 M. Opanasenko, P. Štěpnička and J. Čejka, RSC Adv., 2014, 4, 65137-65162.

40 L. Yin and J. Liebscher, Chem. Rev., 2007, 107, 133-173.

41 M. Mora, C. Jimenez-Sanchidrian and J. Rafael Ruiz, Curr. Org. Chem., 2012, 16, 1128-1150.

42 N. Pal and A. Bhaumik, RSC Adv., 2015, 5, 24363-24391.

43 M. T. Reetz and E. Westermann, Angew. Chem., Int. Ed., 2000, 39, 165-168.

44 P. J. Stang, Metal-catalyzed cross-coupling reactions, John Wiley \& Sons, 2008, p. 554.

45 Á. Molnár, Palladium-catalyzed coupling reactions: practical aspects and future developments, Wiley-VCH Verlag $\mathrm{GmbH}$ \& Co. KGaA, Weinheim, 2013, p. 692.

46 A. Biffis, P. Centomo, A. Del Zotto and M. Zecca, Chem. Rev., 2018, 118, 2249-2295.

47 D. Roy and Y. Uozumi, Adv. Synth. Catal., 2018, 360, 602625.

48 J. Guerra and M. A. Herrero, Nanoscale, 2010, 2, 1390-1400. 
49 L. Djakovitch, K. Köhler and J. G. d. Vries, Nanoparticles and Catalysis, Wiley-VCH Verlag GmbH, Weinheim, 2008, vol. 69, pp. 303-348.

50 A. Kumbhar, Top. Curr. Chem., 2017, 375, 2.

51 V. Polshettiwar, C. Len and A. Fihri, Coord. Chem. Rev., 2009, 253, 2599-2626.

52 S. Sadjadi and M. Heravi, RSC Adv., 2017, 7, 30815-30838.

53 P. Gholamzadeh, G. Mohammadi Ziarani, N. Lashgari, A. Badiei and P. Asadiatouei, J. Mol. Catal. A: Chem., 2014, 391, 208-222.

54 S. Rohani, G. Mohammadi Ziarani, A. Badiei, A. Ziarati, M. Jafari and A. Shayesteh, Appl. Organomet. Chem., 2018, 32, 4397-4408.

55 N. Miyaura and A. Suzuki, Chem. Rev., 1995, 95, 2457-2483. 56 A. Suzuki, J. Organomet. Chem., 1999, 576, 147-168.

57 N. Miyaura, K. Yamada and A. Suzuki, Tetrahedron Lett., 1979, 20, 3437-3440.

58 N. Miyaura, T. Yanagi and A. Suzuki, Synth. Commun., 1981, 11, 513-519.

59 D. A. Horton, G. T. Bourne and M. L. Smythe, Chem. Rev., 2003, 103, 893-930.

60 G. Bringmann, C. Günther, M. Ochse, O. Schupp and S. Tasler, Biaryls in nature: a multi-facetted class of stereochemically, biosynthetically, and pharmacologically intriguing secondary metabolites, Fortschritte der Chemie organischer Naturstoffe/Progress in the Chemistry of Organic Natural Products, Springer, 2001, vol. 82, pp. 1-249.

61 G. A. Molander, D. E. Petrillo, N. R. Landzberg, J. C. Rohanna and B. Biolatto, Synlett, 2005, 2005, 17631766.

62 A. Suzuki, Chem. Soc. Rev., 2011, 40, 5010-5029.

63 K. Sarkar, M. Nandi, M. Islam, M. Mubarak and A. Bhaumik, Appl. Catal., A, 2009, 352, 81-86.

64 C. Yang, H. Wustefeld, M. Kalwei and F. Schiith, Exploring the catalytic activity of metal nanoparticles in functionalized mesoporous silica, Studies in Surface Science and Catalysis, Elsevier, 2004, vol. 154, pp. 25742580.

65 C. M. Crudden, M. Sateesh and R. Lewis, J. Am. Chem. Soc., 2005, 127, 10045-10050.

66 Q. Yang, S. Ma, J. Li, F. Xiao and H. Xiong, Chem. Commun., 2006, 23, 2495-2497.

67 R. Sayah, K. Glegoła, E. Framery and V. Dufaud, Adv. Synth. Catal., 2007, 349, 373-381.

68 P. Han, X. Wang, X. Qiu, X. Ji and L. Gao, J. Mol. Catal. A: Chem., 2007, 272, 136-141.

69 B. Blanco, M. Moreno-Mañas, R. Pleixats, A. Mehdi and C. Reyé, J. Mol. Catal. A: Chem., 2007, 269, 204-213.

70 P. Han, H. Zhang, X. Qiu, X. Ji and L. Gao, J. Mol. Catal. A: Chem., 2008, 295, 57-67.

71 J. Demel, M. Lamač, J. Čejka and P. Štěpnička, ChemSusChem, 2009, 2, 442-451.

72 B. W. Glasspoole, J. D. Webb and C. M. Crudden, J. Catal., 2009, 265, 148-154.

73 X. Feng, M. Yan, T. Zhang, Y. Liu and M. Bao, Green Chem., 2010, 12, 1758-1766.
74 Z. Zheng, H. Li, T. Liu and R. Cao, J. Catal., 2010, 270, 268274.

75 A. El Kadib, K. McEleney, T. Seki, T. K. Wood and C. M. Crudden, ChemCatChem, 2011, 3, 1281-1285.

76 S. El Hankari, A. El Kadib, A. Finiels, A. Bouhaouss, J. J. Moreau, C. M. Crudden, D. Brunel and P. Hesemann, Chem.-Eur. J., 2011, 17, 8984-8994.

77 J. Huang, M. Wang, S. Zhang, B. Hu and H. Li, J. Phys. Chem. C, 2011, 115, 22514-22522.

78 J. Zhi, D. Song, Z. Li, X. Lei and A. Hu, Chem. Commun., 2011, 47, 10707-10709.

79 M. Gruttadauria, L. F. Liotta, A. M. P. Salvo, F. Giacalone, V. La Parola, C. Aprile and R. Noto, Adv. Synth. Catal., 2011, 353, 2119-2130.

80 W. Chang, G. Chae, S. R. Jang, J. Shin and B. J. Ahn, J. Ind. Eng. Chem., 2012, 18, 581-585.

81 B. Karimi and A. Zamani, Org. Biomol. Chem., 2012, 10, 4531-4536.

$82 \mathrm{H}$. Li, M. Yang and Q. Pu, Microporous Mesoporous Mater., 2012, 148, 166-173.

83 A. Alizadeh, M. Khodaei, D. Kordestania and M. Beygzadeh, J. Mol. Catal. A: Chem., 2013, 372, 167-174.

84 S. Rostamnia and H. Xin, Appl. Organomet. Chem., 2013, 27, 348-352.

85 G. Zhang, P. Wang and X. Wei, Catal. Lett., 2013, 143, 11881194.

86 A. Balbín, F. Gaballo, J. Ceballos-Torres, S. Prashar, M. Fajardo, G. N. Kaluđerović and S. Gómez-Ruiz, RSC Adv., 2014, 4, 54775-54787.

87 R. Ghorbani-Vaghei, S. Hemmati and H. Veisi, J. Mol. Catal. A: Chem., 2014, 393, 240-247.

88 S. Rostamnia, K. Lamei and F. Pourhassan, RSC Adv., 2014, 4, 59626-59631.

89 H. Veisi, M. Hamelian and S. Hemmati, J. Mol. Catal. A: Chem., 2014, 395, 25-33.

90 P. Wang, G. Zhang, L. Liu, H. Jiao, X. Deng and X. Zheng, Mater. Res. Bull., 2014, 59, 365-369.

91 P. Sharma and A. Singh, Catal. Sci. Technol., 2014, 4, 29782989.

92 C. Singh, K. Jawade, P. Sharma, A. P. Singh and P. Kumar, Catal. Commun., 2015, 69, 11-15.

93 L. A. Bivona, F. Giacalone, L. Vaccaro, C. Aprile and M. Gruttadauria, ChemCatChem, 2015, 7, 2526-2533.

94 S. Rostamnia, T. Rahmani and H. Xin, J. Ind. Eng. Chem., 2015, 32, 218-224.

95 P. Ncube, T. Hlabathe and R. Meijboom, J. Cluster Sci., 2015, 26, 1873-1888.

96 S. M. Sarkar, M. L. Rahman and M. M. Yusoff, $R S C A d v$, 2015, 5, 1295-1300.

97 P. Verma, Y. Kuwahara, K. Mori and H. Yamashita, J. Mater. Chem. A, 2015, 3, 18889-18897.

98 R. L. Oliveira, W. He, R. J. K. Gebbink and K. P. de Jong, Catal. Sci. Technol., 2015, 5, 1919-1928.

99 A. Pathak and A. Singh, J. Porous Mater., 2017, 24, 327-340. 100 J. Yu, A. Shen, Y. Cao and G. Lu, Catalysts, 2016, 6, 181.

101 S. Rostamnia, E. Doustkhah and B. Zeynizadeh, Microporous Mesoporous Mater., 2016, 222, 87-93. 
102 E. Doustkhah, S. Rostamnia, H. G. Hossieni and R. Luque, ChemistrySelect, 2017, 2, 329-334.

103 F. Ulusal, E. Erünal and B. Güzel, J. Nanopart. Res., 2018, 20, 219.

104 T. Tamoradi, M. Ghadermazi and A. GhorbaniChoghamarani, J. Porous Mater., 2018, 1-11.

105 J. Li, X. Bai and H. Lv, Microporous Mesoporous Mater., 2019, 275, 69-75.

106 T. Das, H. Uyama and M. Nandi, New J. Chem., 2018, 42, 6416-6426.

107 F. Rajabi, F. Fayyaza, R. Bandyopadhyay, F. Ivars-Barcelo, A. R. Puente-Santiago and R. Luque, ChemistrySelect, 2018, 3, 6102-6106.

108 J. Mondal, A. Modak and A. Bhaumik, J. Mol. Catal. A: Chem., 2011, 350, 40-48.

109 R. F. Heck, J. Am. Chem. Soc., 1968, 90, 5518-5526.

110 R. F. Heck, J. Am. Chem. Soc., 1969, 91, 6707-6714.

111 T. Mizutani, S. Honzawa, S. y. Tosaki and M. Shibasaki, Angew. Chem., Int. Ed., 2002, 41, 4680-4682.

112 L. F. Tietze, G. Kettschau, U. Heuschert and G. Nordmann, Chem.-Eur. J., 2001, 7, 368-373.

113 T. R. Burke, D.-G. Liu and Y. Gao, J. Org. Chem., 2000, 65, 6288-6291.

114 H. Dieck and R.-F. Heck, J. Am. Chem. Soc., 1974, 96, 11331136.

115 R. Heck and J. Nolley Jr, J. Org. Chem., 1972, 37, 2320-2322. 116 C. P. Mehnert, D. W. Weaver and J. Y. Ying, J. Am. Chem. Soc., 1998, 120, 12289-12296.

117 L. Li, L.-X. Zhang, J.-L. Shi, J.-N. Yan and J. Liang, Appl. Catal., A, 2005, 283, 85-89.

118 X. Ma, Y. Zhou, J. Zhang, A. Zhu, T. Jiang and B. Han, Green Chem., 2008, 10, 59-66.

119 J.-Y. Jung, A. Taher, H.-J. Kim, W.-S. Ahn and M.-J. Jin, Synlett, 2009, 2009, 39-42.

120 P. Wang, Z. Wang, J. Li and Y. Bai, Microporous Mesoporous Mater., 2008, 116, 400-405.

121 P. Wang, Q. Lu and J. Li, Catal. Lett., 2009, 131, 444-450.

122 P. Wang, Q. Lu and J. Li, Mater. Res. Bull., 2010, 45, 129134.

123 Y. Feng, L. Li, Y. Li, W. Zhao, J. Gu and J. Shi, J. Mol. Catal. A: Chem., 2010, 322, 50-54.

124 J. Zhang, G.-F. Zhao, Z. Popović, Y. Lu and Y. Liu, Mater. Res. Bull., 2010, 45, 1648-1653.

125 P. Wang and X. Zheng, Powder Technol., 2011, 210, 115-121.

126 X. J. Feng, M. Yan, X. Zhang and M. Bao, Chin. Chem. Lett., 2011, 22, 643-646.

127 P. Wang, X. Luo, X. Wu, X. Wei, L. Zhou and X. Zheng, J. Porous Mater., 2013, 20, 1-6.

128 H. Veisi, D. Kordestani and A. R. Faraji, J. Porous Mater., 2014, 21, 141-148.
129 R. L. Oliveira, J. B. Hooijmans, P. E de Jongh, R. J. Klein Gebbink and K. P de Jong, ChemCatChem, 2014, 6, 32233230.

130 S. Rostamnia, X. Liu and D. Zheng, J. Colloid Interface Sci., 2014, 432, 86-91.

131 S. Rostamnia and T. Rahmani, Appl. Organomet. Chem., 2015, 29, 471-474.

132 J. Rathod, P. Sharma, P. Pandey, A. Singh and P. Kumar, J. Porous Mater., 2017, 24, 837-846.

133 K. Sonogashira, Y. Tohda and N. Hagihara, Tetrahedron Lett., 1975, 16, 4467-4470.

134 A. Modak, J. Mondal and A. Bhaumik, Green Chem., 2012, 14, 2840-2855.

135 L. Brunsveld, E. Meijer, R. B. Prince and J. S. Moore, J. Am. Chem. Soc., 2001, 123, 7978-7984.

136 S. Höger, S. Rosselli, A.-D. Ramminger and V. Enkelmann, Org. Lett., 2002, 4, 4269-4272.

137 D. Wang and S. Gao, Org. Chem. Front., 2014, 1, 556-566.

138 D. Milstein and J. Stille, J. Am. Chem. Soc., 1978, 100, 36363638.

139 J. K. Stille, Angew. Chem., Int. Ed., 1986, 25, 508-524.

140 K. Nicolaou, T. Chakraborty, A. Piscopio, N. Minowa and P. Bertinato, J. Am. Chem. Soc., 1993, 115, 4419-4420.

141 M. D. Shair, T. Y. Yoon, K. K. Mosny, T. Chou and S. J. Danishefsky, J. Am. Chem. Soc., 1996, 118, 9509-9525.

142 D. Milstein and J. Stille, J. Am. Chem. Soc., 1979, 101, 49924998.

143 M. Semler, J. Čejka and P. Štěpnička, Appl. Organomet. Chem., 2013, 27, 353-360.

144 Y. Hatanaka and T. Hiyama, J. Org. Chem., 1988, 53, 918920.

145 Y. Hatanaka and T. Hiyama, Synlett, 1991, 1991, 845-853.

146 H. F. Sore, W. R. Galloway and D. R. Spring, Chem. Soc. Rev., 2012, 41, 1845-1866.

147 S.-H. Huang, C.-H. Liu and C.-M. Yang, Green Chem., 2014, 16, 2706-2712.

148 S. Rostamnia, H. G. Hossieni and E. Doustkhah, J. Organomet. Chem., 2015, 791, 18-23.

149 B. Karimi and F. K. Esfahani, Chem. Commun., 2011, 47, 10452-10454.

150 P. E. Fanta, Synthesis, 1974, 1974, 9-21.

151 F. Ullmann and J. Bielecki, Eur. J. Inorg. Chem., 1901, 34, 2174-2185.

152 H. Li, W. Chai, F. Zhang and J. Chen, Green Chem., 2007, 9, 1223-1228.

153 J. Huang, J. Yin, W. Chai, C. Liang, J. Shen and F. Zhang, New J. Chem., 2012, 36, 1378-1384.

154 C. Glaser, Eur. J. Inorg. Chem., 1869, 2, 422-424. 